University of Windsor

Scholarship at UWindsor

\title{
Two set-theoretic approaches to the semantics of adjective-noun combinations
}

Nabil Abdullah

University of Windsor

Follow this and additional works at: https://scholar.uwindsor.ca/etd

\section{Recommended Citation}

Abdullah, Nabil, "Two set-theoretic approaches to the semantics of adjective-noun combinations" (2004). Electronic Theses and Dissertations. 4438.

https://scholar.uwindsor.ca/etd/4438

This online database contains the full-text of PhD dissertations and Masters' theses of University of Windsor students from 1954 forward. These documents are made available for personal study and research purposes only, in accordance with the Canadian Copyright Act and the Creative Commons license-CC BY-NC-ND (Attribution, Non-Commercial, No Derivative Works). Under this license, works must always be attributed to the copyright holder (original author), cannot be used for any commercial purposes, and may not be altered. Any other use would require the permission of the copyright holder. Students may inquire about withdrawing their dissertation and/or thesis from this database. For additional inquiries, please contact the repository administrator via email (scholarship@uwindsor.ca) or by telephone at 519-253-3000ext. 3208. 


\title{
Two Set-Theoretic Approaches to the Semantics of Adjective-Noun Combinations
}

\author{
by
}

Nabil Abdullah

\author{
A Thesis \\ Submitted to the Faculty of Graduate Studies and Research \\ through the School of Computer Science \\ in Partial Fulfilment of the Requirements for \\ the Degree of Master of Science at the \\ University of Windsor
}

Windsor, Ontario, Canada 2003 


\author{
National Library \\ of Canada \\ Acquisitions and \\ Bibliographic Services \\ 395 Wellington Street \\ Ottawa ON K1A ON4 \\ Canada
}

Bibliothèque nationale

du Canada

Acquisisitons et services bibliographiques

395, rue Wellington Ottawa ON K1A ON4 Canada
Your file Votre référence ISBN: 0-612-92516-1

Ourfile Notre référence ISBN: 0-612-92516-1
The author has granted a nonexclusive licence allowing the National Library of Canada to reproduce, loan, distribute or sell copies of this thesis in microform, paper or electronic formats.

The author retains ownership of the copyright in this thesis. Neither the thesis nor substantial extracts from it may be printed or otherwise reproduced without the author's permission.
L'auteur a accordé une licence non exclusive permettant à la Bibliothèque nationale du Canada de reproduire, prêter, distribuer ou vendre des copies de cette thèse sous la forme de microfiche/film, de reproduction sur papier ou sur format électronique.

L'auteur conserve la propriété du droit d'auteur qui protège cette thèse. $\mathrm{Ni}$ la thèse ni des extraits substantiels de celle-ci ne doivent être imprimés ou aturement reproduits sans son autorisation.
In compliance with the Canadian Privacy Act some supporting forms may have been removed from this dissertation.

While these forms may be included in the document page count, their removal does not represent any loss of content from the dissertation.
Conformément à la loi canadienne sur la protection de la vie privée, quelques formulaires secondaires ont été enlevés de ce manuscrit.

Bien que ces formulaires aient inclus dans la pagination, il n'y aura aucun contenu manquant.

\section{Canadä}


Nabil A. Abdullah

(C) All Rights Reserved 
This work addresses the problem of adjective-noun combinations. Conventionally, adjectives belong to a hierarchy. This has the consequence that a uniform treatment of adjectives is unattainable-without resorting to notions such as possible worlds, which are difficult to map into competent computer programs.

In this work, we propose two set-theoretic approaches to the semantics of adjective-noun combinations. The first hypothesizes that an adjective-noun compound is a subset of its constituent noun. The second hypothesizes that the adjective-noun combinations can semantically be thought of as a set intersection involving the adjective(s) and the head noun of the compound.

This work argues that the class of adjectives known as "privative" can be accommodated within an existing class in the adjective hierarchy, known as "subsective". This step is important for the provision of uniform treatments of adjective-noun combinations.

The two approaches make use of types, both for gaining a finer "granularity" of analysis and for imposing structure on the problem domain. It is shown that the "mixture" of a typing system with set theory provides promising results that are manifested in the provision of compositional solutions to the adjective-noun combinations. 
To my wife, Manal, my daughter, Maha, and my son, Mohammed 
This work could not have been accomplished without the support of many people. I am deeply grateful to my supervisor Dr Richard A. Frost for agreeing to supervise my research despite his many responsibilities. I am thankful for his guidance, advice, and financial support through out my thesis work. I appreciate Dr Frost's patience, willingness to listen, and fruitful guidance without which this work would not have come to a satisfactory completion. He has never been short of ideas or insights. Working with Dr Frost has been a rewarding experience.

I am thankful to Dr Walid Saba for his supervision during the early stages of my graduate study.

I am honoured to have Drs Ahmed Tawrik, Marcello Guarini, and Scott Goodwin as member of my thesis committee. I am grateful to Dr Guarini's and Dr Tawfik's suggestions and thoughtful insights about the thesis. Their valuable remarks put the thesis in perspective.

I am thankful for my wife, Manal, for putting up with me during stressful times. It is difficult to imagine how I could have endured without her love and support.

Finally, I am thankful for my friends Rabih Neouchi, Fadi Hanna and Sam Saba for their friendship and support during my graduate study. 


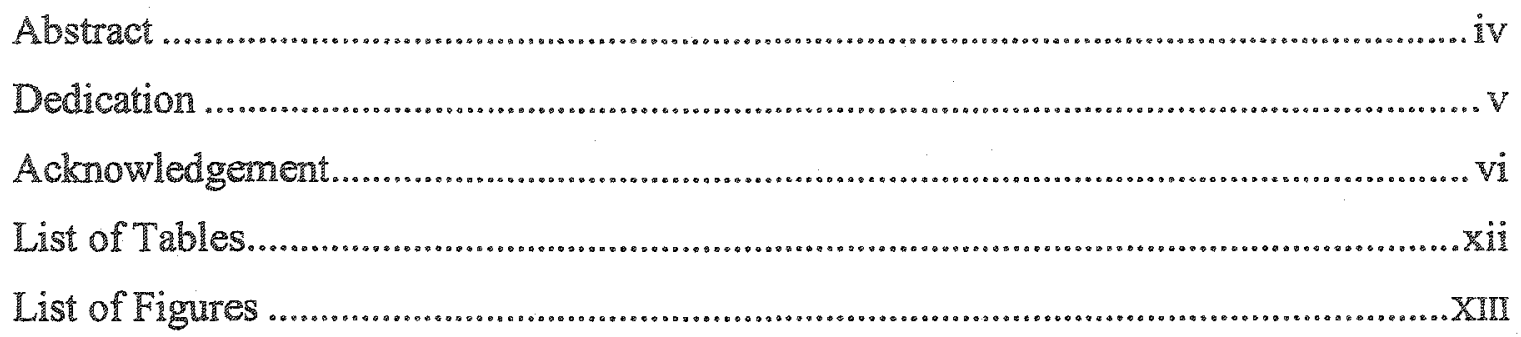

Chapter 1 Introduction ...................................................................................................... I

1.1 Background Statement .................................................................................................

1.2 Computer Science, Natural Language, and Compositional Semantics .......................1

1.3 The Problem of Adjective-Noun Combinations.............................................................. 1

1.4 Approaches to Adjective-Noun Combinations ............................................................... 2

1.5 The Problem Addressed in This Work .......................................................................2

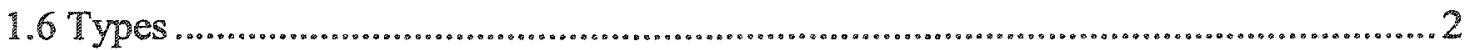

1.7 The Subsective Approach to Adjective-noun Combinations ........................................ 3

1.8 Semantics of multiple-adjective compounds.................................................................. 3

1.9 Implementation: the subsective version ......................................................................3

1.10 Analysis of Subsective Approach ................................................................................3

1.11 The Intersective Approach to Adjective-Noun Combinations................................... 3

1.12 Conclusion................................................................................................................ 4

1.13 Thesis Statement ....................................................................................................

Chapter 2 Computer Science, Natural Language and Compositional Semantics ...............5

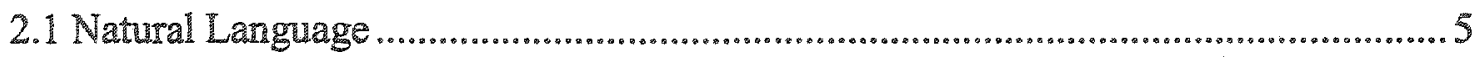

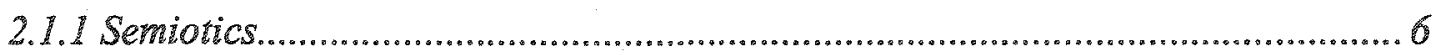

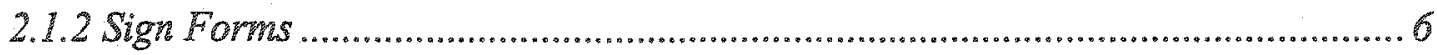

2.1.3 Structure of language ................................................................................... 8

2.1.4 Lexical Morphemes .......................................................................................... 10

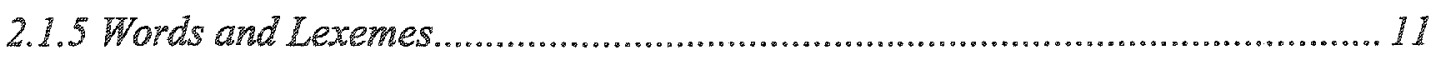


2.1.6 Grammatical Morphemes......................................................................12

2.2 Computer Science and Natural Language ............................................................... 12

2.3 Compositional Semantics of Natural Language ......................................................... 13

2.3.1 Compositionality: motivation......................................................................... 13

2.3.2 Formalizing the Principle of Compositionality............................................. I4

2.3.3 Accounting for Compositionality ...................................................................... 14

2.3.4 Compositionality and the Semantics of Adjective-noun Combinations ........... 16

Chapter 3 The Problem of Compound Nominals............................................................ 18

3.1 Types of Compounding................................................................................................... 18

3.2 Modifier-head versus Compound.............................................................................. 19

3.3 Overview of Nouns and Adjectives ...........................................................................20

3.4 Compound Nominals: problems................................................................................ 21

Chapter 4 Approaches to Adjective-Noun Combinations ................................................223

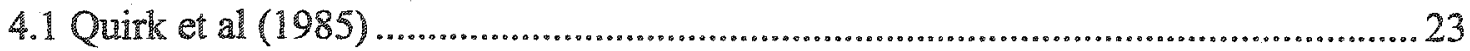

4.2 Muffy Siegel (1976) ...............................................................................................2 24

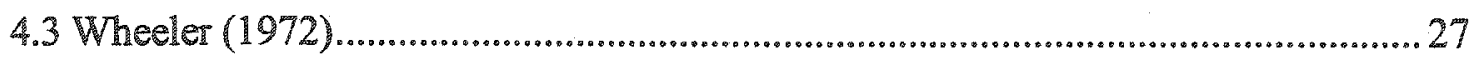

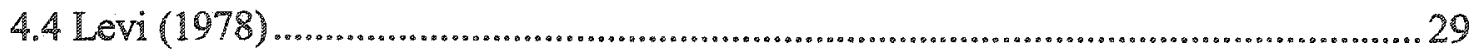

4.5 Dixon (1982), Frawley (1992), and Givón (1984) ................................................31

4.6 Chierchia and McConnell-Ginet (1990) ..................................................................... 31

4.7 Kamp (1975) and Kamp and Partee (1995) ......................................................32

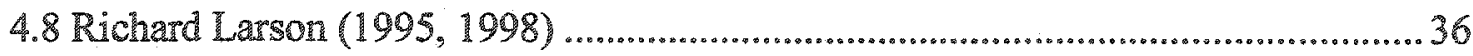

4.8.1 Davidson Semantics ........................................................................................... 36

4.8.2 Larson's Approach to Adjective-Noun Combinations .................................... 37

4.9 Summary ................................................................................................................ 37

Chapter 5 The Particular Problem Addressed in This Work ..............................................40

5.1 Adjectives: conventional view ..........................................................................40

5.2 Adjectives: our view..................................................................................................... 41 


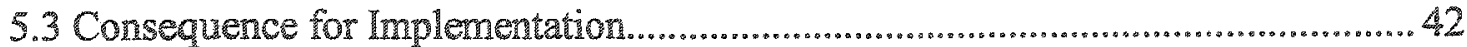

5.4 Overview of the Proposed Approaches........................................................... 42

5.5 Adjective-Noun Combinations not Addressed in This Work .............................. 43

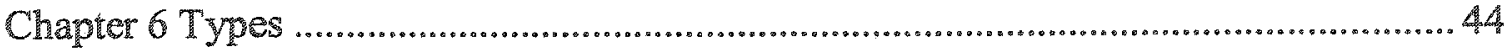

6.1 Types in Mathematics .......................................................................... 44

6.2 Types in Linguistics ........................................................................... 44

6.3 Types in Programming Languages ................................................................ 45

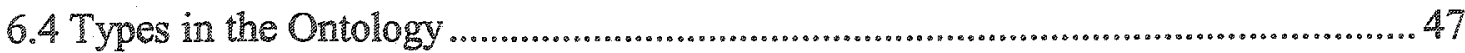

6.5 Types: Miscellaneous Topics.......................................................................... 49

6.6 An Example of a Type Hierarchy ................................................................ 51

6.7 Type Hierarchy Assumed in This Work ....................................................... 52

Chapter 7 Detailed Description of the First Proposed Approach and Examples: the subsective version......................................................................................... 54

7.1 Characteristics of the New Approach............................................................. 54

7.2 Privatives: a different perspective ............................................................. 54

7.2.1 Missing Properties ................................................................................ 54

7.2.2 Fake Guns Are Guns ......................................................................... 55

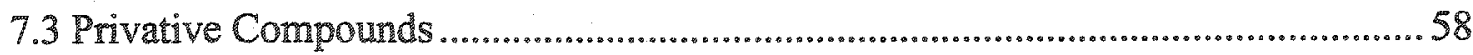

7.3.1 Privative Compounds: a typecasting operation .......................................... 58

7.3.2 Privative Compounds: a subsective componnding..................................... 61

7.4 A Uniform Subsective Approach to Adjective-noun Combinations......................62 62

7.5 Summary of Assumptions ....................................................................... 64

7.6 The Semantics of an One-Adjective-One-Noun Combination ............................65

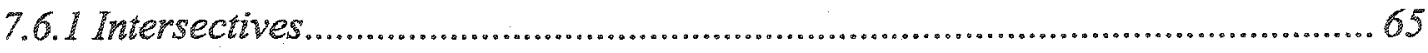

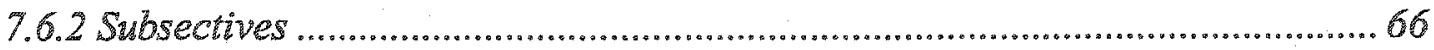

7.6.3 Privatives........................................................................................69 69

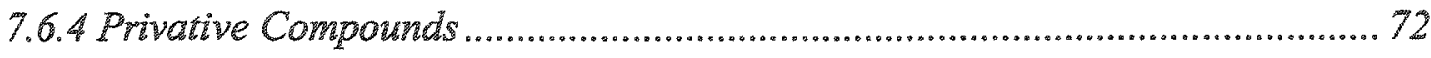

7.6 .5 Summary of Discussion ................................................................... 74 
Chapter 8 Semantics of Multiple-Adjective Compounds ...........................................76

8.1 Privative-Intersective Combination............................................................ 77

8.2 Privative-Subsectives Combination ........................................................ 78

8.3 Privative-Privative Combinations ................................................................... 80

Chapter 9 Implementation: Subsective Version..................................................... 82

9.1. Adjectival Phrase Interpreter ( $A P D)$ : building the lexicon and mapping lexemes to

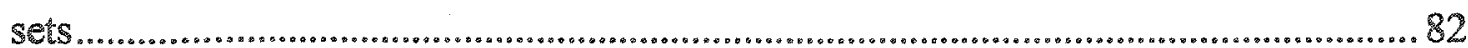

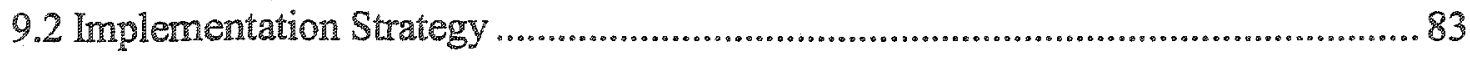

9.3 Coding and Data Representation, ................................................................. 85

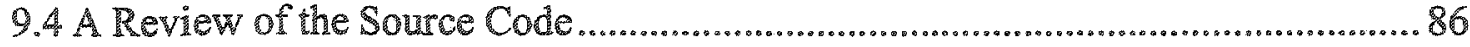

Chapter 10 Analysis of the Subsective Approach .....................................................91

10.1 Argument on Compositionality ............................................................. 91

10.2 Argument on Inference Correctness......................................................... 92

10.2.1 Case 1: single adjective and a head nomn .............................................. 92

10.2.2 Case II: consecutive adjectives and a head noum ................................... 94

10.2.3 Case III: validation of inference correctness........................................ 95

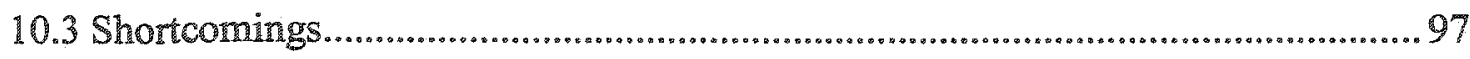

Chapter 11 Detailed Description of the Second Proposed Approach and Examples:

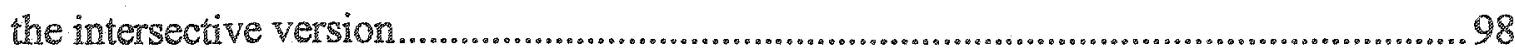

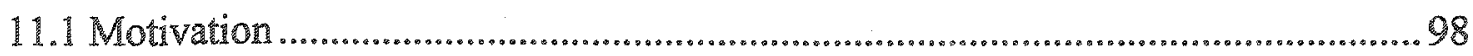

11.2 Equality of Typed Sets ....................................................................... 100

11.3 Examples Using the New Approach ............................................................ 100

11.3 .1 Intersectives................................................................................... 100

11.3 .2 Subsectives ................................................................................

11.3.3 Pure Subsective .................................................................... 103

11.3.4 Privative ................................................................................ 103 
11.3.5 Privative but Extensional Adjectives.......................................................... 105

11.4 Multiple-djectives-one-head-noun Combinations.............................................. 106

11.4.1 An Analysis............................................................................................... 106

11.4.2 A Solution .......................................................................................... 107

11.4.3 More Examples...................................................................................111

11.5 Scalar Adjectives and the Case of Vagueness.............................................................. 117

11.6 Analysis of the Intersective Approach ............................................................... 120

11.6.1 Summary of Intersective Approach ............................................................... 120

11.6.2 The Intersective Approach versus the Subsective Approach........................121

Chapter 12 Conclusion and Future Work ............................................................................ 123

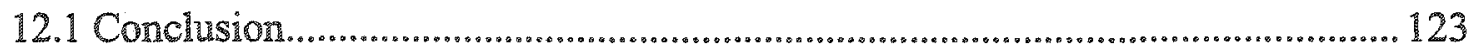

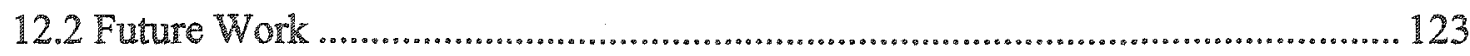

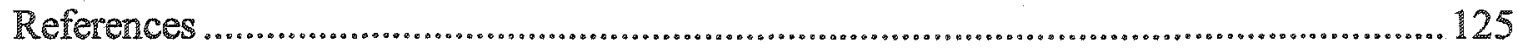

Appendix A: adjective listing.................................................................................... 132

Appendix B: implementation pattern ........................................................................135

Vita Auctoris ...................................................................................................................... 136 
Table 7-1: missing properties ............................................................................................... 55

Table 7-2: missing properties, continued .......................................................................... 56

Table 7-3: common nouns as supersets...................................................................................... 63

Table 7-4: summary of semantic operations on adjectival compounds ..............................74

Table 9-1: Abstracting implementation details .................................................................... 83

Table 9-2: applicability pattern of 'good' ............................................................................... 84

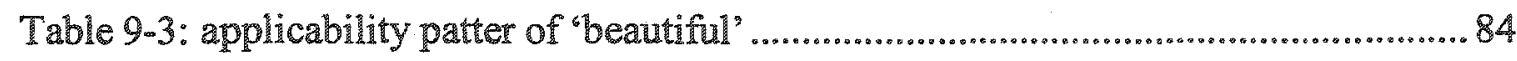

Table 9-4: applicability pattern for 'red'

Table 9-5: applicability pattern for 'veteran' .................................................................... 85

Table 9-6: the impossible pattern ................................................................................................. 85 


\section{LIST OF FIGURES}

Figure 2-1: Links in the three types of signs (Dirven and Verspoor, 1998: 4) ..................8

Figure 6-1: Porphyry's taxonomy (Sowa, 1999: 5) ..............................................................47

Figure 6-2: an example of a type hierarchy........................................................................5 51

Figure 6-3: kind/role distinction........................................................................................53

Figure 7-1: a set............................................................................................................. 64

Figure 7-2: a type/property..............................................................................................6 64

Figure 7-3: a set of people in student role.......................................................................... 65

Figure 7-4: representation of intersective adjectives............................................................66

Figure 7-5: Pure subsective adjectives: reference-modifying ................................................66

Figure 7-6: representation of reference and referent readings ............................................68

Figure 7-7: representation of fake painting .......................................................................... 70

Figure 7-8: fake Rembrandt (painting)....................................................................... 70

Figure 7-9: representation of fake gun ............................................................................. 71

Figure 7-10: representation of wooden man ....................................................................... 73

Figure 7-11: Representation of wooden man, as a subsective reading.............................. 73

Figure 8-1: representation of Student set with respect to the privatives 'fake' and 'former' 77

Figure 8-2: the representation of fake red man ................................................................... 77

Figure 8-3: representation of fake veteran manager ........................................................... 78

Figure 8-4: intersective reading of fake skilful surgeon .................................................... 79

Figure 8-5: Subsective reading of fake skilful surgeon ......................................................80

Figure 8-6: representation of former fake actor .................................................................... 81

Figure 8-7: representation of fake former actor .............................................................8. 81

Figure 9-1:a snapshot of API's database ............................................................................ 86

Figure 9-2: the coding of set operation ................................................................................ 87

Figure 9-3: representing the meaning of common nouns...................................................87

Figure 9-4: representation of subsective readings................................................................ 88

Figure 9-5: representation of adjectives .........................................................................88

Figure 9-6: defining the adjective 'good'.........................................................................89 
Figure 9.7 : definition of 'beautiful' ................................................................... 89

Figure 9-8: defining abstraction ....................................................................... 90

Figure 11-1: a taxonomy with properties ............................................................. 109

Figure 11-2: wide-scope reading of Jane is an attractive blond woman ..................... 109

Figure 11-3: narrow-scope reading of Jane is an attractive blond woman................. 110 


\subsection{Background Statement}

This thesis is about one kind of problem in natural language (NL), the problem of adjective-noun combinations. Existing solutions are investigated and new approaches to uniform treatment of adjective phrases are analyzed; conclusions are made and future work is proposed.

\subsection{Computer Science, Natural Language, and Composithonal Semantics}

One of Computer Science's ambitious goals is to create programs that are capable of "understanding" NL The research in NL involves, besides computer science, fields such as philosophy, linguistics, cognitive science, and logic.

A necessary feature of "computational" NL semantics is that of being compositional-the meaning of a compound should be a function of the meaning of its parts and the mode of syntactic combination. Thus, any approach to the semantics of NL, that is to be "implemented" on a computer, must adhere to this principle.

\subsection{The Problem of Adjective-Noun Combinations}

It has been conventionally noticed that adjective-noun combinations do not assume a uniform semantic behaviour. Some existing theories of adjective-noun combination blame the adjective for this discrepancy, while other theories blame the noun.

However, the majority of theories blame the adjective. This leads to the conclusion that adjectives belong to a hierarchy. According to this view, the semantic behaviour of the 
adjective-noun combination is anticipated if one knows the class to which the respective adjective belongs to in the adjective phrase.

\subsection{Approaches to Adjective-Noun Combinations}

Interest in compound nominals can at least be traced back to Montague (1970), Kamp (1975), and Siegel (1976), amongst others. The past work on compound nominals has mostly been an analysis of the problem, with solutions to a limited type of adjective-noun combination. Yet, a lot of work needs to be done especially on noun-noun combinations, which relies heavily on world knowledge, and uniform treatment of adjectives.

\subsection{The Problem Addressed in this Work}

In this work, we investigate two approaches to the semantics of adjectivenoun combinations. We show that there are in fact ways that adjective phrases can be treated uniformly.

In the course of the investigation, we analyze a special class of adjectives called privatives, e.g. fictitious, fake, counterfeit etc. In this class of adjectives, as the common wisdom has it, the set of objects denoted by a compound containing such an adjective is characterized by not being a subset of the objects denoted by the noun alone. We argue for an analysis contrary to that of conventional view. The new analysis helps in providing a uniform treatment of adjectives.

\subsection{Types}

The term "ype" is used in many disciplines: Mathematics, Linguistics, Philosophy, and Computer Science. The unifying theme for the use of types is to impose structure on the domain of interest.

Types are essential to our current work. Specifically, type-endowed sets are capable of better representing the complexity of natural-language expressions. 


\subsection{The Subsective Approach to Adjectivenoun Combinations}

In chapter 7 , we present an analysis of adjectives that results in the re-organization of the conventional adjective hierarchy. In particular, the class of adjectives known as privative is treated as being subsective. Consequently, we argue that adjectives are generally subsective; some of these adjectives are also intersective.

\subsection{Semantics of mutiple-adjective compounds}

Chapter 8 presents a treatment of adjective phrases that contain more than one adjective and a head noun.

\section{9 implementation: the subsective varsion}

In chapter 9 , we present an implementation to adjective-noun combinations based on the analysis given in chapter 7 . Strategies for the implementation and examples of execution are presented.

\subsection{Analysis of Subsective Approach}

Chapter 10 discusses the implementation of the subsective approach presented in chapter 9. Aspects of the implementation such as compositionality and validity of inferences as well as the shortcomings of the approach are discussed.

\subsection{The intersective Approach to Adjective-Noun Combinations}

Chapter 11 presents an approach to adjective-noun combinations under the claim that "all adjectives can be semantically treated as set intersection".

This approach makes extensive use of types. In this view a set contains typed elements. This conception makes it possible that adjectives and common nouns are represented differently. We argue this difference in representation mirrors their ontological differences. 


\subsection{Conclusion}

We conclude that adjectives are systematic in their behaviour and can be treated within set theory.

\subsection{Thesis Statement}

Despite their apparent semantic discrepancies, adjectives are systematic in their behaviour and can uniformly be treated within set theory. In support of this hypothesis, we propose two approaches: one subsective, and one intersective. These approaches, we argue, are both compositional and computationally tractable.

We also argue that the class of adjectives known in the literature as privative can be analyzed as belonging to the subsective class. This step is crucial in our argument for the uniform semantic behaviour of adjectives. 


\subsection{Natural Languge}

Language is at the nexus of human cognition. It is what sets humans apart from other species. Linguistic competence by native speakers, even at a young age with no explicit training, has puzzled philosophers for centuries. Bell (1996) writes:

It is astonishing what language can do. With a few syllables it can express an incalculable number of thoughts, so that even if a thought has been grasped by an inhabitant of the Earth for the very first time, a form of words can be found in which it will be understood by someone else to whom it is entirely new.

It is not a surprise that the study of language occupied centre stage for the bulk of the past two centuries. Fine minds tried to unlock the mysteries of language; these include Gottlob Frege, Bertrand Russell, Ludwig Wittgenstein, Rudolf Camap, and Richard Montague. In appreciation of its complexity, Allen Turing (1950) set out his famous, but debatable, test as a criterion of intelligence, which roughly states a computer program is intelligent if it can pass a natural-language competence test. More than 50 years has passed and the world is still awaiting such a program.

Despite the complexity of natural languages and being described by some linguists and philosophers as unsystematic, two daring hypotheses were advanced in the past century: one at the syntactic level, advanced by Noam Chomsky, and the other at the semantic level, advanced by Richard Montague. Peregrin (1997) states that formalization of natural language-as conceived by authors such Carnap, Tarski, Morris, and articulated in Montague (1974)--seems to be established on the view that language consists of: i) a list of words, i.e. the lexicon; ii) a set of rules for generating new expressions from the basic 
ones, i.e. the syntax; in an assignment of some basic set-theoretic objects to the basic expressions of the language; and, iv) an assignment of operations over the set-theoretic objects to complex expressions ${ }^{!}$. It seens that the bulk of research in language is either in Ine with these hypotheses, stimulated by them, or provoked by them, with Al as the testing ground.

\subsubsection{Semiotics}

All species have certain forms of communication. Communication can be verbal or non verbal. A bee, for example, indicates to its peers the distance to the source of food by dancing; monkeys produce different cries that are understood by the rest of the herd, as waming signs that a predator is approaching, for example.

Semiotics is the systematic study of signs. There are three types of signs: indices, icons, and symbols. Different species use some of these signs for communication. Human language stands out as the only form of communication that involves the use of all forms of signs.

\subsubsection{Sign Forms}

In its widest form, a sign signifies (or stands for) something in the world, i.e., its meaning. An indexical sign is a means of pointing at some thing(s) within the observable reach of the communicating parties involved in some sort of communication. Gestures, finger pointing, facial expressions, and signs are example of indexical signs.

An iconic sign is a means of communication using some form of perceptual images that bear close resemblance to the thing in the world. This type of communication was used by ancient cultures. For example, in ancient Egypt it was extensively used. This is indicated by the name of the language of ancient Egypt, know as hieroglyphics. Nowadays, we still use icons such as that of a heart, which symbolizes love, and more recently icons are used extensively in the software industry.

\footnotetext{
${ }^{1}$ In fact, Montague's approach assigns functions, not set-theoretic semantic objects to expressions of the language. See Dowty et al (1981).
} 
The third, most important and more complex form of cormunications is the use of symbolic sigms. What distingushes this form from the other two forms of signs is that the symbols used in communication have no natural resemblance with the thing(s) represented. Word forms, and stop signs are examples of this system of signs. Another example is the word beauty, which bears no visual relation to its meaning.

Indexical signs are considered to be the most primitive form of communication. They camnot go beyond the time-place proximity where the communication process takes place. This kind of sign characterizes animal communication. However, humans make an extensive use of it in their daily life.

Iconic signs may range from simple to complex in their expressiveness. In their simplest form, they bear a plain resemblance to their designata; and, in their sophisticated form they are highly stylistic, as is evident in logos of companies, and sporting and artistic events.

Symbolic signs fall totally within the human-cognitive capability. The use of symbols requires transcendence over the time-place dimension. This is because humans require more tools for communication than mere pointing or replicating things that physically exist within the range of their auditory or visual systems. Humans want and are capable of talking about things that do not exist "here" and "now", even about things that never existed, such as figures in mythologies. Also, humans want to talk about things that exist out of the realm of time and space, i.e. abstract things. Another unique characteristic of symbols is that they can be used refexively, i.e. symbols can mention other symbols.

The distinction between the different forms of signs is depicted in Figure 2-1 (Dirven and Verspoor, 1998). 


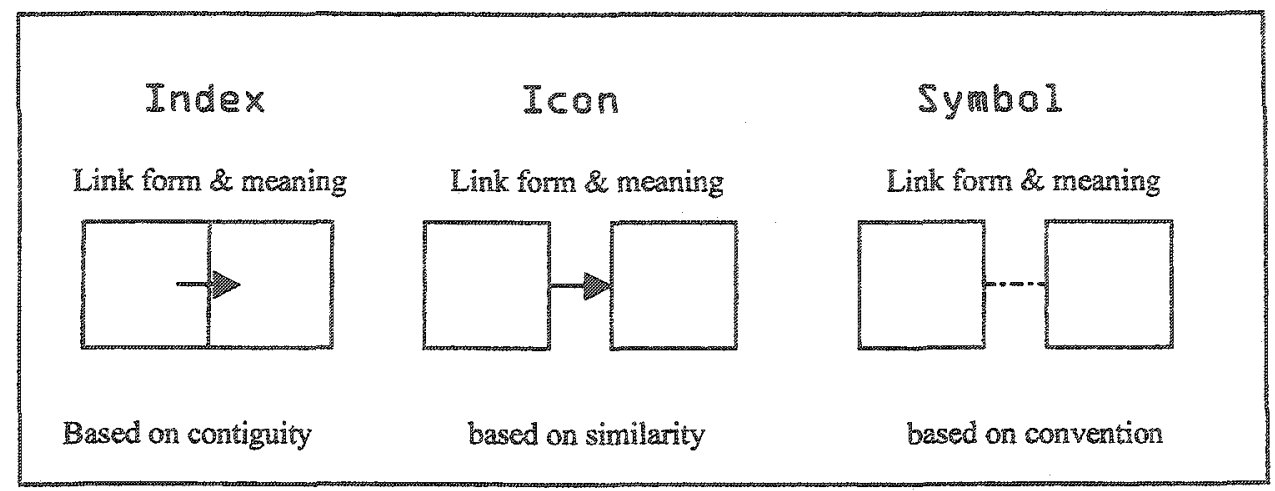

Tigure 2-1: Links in the three types of signs (Dirven and Verspour, 1998: A)

As Figure 2-1 shows, there is a link between form and meaning in the cases of indexical and iconic signs-indicated by solid arrow. The link between symbols and meaning, however, is arbitrary-this arbitrariness is indicated by a dashed line in the figure.

Despite its symbolic nature, language makes use of the other two forms of signs, i.e., indexical and iconic signs. The indexicality effect in the (symbolic) language is evident in words such as here, there, $I$, you, we, now, etc. Similarly, the iconic effect can be found in very obvious cases in words such as the cry of a cat's meow; and the more subtle cases as in word order-the subject, the verb, and the object in English sentences, for instance.

\subsubsection{Structure of language}

The division of semiotics-the discipline that studies systems of signs in thl their manifestations-into the shree parts of symtax, semantics, and pragmatics is widely acknowledged, in philosophy and linguistics. This trichotomy can be traced back to the philosopher Charles Sanders Peirce (1839-1914). This trichotomy is described in Charles Morris (Sowa, 2000). Morris systematically articulated what he called the theory of signs (or "semiotics") into the three parts: syntax, semantics, and pragmatics. Each of these parts is defined by its subject matter. Pragmatics is defined as the study of the relations of signs to interpreters. Semantics is the study of the relations of signs to the objects to which the signs are applicable. Syntax is the study of the formal relations of signs to one another. 
Camap accepted Peirce's threefold classification of semiotics into syntax, semantics and pragmatics, and added his own definitions for each part. Carrap's conception of pragmatics, semantics, and syntax goes as follows: "If, in an investigation explicit reference is made to the speaker, or, to put it in more general tems, to the user of the language, then we assign it to the field of pragmatics... If we abstract from the user of the language and analyze only the expressions and their designata, we are in the field of semantics, and if, finally, we abstract from the designata also and analyze only the relations between the expressions, we are in (logical) syntax" (Lyons, 1977).

In the natural language understanding (NLU) literature and linguistics this division is further elaborated to include more parts. Allan (1995), lists the following levels of analysis in $\mathrm{NLU}$

- Phoretic and phomological knowledge. This level investigates the relation between words and the sound, generated by the human-speech-producing organs, that realizes them.

- Morphological knowledge. Morphology investigates how words are constructed from more basic units called morphemes. For example, the comparative adjective 'Ticher' is composed of the lexeme 'rich" and the suffix 'er'.

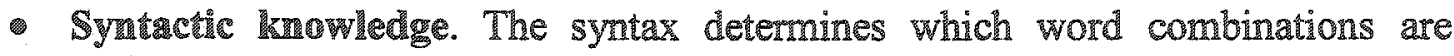
allowed. That is, the syntactic well formedness.

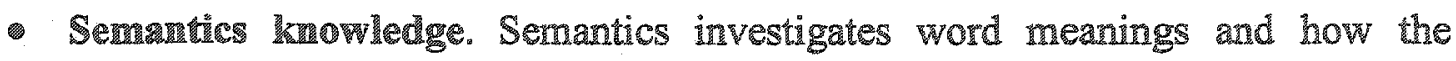
meaning of an expression is determined from the meaning of its constituent words.

- Pragmatics knowledge. Pragmatic knowledge is concemed with determining how sentences are used in different simations and how use affects the interpretation of the sentence.

- Disconrse knowledge. Discourse knowledge takes a wider approach for amiving at an appropriate interpretation of a certain utterance that goes beyond a single sentence. Such knowledge can be used, among other things, to resolve anaphoric ambiguity. 
- World knowhedge. Language users mploy knowledge about the world in order to conduct successful communication. Such lmowledge is necessary in order to understand each other's goals and beliefs.

Furthermore, Allen provides the following example, which aims at providing a clear distinction between syntax, semantics, and pragmatics (in an initial statement to a $\mathrm{N} U \mathrm{U}$ text book):

1. Language is one of the fundamental aspects of human behaviour and is crucial a component of our lives.

2. Green hogs have large noses.

3. Green ideas have large noses.

4. Large have green ideas nose.

Sentence (1) is in accordance with the grammar of English, semantically well formed, and relatedness to the context (i.e. NLU content) makes it a plausible sentence. Sentence (2) is both grammatically and semantically acceptable, but fails on the pragmatic account. Sentence (3) is syntactically well formed, but fares badly on the both the semantic- - for it cannot be affimed or denied in a coherent way- and pragmatic accounts. Finally, sentence (4) fails on all accounts.

This division of labour of semiotics, as stated above, is usually applied to both constructed and natural languages. It seems that the Peirce-Morris's three-part division is gencrally accepted within the AI community (at least classical AD). However, this trichotomy of semiotics has not gone unchallenged. For example the distinction between syntax and semantics as in (3) is not clear, and it is theory-dependent.

\subsubsection{Lexical Morphemes}

Language is a system that is composed of vocabulary and string of words formed in accordance with the grammar of the language. This defmition suggests that words are the smallest units in the language. However, some words can be analyzed further into more 
basic units or morphemes. Morphemes are traditionally defined to be the smallest meaningful unit in the language this definition is controversial as is evident in a word such as cranberry, where the morpheme cran has no clear meaning as opposed to the berry. Morphenes are of two types, grammatical and lexical. A morpheme, grammatical or lexical, can be basic or free or bound. Words are built out of these two types. For example, a free morpheme such as 'teach' can combine with an affix er to form the word "teacher". In this example 'teach" is a free morpheme while the postrix er is a bound morpheme. Thus, free morphemes can alone function as words, while bound morphemes cannot.

Composite words can mainly be built in two ways: compounding and derivation. A compound consists of two free morphemes, as in "physics book"; and, a derivation consists of a free morpheme and one or more bound morphenes, as in 'lawlessness'. Complex types of composites may involve one or more of the above, e.g." music-loving child", 'prehistoric creature', etc.

\subsubsection{Words and Lexemes}

The tem 'word' is pre-theoretical and can have different senses. Linguists use the more technical tem 'lexeme' to represent an abstract linguistic entity, which might be realized by different word forms. These forms can be orthographic-as a string of certain shape on a paper, for instance, or phonological-as generated by the auditory system. A conventional dictionary lists the citation forms of lexemes of the language, not the lexemes themselves. Thus, for example, the lexeme 'write' has the ciration form write and the forms writes, wrote, etc. New lexemes can be generated from existing ones by means of derivation. Lexemes can be simple as well as complex. Phrases such as "red hering" and 'kick the bucket' are also referring to lexemes that are distinct form wordlexemes. This point is made clear by Lyons $(1977, p 23)^{2}$ : "Roughy speaking, we can say that lexemes are the words and phrases that a dictionary would ist under a separate entry."

\footnotetext{
${ }^{2}$ In this report and following Lyons(bid $)$ we will use single quotes to indicate lexemes.
} 


\subsubsection{Grammatical Morphemes}

The morphological effects are also evident in the grammar as well as the lexicon. Grammatical morphemes distinguish two types of morphemes, free morphemes like the particle to in to go and bound morphemes like the third person ending $s$ in He loves her. This combination of bound grammatical morpheme, i.e. $s$ and word such as love is called inflected form. The free grammatical morphemes, also called functional words, are to be contrasted with content words such as dog or love. The combination of a function word with one or more content words is called a syntactic group.

\subsection{Computer Science and Natural Language}

It is of a great interest to Computer Science and its sub-field Artificial Intelligence to produce competent applications that model human cognition. Interest in language comes to the fore. Research in natural language involves text-based and dialogue-based applications. Text-based applications include information retrieval from databases, internatural-language translations, and text summarization.

Dialogue-based applications involve human-machine communication, directly or using computer input peripherals such as keyboards. Examples of such applications are database question-answering systems, educational systems, automatic customer service on phones or over the Internet, etc.

It is worth mentioning that it is not sufficient for an application to receive a string of characters in some natural language and produce some kind of response to qualify as "understanding" natural language. For example, current Internet search engines do a very good job in responding to some query posed by Internet users. Such systems match the query against some keywords associated with the documents. These systems do not seem to understand the phrases in the queries. This is evident from the many irrelevant documents that are retrieved as potential responses for the query. The methods that are used in these systems apply brute-force techniques that are far from being real understanding. Understanding involves the creation of representations for the target data and query. Also, in dialogue applications, accumulating information as the dialogue goes 
on is essential; in effect, representation goes beyond phrases and sentences and towards building a discourse representation.

\subsection{Compositional Semantics of Natural Language}

\subsubsection{Compositionality: motivation}

One of the puzzles that face scholars of natural language is the ability of language users to grasp/produce (almost) infinitely many utterances. Yet a user has finite mental resources, e.g. memory. A reasonable explanation of such a phenomenon is that a language user knows the meaning of the individual lexemes and the rules for building complex phrases from simpler compounds. These lexemes retain their meanings in whatever utterances they participate in. For example, the lexeme ' $k i c k$ ' has the same meaning in the following utterances:
a) The boy kicked the ball.
b) The boy kicked the dog.
c) The horse kicked his jockey.

This observation led to the formulation of what has become known in the semantics literature as the Principle of Compositionatity, PC. PC states that the meaning of an expression is a function of the meaning of its constituents and the mode of combination. Another definition of compositionality is postulated as the existence of a homomorphism from syntax to semantics (Partee et al, 1990).

Unfortunately, not all namual-language expressions have straightforward or even known rules that reveal how they are compositionally composed. Kicked in the old man kicked the bucket seems to have lost its regular meaning. Also, modal expressions and some compound nominals seem to be difficulty accommodated within $\mathrm{PC}$. This is a challenge that semanticists must take in order to show that their systems have general applicability. 


\subsubsection{Formalizing the Principle of Compositionality}

Many authors (e.g. Zadrozny $(1992,1994,1999)$, Hirst (1988, 1987), Kamp \& Partee (1995), and Janssen (1997)) stress that PC, as stated above, is not formal. In criticizing Woods $(1967,1968)$ as being non-compositional, Hirst (1988) suggests that PC should be rephrased as follows in order for it to be formal:

"The meaning of the whole is a systematic meaning of the parts"

Zadrozny (1992) agrees with Hirst's analysis and further suggests providing a formal account of systematicity. Zadrozny claims that without these changes to the PC statement, $\mathrm{PC}$ is vacuous.

Kamp \& Partee (1995) states that clarifying the following notions is a minimum requirement in order for $\mathrm{PC}$ to be precise:

a) A theory of lexical semantics in order to account for the smallest parts.

b) Specification of the part-whole structure.

c) Specification of the functions responsible for calculating the meaning of wholes from their parts.

In Montague's highly formalized system (b) and (c) are accounted for by the use of a strongly typed system and the mapping of syntactic rules into semantic rules such that for every syntactic rule there is a semantic rule that computes the meaning of the whole from its constiments. Montague's approach appears to satisfy all of the above definitions of compositionality.

\subsubsection{Accounting for Compositionality}

In logic, as Janssen (1997) notes, PC is taken for granted. Propositional logic is an obvious case where compositionality is adhered to: the meaning of a logical formula is its truth-value, and the meaning of a compound formula is a function of the truth-values of 
its pars. In predicate logic, due to quantification, the interpretation process is more complicated, but ultimately it is compositional.

Compositionality occupies centre stage in programming languages. Programming languages have come long way: from primitive instructions that control the hardware, i.e. machine language, to full-fledged languages with syntax and semantics. This enabled computer scientists to prove or disprove the correctness of an algorithm. Such concerns are the realm of Denotation semontics.

Because of the diversity and complexity of natural-language expressions, accounting for compositionality is not straightforward. For example, consider the treatment of the noun phrase the US president in the following examples:
a) The US president is traveling to Europe.
b) The US president was assassinated in 1963.

The expression the US president extensionally denotes two distinct individuals. Thus, it would seem contradictory to PC. Intuitively, this is due to the time-variability factor. Once such a time variability is incorporated into the notion of meaning, as suggested by Lewis (1970), compositionality is maintained. This is achieved by considering noun phrases as functions with indices as domain and individuals as values of the functions, i.e. intensions. Thus, in $(2-3-a)$ and $(2-3-b)$ when the noun phrase The US president is treated as a function, compositionality is maintained.

In the philosophy of language, writers such as Frege, Carnap, Lewis, and Montague are among the main contributors to the provision of a compositional account of naturallanguage expressions. Montague's PTQ is a classical work in providing compositional interpretation of a fragment of English. In this work, Montague resorted to more abstract notions of meaning, as was shown in his well-known Imensional Logic (IL). However, because of its invocation of higher order-logic and notions such as possible worlds, IL (in its original form) is not readily transferable into a computer program, i.e. machine- 
tractable. Also, as stated in Hirst (1988), Montague semantics is truth-conditional, "IIn Al] we are interested not so much whether a state of affairs is or could be true in some possible world, but rather in the state of afrairs itself". Consequently, semantic theories such as Knowhedge-base semantics suit Al applications more.

It should be noted that Frost and Boulos (2002) regards Montague semantics not as truthfunctional. They ignored the intensional logic and implement Montague's semantics directly (although they convert the function space of Montague's semantic ontology to set theory).

\subsubsection{Compositionaliy and the Semantics of adjectivenoun combinations}

Adjectival phrases are of great interest to scholars who are concemed with compositionality. It tums out that, hough syntactically simple, adjective-noun combinations do not exhibit a simple homomorphism between syntax and semantics. This leads some authors to go as far as arguing against compositionality, e.g. see Lahav (1989).

This thesis is concemed with the compositionality of adjective-noun combinations such as "red car", "former senator", and "beautiful dancer". Some of these combinations such as "red car" have simple compositional semantics. Other combinations are more problematic, as discussed in more detail in chapter 7.

Suppose the syntax of adjective-noun combinations is:

$$
\text { an::=adi moun }
$$

then, the challenge is to determine the function $F$ in the semantic rule: where $\|x\|^{3}$ represents the denotation of $x$.

$$
\| \text { and }=F(\| \text { adj, Mnoun }
$$

\footnotetext{
${ }^{3}$ The symbols "III" represent the interpretation finction.
} 
In this work, we will provide semantic accounts of privative adjectives and adjectives in general that are both compositional and setheoretic, within the framework of denotational semantics. 


\subsection{Types of Compounding}

There are different types of compounding. They are syntactically motivated. Phonologically, the first element in the compound receives the main stress. However, it is generally the second element that detemines the compound's new word class. In turn, the head of the compound belongs to one of the three major word classes, noun, verb, or adjective. The following examples illustrate these different combinations:

\section{(3-1) Novin Compounds}
a) Kitchen chair, wheel-chair (noun + noun)
b) rocking chair, swivel chair (verb + nown)
c) highchair, easy chair (adjective + noun)
d) over dose, over imagination (prepositiont noun)

The semantics of noun compounds is determined by the semantics of their constituents. Typically, nouns denote stable states, (transitive) verbs denote relations, and adjectives can denote both. World knowledge is essential in detemining the correct meaning of compounds. For example, criminal lawyer is typically not a lawyer who is criminal. Rather a lawyer who takes criminal cases. Similarly, alligator shoes are not shoes wore by alligator. Rather shoes made of alligator skin.

\section{(3-2) Verb Comapoudis}
a) to vacume-clean, to manhandle noun + verb
b) to sleep-walk, to blow-dry verb + verb
c) to dry-clean, to highlight adjective + verb

As Dirven and Verspoor (1998) observe, verb compounds usually denote an event in the head of the compound, while the first constituent indicates the circumstances under which the event occurs. 
Adjective Compounds

(a) colour-bind, duty-free roun + adjective

(b) soakingwet, stinking-rich verb + adjective

(c) dark-blue, pale-yellow adjective + adjective

In (3-3), the adjective head is further specified by the frrst element of the compound; in (3-3-a) the noun provides the field to which the adjective head applies; in (3-3-b) the verb has a sense of "very"; and, (3-3-c) the rirst adjective futher specifies the shade of color denoted by the head adjective.

\subsection{Modifler-head versus compound}

Compounds can be dissimilar semantically and phonologically. This is illustrated in the following examples:

(3-4) Compound (idiomatic)
(a) black board
(e) black board
(b) paper basket
(1) paper basket
(c) 'brick factory
(g) brick factory
(d) "toy store
(b) toy store

The compounds $(3-4-2)$ to $(3-4-d)$ have one main stress usually on the first element of the compound, while modifier-head-called "syntactic group" by Dirven and Verspoor (1998)-receive a primary stress on the second element of the compound and a secondary stress on the first element of the compound.

Semantically, in the compounds, i.e. $(3-4-a)$ to $(3-4-a)$, the sum of the meanings of the composing elements is not equal to the meaning of the compound (ibio). A board in 'black board is not necessarily black, and a basket in "poper basket is not necessarily made of paper-is is used for disposable papers. Similarly, a store in "toy store is not a toy. Instead, it is a store that sells toys. These examples are to be contrasted with the examples in $(3-4-e)$ to $(3-4-h)$. For example, toy store is a toy. Toy in this example 
functions as an adjective, which according to Kamp and partee (1995) means "a toy version of...".

The compounds are heavily context-dependent. Thus, an adequate semantic treatment for them must rely on encyclopedic knowledge. Generally speaking, compounds, in the senses illustrated above, originate as syntactic compounds. They acquire a more specialized meaning by virtue of frequent use, as in 'country house'. It is due to this fact that new (compound) lexemes are included into the dictionary. For example, due to the increased use of the Intemet and the popularity of the World Wide Web, more recent dictionaries contain compounds such as 'Intemet cafe' or 'chat room'.

This work is concerned with providing a semantic account for adjective-noun combinations, which are compositional, as opposed to those having fixed meaning. Thus, when we say compound nominals, we mean those that admit compositional interpretation.

\subsection{Overview of Nouns and Adjectives}

A noun denotes a class of things that falls under its denotation. The meaning of the noun can be modified. Noun qualification is a task mainly achieved through another member of the syntactic category: the adjective. An adjective usually denotes some properties denoted by the noun it combines with, as mainstream linguistic tradition has it. This semantic relation between an adjective and its head noun is expressed by Jespersen (1929, see Raskin and Nirenburg (1995)). He notes that adjectives are more applicable than nouns (termed 'substantives' by Jespersen). Jespersen states:

on the whole, substantives are more special than adjectives, they are applicable to fewer objects than adjectives, in the parlance of logicians, the extension of a substantive is less, and its intersion is greater than that of an adjective. 
Syntacticaly, as the traditional literature has it, and as stated in lyons (1977: 438-439), atributive adjectives act as modifiers to the nouns hey combine with. However, Lyons realizes that this statement about adjectives is not universally valid, or at least questionable, regarding some subclasses of adjectives. This can be demonstrated by considering the following examples (from Raskin and Nirenburg, 1995):

a) This is a good book i.e. attributive use

b) This book is good i.e. predicative use

In (3-5) the good is (syntactically) used atributively in (3-5-a) and non-atributively (i.e. predicatively) in $(3-5-b)$.

There are some peculiarities that adjectives have as Lyons (ibid) notes: contrary to nouns, adjectives are usually defined (by dictionaries) by appealing to syntax rather than scmantics; there are languages that do not have adjectives in their syntactic categories; in such languages adjectives' semantics spans over that of typical verbs and typical nouns.

\subsection{Compound Nominals: problems}

The grammars of many languages allow the combination of noun(s)/adjective(s) with the head noun to form a compound nominal. The semantics interpretation of such a compound has proved to be very hard to account for. Consider the following examples:
a) baby shoes
b) alligator shoes
c) designer shoes

Each of these compounds expresses different semantic relationships between the modifier and its head noun. That is, there is no easily-recognizable pattem that accounts for their semantics. 
Similarly, adjective-noun combinations exhibit variation in sernantics interpretations. Consider the following adjectival phrases:
a) red apple.
b) skilful surgeon; beautiful dancer; old friend.
c) potential candidate.
d) fake gun.
e) holy grail.

Intuitively, adjectives constrain the domains denoted by the noun they modify. Alternatively, they denote some properties of things denoted by the noun. If we consider the head noun as a predicate or a set, the effect that an adjective has is to reduce the extension of the set denoted by the noun to a subset of it. This applies to (3-7-a) and (3-7b) above, but not (3-7-c) and (3-7-d). Further (3-7-a) and (3-7-b) are not amenable to the same semantic treatment since red in (3-7-a) is semantically different from skilful in (3-7b). The former can be semantically represented as an intersection of the denotation of two predicates while the latter cannot. Adjectives such as red are called intersectives while those similar to skilful are called subsectives.

Adjectives such as those in (3-7-c) and (3-7-d) are non-subsective. In (3-7-c), a potential candidate could be a candidate but could equally be otherwise. Other adjectives in this class are possible and likely. This class of adjectives has modal behaviour. Therefore, a modal-theoretic approach to this class of adjectives seems promising. 


\section{Chapter 4 APPROACHES TO ADJECTIVE-NOUN COMBINATIONS}

This chapter presents a survey to approaches and analyses involving a special kind of compound nominal: adjective-noun combinations.

\subsection{Quirk et al (1985)}

For Quirk et al, adjectives can be classified semantically into three subclasses. These are stative/dynamic, gradable/nongradable, and inherent/noninherent.

The stative/dynamic view of adjectives is compatible with those expressed by (Givon, 1984). In such a view, adjectives occupy a middle position on a scale, with nouns and verbs at two opposing extremes. This is evident in the case of adjectives derived from nouns. Such adjectives are seen to be more stable-i.e., they attribute stable properties to entities denoted by the noun they combine with. This is to be contrasted with other adjectives, which seem to express transitory properties to activities or behaviours--.e.g. 'Playful'. Stative and dynamic adjectives can be told apart by means of the combination with the verb 'to be' and imperative verbs. The adjectives 'tall' and 'unreasonable' in (11) are examples of the static/dynamic distinction, respectively.
a) The boy is tall
versus
* The boy is being tall
b) The boy is being unreasonable.

Gradability is another way of distinguishing adjectives. All dynamic adjectives are gradable, whereas most stative adjectives are non-gradable. This is usually achieved through the use of adverbs such as 'very', or by means of the morphological comparative and superlative. In fact, Quirk et al are examples of scholars who believe that the criterion of gradability is such a defining property of adjectives whereby the status of 
relational adjectives is questionable of being truly adjectives. Some scholars go the distance by describing relational adjectives as "pseudo-adjectives" (Maurel, 1993) and Melis-uchulu, 1991).

Inherent adjectives characterize the referent of the noun they combine with, while the noninherent do not. This is illustrated by the following key examples:

a) That is my old friend

b) That is an old man

Old in the first example characterizes the intension of the noun 'friend", hence, it is noninherent. While old in the second example modifies the referent, hence, it is inherent. Quirk et al, also, use the inherent/non-inherent argument as a distinguishing criterion between adjectives at the syntactic level. Based on that view, non-inherent adjectives are typically attributive, and some can be predicative as in (4-3), (from Peters and Peters, 2000)

(4-3) That Student is new

\section{Mutfy Siegel (1976)}

Siegel observes that the part of speech traditionally called "adjective" in fact underlies two syntactically and semantically distinct classes as discussed below:

CLASS

Nonintersective Adjective relative

intensional

reference-modifying

ad-common nouns

\section{CLASS}

Intersective Adjectives

absolute

extensional

referent-modifying

one-place predicates

\footnotetext{
${ }^{4}$ Relational adjectives are morphologically derived from nouns (i.e. denominal) or derived from verbs (i.e. deverbal). Syntactically, they appear only atributively. Semantically, they are neither gradable nor comparable. Medical in That is a medical doctor is an example of a relational adjective.
} 
$\mathrm{CN} / \mathrm{CN} \quad$ te or $\mathrm{t} / \mathrm{le}$

Where $\mathrm{CN} / \mathrm{CN}$, $t e$, and $\mathrm{w} / \mathrm{e}$ are (syntactic) categorial grammar notation. $\mathrm{CN} / \mathrm{CN}$ designates the category that take a common noun to form a common noun, i.e. the atributive adjectives, while $/ / e$ or $t / / e$ designates things that take an entity to form a sentences, i.e. predicates. Siegel uses "w//e" to distinguish predicative adjectives from other predicates such as intransitive verbs that are assigned the category ${ }^{64} / \mathrm{e}^{93}$.

Siegel provides syntactic and semantic arguments to support her claim. Consequently, an adjective, according to Siegel's analysis, can be exclusively reference-modifying (class 1 in (4-4) such as "veteran', exclusively referent-modifying (class II in (14)) such as 'carnivorous', or both such as 'beautiful', as in (15).

$(4-5)$

Maria is a beatiful dancer.

(4-5) has two readings. One reading describes Maria's physical beauty. In this reading beautifinl has absolute sense, for it describes the referent of "dancer". This is expressed as set intersection involving the denotations of the predicates Beautiful and Dancer, the intersective reading. Since this reading involves the referent of dancer, it is extensional. In the other reading, the meaning of beautiful is relative to that of the noun 'dancer'. It says that, "Maria dances beautifuly". Since entertaining this thought involves knowledge about dancing, it is intensional. In set-theoretical terms, is says that Maria belongs to the set of dancers-the subsective reading. These readings are possible since beautiful, according to Siegel, belongs to two distinct syntactic categories, i.e. CN/CN for the subsective reading and $t / / \mathrm{e}$ for the intersective reading, and two distinct semantic types, 1.e. (according to Montague Grammar) $<<,<s, e>, t>>,<s, e>$, $p>$ for the subsective reading and $<s, e>, p$ for the intersective reading. This behavior of the adjective 'beautiful' and many others, lead Siegel to advance her theory of double adjectives.

The syntactic position of the adjectives doesn't readily reveal this behavior. However, the attributive-only ("prenominal") of the category CN/CN are reference-modifying, while 
the predicative-only adjectives of the category $/ / / \mathrm{e}$ are referent-modifying, But, according to the author, the majonty of adjectives can occur in both positions, as CN/CN and as $t / / e$, see the Appendix A.

Siegel provides rules $(4-6)$ and $(4-7)$ to account for the predicate-to-prenominal and prenominal-to-predicate transformation of the adjectives, respectively.

$\mathrm{CN}_{1}\left\{\right.$ which, that, who\} be $\mathrm{ADJ}_{4 / \mathrm{e}} \rightarrow \mathrm{ADJ}_{\text {U/e }} \mathrm{CN}_{1}$

be $a[A D J] C N / C N \triangle_{C N} \rightarrow$ be $[A D J] C N / / C N$

Where " $\Delta$ " is a variable of type "common noun".

Using rules (4-6) and (4-7), Siegel accounts for the ambiguity of (4-8) between the intersective and non-intersective readings.

(4-9) That lutist is good.

Thus, according to rules (4-6) and (4-7), (4-8) can have the following readings .
a) That lutist is a good $\mathrm{CN} / \mathrm{CN} \triangle \mathrm{CN}$
b) That lutist is goodt//le

The dummy common noun " $\Delta$ " is understood to be lutist. However, Siegel leaves open the possibility of having a different common noun that might be supplied to the semantics by the linguistic or pragmatic context, e.g. That lutist is a good golfer.

An adjective can be in a prenominal position as a part of the predicate, as in (4-10). (40-10)

That is a good lutist. 
In $(4-10)$, although good is in the prenominal position, it is still ambiguous. It has the following two possible readings.
a) That utist is a goodcn/CN lutist
b) That is a lutist who is goody/le

Siegel uses the consistency test, as many authors do, to tell apart the intensional and extensional adjectives. This test roughly states that when an intersective adjective combines with co-extensive nouns, the resulting noun phrases remain co-extensive.

As with regard to scalar (or "relative") adjectives, Siegel supports Kamp's (1975) argument that scalar adjectives should be classified as type t//e other than type $\mathrm{CN} / \mathrm{CN}$. Despite the apparent observation that scalar adjectives fail the consistency test. This is due to context and/or the vagueness of scalar adjectives. Siegel notes that vague and context-dependent intersectives can be rephrased with for-phrase as in John is tall for a 10-year old boy; while non-intersective adjectives can be rephrased with as, e.g. skilful as a footboll player. Siegel concludes that there are no adjectives of type CN/CN that can function as scalar adjectives. On the other hand, not all $t / / \mathrm{e}$ adjectives are scalar.

\subsection{Wheeler (1972)}

Wheeler (1972) notes that some attributes create intensional contexts others do not. For example, if John is a tall man, and all and only men are featherless bipeds then John is a tall featherless biped is valid. However, the adjective 'good" does create an intensional context as in if Jack is a good nail-hammerer and all and only nall-hommerers are carpenters it doesn't follow that Jack is a good carpenter, for Jack might only master the very one aspect of carpentry which is nail hammering.

Wheeler challenges the-then-conventional wisdom of treating adjectives as one-place predicates in analyzing atributives (be it an adjective or an adverb). Instead he suggests the use of a binary relation and a membership sentence expressing the relatedness 
between the individual and the class to which the individual belongs. Thus a sentence such as John is a tall man is rendered:

Tall $\left(j, \wedge_{y}(y\right.$ is a man $\left.)\right) \&$ je $\wedge(y$ is a man $)$.

This formula says, "John is a tall relative to the class of men, and John is a man". The emphases here are on the reading of the first conjunct. The first conjunct cannot be read as "John is a tall man" since the second conjunct implies such reading. Instead it should be read, "John is tall relative to the class of men". This phrasing allows Wheeler to account for negation effectively. For example, the negation of the sentence Worf is not a tall man is as $(4-12-b)$.

$(4-12)$

a) Worf is not a tall man.

b) $\rightarrow[T a l l(w, A x(x$ is a man $)) \& w \in \wedge(x$ is a man $))]$

- Tall (w, $\wedge_{x}(\mathrm{x}$ is a man) $) \vee \neg\left[\mathrm{w} \in \wedge_{\mathrm{x}}(\mathrm{x}\right.$ is a man $\left.\left.)\right)\right]$

This analysis admits the case where Worf, the science fiction Star Trek figure, is not even considered a man.

Wheeler applies this analysis to other cases such as Maria is a beautifal dancer. This analysis is represented in (4-13).

(4-13)

a) Maria is a beautiful dancer.

b) Beautiful $(m, \wedge y$ ( $y$ is a dancer $))$ \& me $\wedge y$ ( $y$ is human)

Wheeler's use of sets as a second argument in the relation between an individual (or a thing) and the respective set was criticized by Platts (1979). Platts used the co-extensive expressions renates and cordates, creatures with kidney and heart, respectively, as a counterexample. 

a) Fido is a big renate.
b) Fido is a big cordate.

In the actual world these two expressions are co-extensive, so whatever is said about renates and tumed out to be true î is also true about cordates, by virtue of com extensionality. However, one can imagine a different world where these two predicates have different extensions. Or as Chamers (2001) puts it, "they are cognitively and rationally distinct." Thus, Wheeler's analysis would fail to hold.

To overcome this shortcoming, it was natural for Platts to take an intensional approach instead. Accordingly, the second argument to the two-place predicate is now a property. Given this analysis, $(4-14)$ is given the representation in $(4-15)$.
a) big (f, $\lambda y[y$ is a renate $])$
b) big ( $f, \lambda y[y$ is a cordate])

The lambda expression $\lambda y[y$ is a renate] is to be understood in this context as the abstract property of "renateness" and "cordateness". According to this new conception, $(4-15-a)$ and $(4-15-b)$ are distinct even of they happen to have the same extension in some world $(s)$.

\subsection{LeVi (1978)}

Levi syntactically distinguishes between predicating and nonpredicating adjectives. Adjectives such as those in (4-16) can occur only nonpredicatively, i.e. relative to the noun they modify.
a) Electric clock
b) Electrical enginecring
c) Musical clock
d) Musical criticism 
Some nonpredicating adjectives can occur predicatively but with change in meaning. For example, the occurence of criminal in criminal lawyer and in That lawyer is criminal is syntactically valid but with different senses. Levi claims that these adjectives are transformationally derived from nouns. Hence, they share some properties with the nouns they derive from. These properties are:

- nondegreeness i.e. very urban rior

- nonconjunction of nonpredicating and predicating adjectives i.e. the tall and corporate lawyer

- Qualification i.e. can be prefixed by bi-, tri-, poly-etc.

- Semantic features i.e. def, concrete, human, masc, fem, etc.

- Case relations i.e. thematic roles such as agentive-e.g. presidential refusal-and instrumental-e.g. manual labor.

- Nonnominalization

As for the last feature, nonnominalization, it is the observation, by Levi and mentioned by many authors, that predicating adjectives can be nominalized, i.e. the politeness of the prince, while nonpredicating cannot be nominalized, e.g. the mechanicalness of the engineer.

Those observations stem from a more comprehensive thesis put forward by Levi: compound nominals result from a syntactic transfomation in which relative clauses are converted into compound nominals. For example, the compound gun wound is resulted from the relative clause a wound caused by a gun. Thus, according to Levi's analysis, in order to account for the meaning of a compound nominal one has to reconstruct it from its recoverably deleteable predicates such as "for", "in", "have", 'be', and 'in'.

Lehnert (1988) points to the diffeulty a Levi analysis might have with a construct such as dog collor. This compound cannot be mapped into a single phrase-a dog 
collar may result from two phrases a collar that belongs to a dog or a collar used by a dog.

\subsection{Dixon (1982), Frawley (1992), and Givón (1984)}

Givon (1984) subscribes to the view that adjectives occupy a middle position in the timestability scale. The two ends of this scale are occupied by the nouns-the most timestable-and verbs - the least time-stable. Many adjectives are derived either from verbs or nouns and some are core adjectives. The noun-derived adjectives encode more timestable meaning, while verb-derived adjectives encode less time-stable meaning.

Dixon (1982) argues that even in almost adjective-free languages-where the adjectival function is played by nouns/verbs-there are underived adjectives that can be divided into seven categories:

1) DIMENSION - big, large; little, small; long, short; wide, narrow; thick.

2) PHYSICAL PROPERTY - hard, sof; heavy, light; rough, smooth; hot, cold; sweet, sour.

3) COLOR-black, white, red, and so on.

4) HUMAN Propensity-jealous, happy, kind, clever, generous, gay, cruel, rude, proud, wicked, etc.

5) AGE-new, young, old, etc.

6) VALUE-good, bad, ine, etc.

7) SPEED-fast, quick, slow, etc.

Frawley(1992) provides a similar taxonomy of adjectives. It inciudes: Value, Human Propensity, Physical Property, Colour, Age, Quantity, and Possession.

\subsection{Chierchia and McConnell-Ginet (1990)}

Chierchia and McConnell-Ginet note that adjectives (semantically) can be divided into three types: intersective, subsective, and nonpredicating. Intersective adjectives are characterized by being absolute in the sense that they do not denote relative to the noun 
they combine with. The combination red rose is such an example. In this example one can infer that the thing denoted by the compound is both a red thing and a rose. That is, an intersection of the things denoted by the noun and those denoted by the adjective.

The second class of adjectives addressed by Chierchia and McConnell-Ginet is subsective adjectives. In this class, the things denoted by the compound are subset of those denoted by the noun. The compound skilful surgeon is such an example. The adjective 'skilful' doesn't denote by itself. It does relative to the noun it combines with in this case 'surgeon'. Both intersective and subsective adjectives express properties and can be used predicatively.

The third type of adjectives discussed by the authors is the nonpredicating. Nonpredicating adjectives, according to Chierchia and McConnell-Ginet, differ form the previous two types in that the denotation of the compound containing them does not select a subset from the set denoted by the noun of the compound. The authors suggest nonpredicating adjectives be treated as functions from properties to properties. Adjectives such as 'former' and 'fake' are of this type.

\subsection{Kamp (1975) and Kamp and Partee (1995)}

Kamp and Partee (1995) distinguish three types of adjectives: intersective, subsective, and non-subsective. Within the non-subsective, there are those that are non-privative--e.g. 'alleged', 'possible', etc.-and those that are privatives-e.g. 'counterfeit', 'toy', etc. In fact the term privative was coined in $\mathrm{Kamp}(1975)$.

For example the adjectival phrase red apple in (4-17) is interpreted as follows.

$$
\begin{aligned}
& \| \text { red apple }\|=\| \text { red }\|\cap\| \text { apple } \| \\
& \text { or, generally, for all noun } N \| \text { red } N\|=\| \operatorname{red}\|\cap\| N \|
\end{aligned}
$$

When analyzed as functions, the adjective 'red' is of type $\langle e, t\rangle$, i.e., functions from entities to truth values. This is considered the simple form of adjective-noun combination 
and to the authors it is a reminiscent of $\mathrm{Katz}$ and Fodor's Semontic Features approach. This analysis, as we have seen, is consistent with the authors surveyed in this chapter.

The subsective adjectives, according to the authors, includes adjectives such as "skilful" and 'talented", as in $(4-18)$.

(4-18)

(a) Skiful surgeon

(b) Talented musician

Where the conceptual combination in the previous examphes, obviously, is not intersective, i.e., of the form

\| skilful surgeon $\|=\|$ skiful $\|\cap\|$ surgeon $\|$

For this obviously wrong analysis would license the following inference.

Mary is a skilful surgeon

Mary is a violinist

Therefore, Mary is a skilful violinist

It is true that adjectives such a 'skilful' are not intersective, according to Kamp and Partee, but they still confirm to the following schema.

$$
\|A d j\| \subseteq\|N\|
$$

That is, as denoted by a noun phrase is a subset of the set denoted singly by the noun. This is explains the term subsective. Adjectives such as 'skilful', 'good', 'beautiful', etc. are of type CN/CN. Thus, subsective adjectives are intensional, according to $\mathrm{Kamp}$ and 
Partee. This is consistent with Siegel and Larson. However, Larson (see, next section) considers these kinds of adjectives party intensional.

The third type of adjective analyzed by Kamp and Partes are the non-subsective adjectives such as alleged in (4-20).

$(420)$

(a) John is an alleged criminal.

(b) This child is a potential mathematician

Non-subsective adjectives fail the schema in (4-19). This criterion set them apart form subsective adjectives. According to Larson (2002) these kinds of adjectives are fully intensional and Chierchia and McConnell-Ginet call them non-predicating since the adjective alleged in (4-20) cannot be predicatively expressed as 'is alleged".

The adjectives in (4-20) are examples of non-subsective adjectives. Within the nonsubsective adjectives, there are the subclasses "privative" and none-privative. What distinguishes the former is the denotation of the adjective-noun combination is never an instance of the noun alone. Adjectives in (4-20) are to be contrasted with adjective such as 'fake'. In the latter case, a fake gum is not a gun, while an alleged criminal could be and could not be a criminal. Partee (2001) terms non-subsective adjectives such as alleged "plain" non-subsective and characterizes them as being "noncommital"-also called by Franks (1995) "equivocating". This includes adjectives such possible, alleged, arguable, likely, and putative. In other words, privative adjectives license some form of entaiment: the adjective-noun combination entails the negation of the noun propery. This can be summarizes as follows.

$$
\|A d N\|\|N\|=\varnothing
$$

However, there is no clear-cut distinction between adjectives faling within the non subsective class. Indeed Kamp and Partee express disagreement among themselves 
regarding the adjective "fomer" whether it is privative or not. Further, some adjectives such as 'wooden' as in (4-21) can be both private and intersective.

(a) Bob bought a wooden table.

(b) My 4-year-old daughter has a wooden elephant.

In (4-21-a), a wooden table is a table, while in (4-21-b) a wooden elephant is not an elephant.

Some adjectives are vague as well as context-dependent. In (4-22), the adjective 'tall' is still intersective and contextependent, though. "Tall building" is characteristically quite deferent from "tall man", for example. Adjectives such as "tall', 'short, and "small" are subsumed under the "relative adjectives" class.

As pointed out by $\mathbb{K a m p}$ and Partee context may have effect on the interpretation of adjectives. Adjectives such as 'tall' and 'heavy' can be confused, because of context, for being non-intersective though they are intersective. The authors cite (4-22) as an example

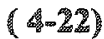

(a) My 2-year-old son built a really tall snowman yesterday.

(b) The D.U. fratemity brothers built a really tall snowman last weekend.

This is consistent with Siegel's observations that truly non-intersective adjectives can be rephrased using "as' "phrase, "good as professor" or "talented as a musician". This is to be contrasted with context-dependent intersective adjectives such as 'tall', which involves inter-class comparison; this case can be rephrased using the 'for' phrase: "tall for a 2year-old boy", for instance.

Along Montague's approach to semantics and Lewis (1972) analysis, the authors account for the semantics of adjectives as functions from intension to intension. That is, the

${ }^{5}$ The term "relative" has two different senses in the literature. The furst is relative/absolute and the second is synonym to scalar or measure. In this report we will be using the term "relative" in the former sense. 
meaning of former senator is a function that takes the property of senator to produce the property of Somer senator.

\subsection{Richard Larson (1995, 1998)}

Larson provides a contrasting treatment of adjective to those well-known in the literature, especially those of Siegel's. In accounting for the discrepant semantic behaviour of the adjectivenoun combination, Larson blames nouns that adjectives combine with rather than-as widely accepted-adjectives. He believes that all adjectives are intersective and that the noun has complex structure.

\subsubsection{Davidson Semantics}

The Larson approach is based on Davidson event semantics. Davidson (1967) noticed that the sentence $(4-23-a)$ entails $(4-23-b)$ and $(4-23-c)$.

a) Jones buttered the toast with a knife in the bathroom at midnight

b) Jones buttered the toast with a knife

c) Jones buttered the toast.

In traditional predicate logic, the readings in (4-23), respectively, would be represented using quatemary, ternary, and binary predicates. Instead, Davidson realized that in sentences such as (4-23-a) there is an implicit reference to events. Davidson's solution was based on the inclusion of events as types in the ontology. Once events are reified (i.e. to suppose that an event can be treated as a thing), the sentence $(4-23)$ is expressed as follows:

$(3-20)$

$\exists e$ [Butter(Jones, the toast, $e) \&$ With(a knife, e) \& In(the bathroom, e) \& At(midnight, e)]

In (4-24), there is only one main predicate, Butter, involving a variable of type event $e$. Other predicates (e.g. With, In, and At) that modify the event $e$ can be added/removed at ease. 
It is common nowadays, that predicates involving events are expressed using thematic roles, as originally used in case grammar (Allen, 1995, p 242). The thematic roles idea is based on the observation that there are abstract relations between a verb and is arguments. Such roles, as used by Larson below, include agent, theme, instrument, etc.

\subsubsection{Larson's Approach to Adjective-Noun Combinations}

Larson argues that adjectives are better analyzed with Davidson semantics. Also, he urges that the event variable $e$ be extended to include states in addition to events. In this new approach, Larson provides the following semantics for the intersective adjectives 'aged' in Jery is an aged president and the non-intersective adjective "former' in Jerry is a former president:

$(4-25)$

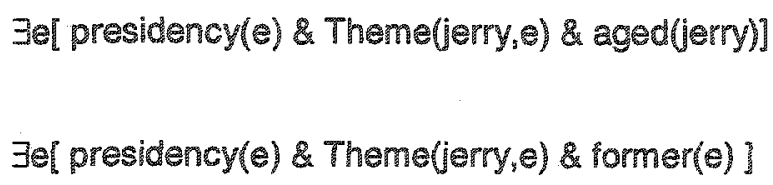

Thus, the intersective adjective 'aged' modifies the referent, Jery, while the adjective 'fomer' modifies the state of being president. Other adjectives such as 'good' can modify both event and non-event entities. However, in all cases, adjectives are treated as one-place predicate of event or non-event types.

Also, Larson claims, along the line of argument held by McConnell-Ginet, that his approach provides a more intuitive account of comextensivity without resorting intensionality arguments used by other authors, notably Siegel (1976).

\subsection{Summary}

The work reviewed in this chapter ultimately seeks to provide a compositional account for adjectives. As a first step, in all of the work reviewed, the syntactic position of the adjective-i.e. attributive, predicative, or both-provides some clues. Unfortunately, the syntax doesn't provide an exhaustive analysis for all adjectives" semantic behaviour. 
Besides, some languages have a very limited number of adjectives, if not at all, in their vocabulary.

Semantically, adjectives are broady categorized along the extension-intension distinction. The former modify the referent, while the latter modify the reference. Extensional adjectives are interpreted as setweoretic intersection, while some intensional adjectives can be accounted for as a set-theoretic subset operation of the denotations of both the noun and the adjective of the compound. This semantic behaviour is irrelevant to the syntactic position of the adjective, as Sicgel's work demonstrates.

The semantic categorization of adjectives into inherent and non-inherent, as done by Quirck et al, almost corresponds to Chierchia \& McConnell-Ginet's and Kamp \& Partee's approaches, respectively, intersective, subsective, and nonpredicating, and intersective, subsective, non-subsective. However, Quirck et al's inherent/non-inherent criteria are not as sharp as the other two. In other words, the distinction intersective/subsective/non-subsective is exhaustive, while the inherent/non-inherent distinction is not. Kamp \& Partee's approach has the advantage in recognizing privative and non-privative (or non-committal) adjectives within the non-subsective category.

Siegel and Wheeler address the issue of vague adjectives such as "tall", 'small', and "heavy" using different approaches-as discussed above-and different terminology. Wheeler calls such adjectives "relative" adjectives, as most of the literature does, while Siegel call them "measure" adjectives. Siegel uses the tem "relative", as opposed to "absolute", to describe the class of adjectives that are intensional. We agree with siegel's position that this class of adjectives is extensional but inferentially behave as if they were intensional.

Larson's work stands out among the other work reviewed in this chapter by deviating from the conventional wisdom that adjectives are to blame for the semantic discrepancy 
of adjective-noun combinations ${ }^{6}$. Also, Larson makes the bold clam that all adjectives are intersectives-i.e. he claims that there are no such things as intensional adjectives. In fact, Larson argues that intensional contexts exist in propositional atitudes only. However, his work does not treat all of the somalled non-subsective adjectives, with the exception of the adjective 'fomer', which fits well within Davidsonian semantics. Another shortcoming is that vague adjectives were not addressed.

\footnotetext{
'Putsejovsky (1995) expresses a sonewhat similar view. In such a view, nouns" semantic make up include what he terms "qualia". The "qualia" is a structure that contains specifications- such as appurtenances, functions, and how they come into being-regarding the denotation of nouns.
} 


\section{Chapter 5 \\ THE PARTICULAR PROBLEM ADDRESSED IN THIS WORK}

This work attempts to provide a uniform semantic treatment of adjective-noun combinations. We present two approaches for this purpose. Both approaches are characterized by being set-theoretic, and compositionally computational.

\subsection{Adjectives: conventional view}

As noted in the previous chapter, there is consensus among language scholars that adjectives assume a semantically motivated hierarchy. This hierarchy is listed below:

- Intersective

- Subsective:
a. Pure
b. Double (explained below)

- Non-subsective:
a. Non-privative
b. Privative

Intersective adjectives are the most restricted ones. The adjective angry in the sentence That man is angry is an example of an intersective adjective. The meaning of "angry" then can be computed as the intersection of angry things and men.

The second class of adjectives is called subsective. They are called so because they are not intersective. All that can be said about them is that the denotation of an adjectivenoun cormbination is a subset of the denotation of the noun. The adjective 'accomplished' is an example of such adjectives. Accomplished in Maria is an accomplished horse rider does not mean that the denotation of Maria is accomplished and is a horse rider. All we can say is that Maria is in the set Horse-Rider, i.e. accomplished horse riders are horse riders. Syntactically, adjectives similar to 'accomplished' are always in the attributive 
position, see appendix A for more adjectives of this kind. We term these adjectives "pure subsective" to distinguish them from the other kind of adjective in the same class-the double adjectives.

There is another kind of adjective that belongs to the class of subsective adjectives. These are double (or doublet) adjectives, as called by Siegel (1967). Syntactically, these adjectives can be in either position: the attributive or predicative. Semantically, they can have an intersective reading and a subsective reading. Beautiful in the sentence That dancer is beautiful is an example of a double adjective. Thus, beautiful can either be understood as attributing beauty to the dancing of the denotation of that or the physical beauty to the denotation of that. In the intersective reading the denotation of that belongs to the intersection of beautiful things and dancers. In the subsective reading the denotation of that belongs to a subset of the set of dancers, i.e. those who dance beautifully.

Finally, there are those adjectives that are neither intersective nor subsective, the socalled non-subsective adjectives. Within this class two sub-classes can be recognizedprivative adjectives and non-privative. Adjectives such as 'former' and 'fake' are privative, while 'potential' and 'possible' are non-privative.

The existence of the adjectival hierarchy has lead to the conclusion that a uniform approach to the semantics of adjectives is possible only if they are treated as functions from properties to properties. This renders a set-theoretic approach to the semantics of adjectives unattainable from the conventional viewpoint.

\subsection{Adjectives: our view}

In our treatment of adjectives, we present two approaches that capture the intuitive meaning of adjective-noun combinations. Both are computationally attainable. This approach falls within denotational semantics. 
However, in order to be able to provide a general setweoretic approach to adjectives, the abovementioned adjective hierarchy needs to be re-analyzed. In particular, we argue, see chapter 7 , that the so-called privative adjectives can be treated as subsectives. Based on the argument put forward in Chapter 7 , the revised adjective hierarchy is as follows:

- Intersective

- Subsective:
a. Pure
b. Double
c. Privative

Once this "re-definition" of privative adjectives is in place, a generalized set-theoretic approach to adjectives is possible. We provide two approaches based on this idea: one is subsective, chapters $7 \cdot 10$, and the other is intersective, chapter 11.

\subsection{Consequence for implementation}

Logicians and philosophers utilize different tools than those used by AI researchers. A logician invokes notions such as properties, intensions or higher order logics to deal with a problem in hand. This luxury of choice is usually not available to a computer scientist or an AI worker. This is due to computability issues (see Hirst $(1987, \mathrm{p} 32)$ and Friedman et al, 1978) for discussion of implementing issues pertaining to Montague system).

We argue that, with the analysis of adjectives as being subsective or interactive only, and the use of types, a computationally parsimonious approach to adjective-noun combinations is attainable.

\subsection{Overview of the Proposed Approaches}

Based on denotational semantics, our approach assumes a type hierarchy. The hierarchy serves as a taxonomy for our proposed ontology in which the semanics of adjective-noun combinations is based. 
We view adjectives as either being role-modifying, e.g. veteran in John is a veteran manager, or kind-modifying, e.g. camivorous in That animal is camivorous. The former are conventionally considered intensional and the latter are extensional.

Our first generalized approach to adjectives assumes that they are all subsective, with intersective as a special case. Adjectives such as 'fake', 'bogus', 'artificial', and 'counterfeit' are argued to be subsective. The ambiguity of double adjectives is considered to be lexical ambiguity. For example, a double adjective such as "intelligent" will have a predicative reading and an atributive reading. The former will be treated intersectively, while the latter subsectively.

Our second generalized approach to adjectives treats then intersectively in chapter 11. Here, our approach is based on the view that a member of a set also has a type. Consequently, equality of set members depends on their types, too. This view allows sets to have a structure that captures complex natural-language constructs.

The subsective and intersective approaches are alternatives. Both approaches have advantages and disadvantages. These issues will be discussed in due course.

\subsection{Adjecthe-noun Combinations not addressed in this work}

This work does not treat adjectives with modal impor, i.e. non-subsective, non-privative adjectives. This class includes adjectives such as 'possible', 'likely', 'alleged', and 'potential'. Adjectives of this class also fail to be intersectives and also fail to be subsective. For example, an alleged criminal may be or may not be a criminal. We believe that such constructs are better treated using modal logic. 
The term 'type' is an overloaded term. In everyday life is is synonymous with other tems such as 'class', 'category', 'kind', 'sort, or 'group'. In disciplines such as philosophy, mathematics, semantics (of both natural and artificial languages), "type' has specific meanings that are relative to these fields.

\subsection{Types in Mathematics}

In mathenatics, type theory has its origin in the philosophy of Russell. It was motivated by a contradiction in Gottlob Frege's logic of classes. In Frege's originally proposed logic, a definition such as the class $R$ of all classes that are members of themselves is possible. As it tumed out this implies that such a class $R$ does not exist or that some definitions do not specify classes-not what Frege hoped for.

Russell's solution was the introduction of a type hierarchy to the discourse of investigation. In such a hierarchy, objects are of different levels or types, the type of a class differs from the types of its members, and every class may contain members of one and only one type. In the Principia Mathematica (1910-13), in order to eliminate certain semantic paradoxes, Russell further added that sets and their members must be of different types and different orders.

Russell's theory of types did not meet with a great success as other remedies to naive set theory. Altematives such as Zemelo-Fraenkel set theory dominated the scene. However, recently, there is a renewed interest in type theory in different areas: logic and the foudation of mathematics (Martin-Lof, 1975, Dyckhoff 1988, Girard 1989), and in computer science (Nordstrom and Smith 1984, Dijkstra 1990, Thompson 1991).

\subsection{Types in Linguistics}

In Categorial Grammar and, subsequently, in Montague Grammar, it was observed that syntactic categories of natural languages are analogous to types in formal languages and typed logics. This analogy is exhibited in the form of argument-function structure. For 
example, in a programming language the function scuare $(1$ is expected to have a number as an argument. Thus, the expression square (4) is well-yped and the expression square("string") is not. This is because the underling type system for the function square () has the following form: $F \rightarrow F$, where $F$ represents the type of floating numbers. In English adjectives such as 'red' modifies nouns such as 'rose' to give the noun phrase red rose. If the noun 'rose' is assigned the type $N$ and 'red" the type $N \rightarrow N$, then the expression red rose is well-typed on grounds of applying the operator 'red' on the argument 'rose'. A different arrangement of words such as rose red would be deemed not well-typed, i.e. non-grammatical.

Montague Grammar goes beyond strict classical categorial grammars, which are equivalent to context-free grammars, in not just using concatenation as the sole syntactic operation. In Montague Grammar, operations such as the "Quantifying In" rule and the relative-clause rule are not concatenation operations (Partee and Hendriks, 1997, pp 29. 30). However, categorial grammars, as discussed by Montague, have the atractive feature that category names encode an intimate correspondence between the syntactic and semantic categories-a fundamental requirement for compositionality.

It is worth mentioning that types in Montague Grammar are called semantic types. This is because typing systems are used in the semantic part of the grammar, rather than the syntactic part.

\subsection{Types in Programming Languages}

In programming languages, computing is a process that works on objects. These objects are a set of values defined within the programming language. They can be of different types- simple ones such as Boolean, character, and numbers; and, complex ones such as arrays, and linked lists. Each data type is involved in operations that might not be allowed with other type(s). For instance, adding values of type Boolean is meaningless since the operation " + " is not defined over values of rype Boolean. 
In Object Oriented (00) programming, typing is one of the main concepts. New complex types are built out of basic ones. Booch $(1993$, p66) defines typing as follows:

\begin{abstract}
Typing is the enforcement of the closs of an object, such that objecss of different types moy not be interchanged, or at the most, they may be interchanged only in very restricted ways.
\end{abstract}

Programming languages vary in dealing with typing to the extent that it can be used as a distinguishing criterion of different facets among programming languages and paradigms: weakly-typed versus strongly-typed, versus untyped; polymorphic versus monomorphic; and, dynamic versus static binding. The first is connected to the way in which a programming language enforces (or does not enforce) typing. This criterion runs across the different kinds of programming languages.

Polymorphism is connected mainly with 00 and functional paradigms. An identifer in a polymorphic language may denote instances of different classes as long as they belong to a common super class. Also, a polymorphic function can take different data types as argument(s) as long as they have a common supertype that the function accepts. This is to be contrasted with monomorphic languages wherein a variable is interpreted as belonging to one and only one type.

Binding is connected with the time at which an identifier binds with the things it denotes. Such a binding is accomplished after type matching is checked. If such a checking is perforned during the compilation time then it is called static binding, otherwise (i.e. during execution or run time) it is called late or dyamic binding.

The use of typing in programming languages is motivated by the need for the following features:

- The elimination of potential errors (at execution time).

- Making the job of the semantic module easier. 
- Encoding partial specifications.

Some implementations of 00 paradigns "mix" the notions of a type and of a class. In the programming language Java, types are enforced through the interfoce mechanism. In $\mathrm{C}+$, there is no clear distinction between a type and a class. However, sub-classing and sub-typing can be enforced in $\mathrm{CH}$ : a public inheritance enables the inheriting class to have both the type and implementation (i.e. the class) of its super-class, while inheriting a wirtual class (i.e. a class that has no implementation) is a sub-typing operation.

\subsection{Types in the Ontology}

The extemal world is very complicated. It is a long-standing human ambition to provide a systematic account of "what is there". One of the oldest endeavours to achieve this quest is that of Aristotle's. Aristotle claims that things in the world can be classified into ten categories: substance, quantity, quality, relation, place, time, posture, state, action, and passion. Based on Aristotle's analysis, the philosopher Porphyry (233-309) constructed one of the oldest known trees involving categories for the representation of ontologies. This is depicted in Figure 6 1.

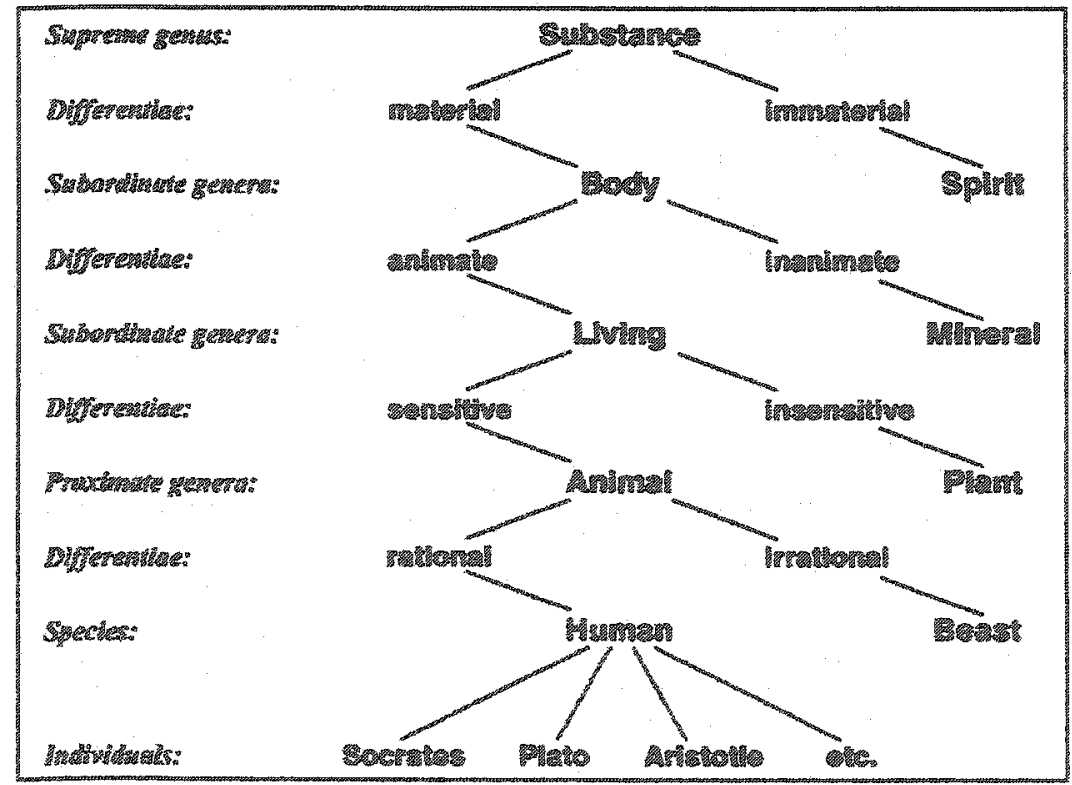

Figure 6-1: Porphyry's taromomy (SOwa, 1999: 5) 
Every node in Figure 6-1 represents a type, except for the lowest leaves of the tree where individuals (i.e. instances or referents) are represented. Thus, the individual Plato is an instance of human being and in tum human beings are rational animals, i. . human is a subtype of rational animals. Aristotle, also, is credited for introducing the technique of generating new categories from existing ones by means of genus and differentiae, Figure 6-1, for example, "Sensitive" and "insensitive" are the differentiae that generate the species "Animal" and "Plant". This technique as Sowa (1999) notices is still in use in Al, Object-Oriented design, and dictionaries.

Interest in ontologies is not limited to philosophy. Their importance is realized in various fields such as NLU, and information-management systems. However, the grand ambition of building or "discovering" an ontology that encompasses the whole knowledge of the universe, due to its extreme difficulty, is replaced by modest approaches which attempt to build ontologies for specific domains. Nonetheless, there are consistent efforts aimed at building upper-level ontologies, as in systems such as WorldNet and Cyc. However, such efforts are not without difficulties, (see, e.g. Guarino (1992)).

Regardless of the range of its applicability, an ontology is supposed to capture universal truth about the world in terms of a type hierarchy. This point is anticulated in Sowa (1999, p 492), "The subject of ontology is the study of the categories of things that exist or may exist in some domain. The product of such a study, called an ontology, is a catalogue of the types of things that are assumed to exist in a domain of interest $D$ from the perspective of a person who uses a language $L$ for the purpose of talking about $D$ ".

A successful ontology is supposed to provide a means of communication between heterogeneous systems (Uschold and Gruninger, 1996); a basis for semantics and be an effective tool in lexical disambiguation (Bachimont, 2001); and, an explicit partial representation of conceptualization of reality so that such a representation can be exploited by inferences (Mizoguchi and Kkda, 1997). 


\subsection{Types: Miscellaneous Topics}

In this subsection, we briefy review some topics regarding types. This review applies to all types discussed in this chapter.

Types are astrom entites. Nodes in type graphs, lattice, or trees always indicate abstract things. If we go back to Porphyry's tree Figure 6-1, we find types such as "Human", "Plant", and "Beast". These are names, or labels, of types that name groups, hence abstract things. For example, we cannot point at Human type but to a referent of the type, e.g. Plato, the concrete thing.

Ways of demining types. There are four different ways of defining types. These are:

- Definition by extension: by listing all individuals that falls under a certain type.

- Definition by intension: by listing the features the individuals are presumed to have ir common

- Definition by axioms: by setting out axioms describing the entities in mind, e.g. types in Montague Grammar, and Peano's axioms of natural numbers.

- Definition by reference: a new type that is defined by reference to an existing type.

Type Herarchy. Types are organized in type hierarchies in the form of a mathematically well-defined graph, e.g. a lattice, tree, etc. In a lattice, the types are ordered in a partial order relation called a subtype relation. The important subsumption or inheritance relation, then, is a by-product of the hierarchy.

Types versus Tokex. In philosophy of language the terms "type" and "token" are used to distinguish the abstract form of a linguistic item, i.e. the type, from its physical realization, i.e. the token. For example, the sentence The cat sat on the mat next to another cat on another mat has two cat, amother, and mat tokens. On the other hand, the 
sentence only has one type of 'mat', 'another' and 'cat'. Type/token is analogous to universalparticular distinction. 


\subsection{An Example of a Type Hierarchy}

An example of a type hierarchy may look like the one in Figure 6-2.

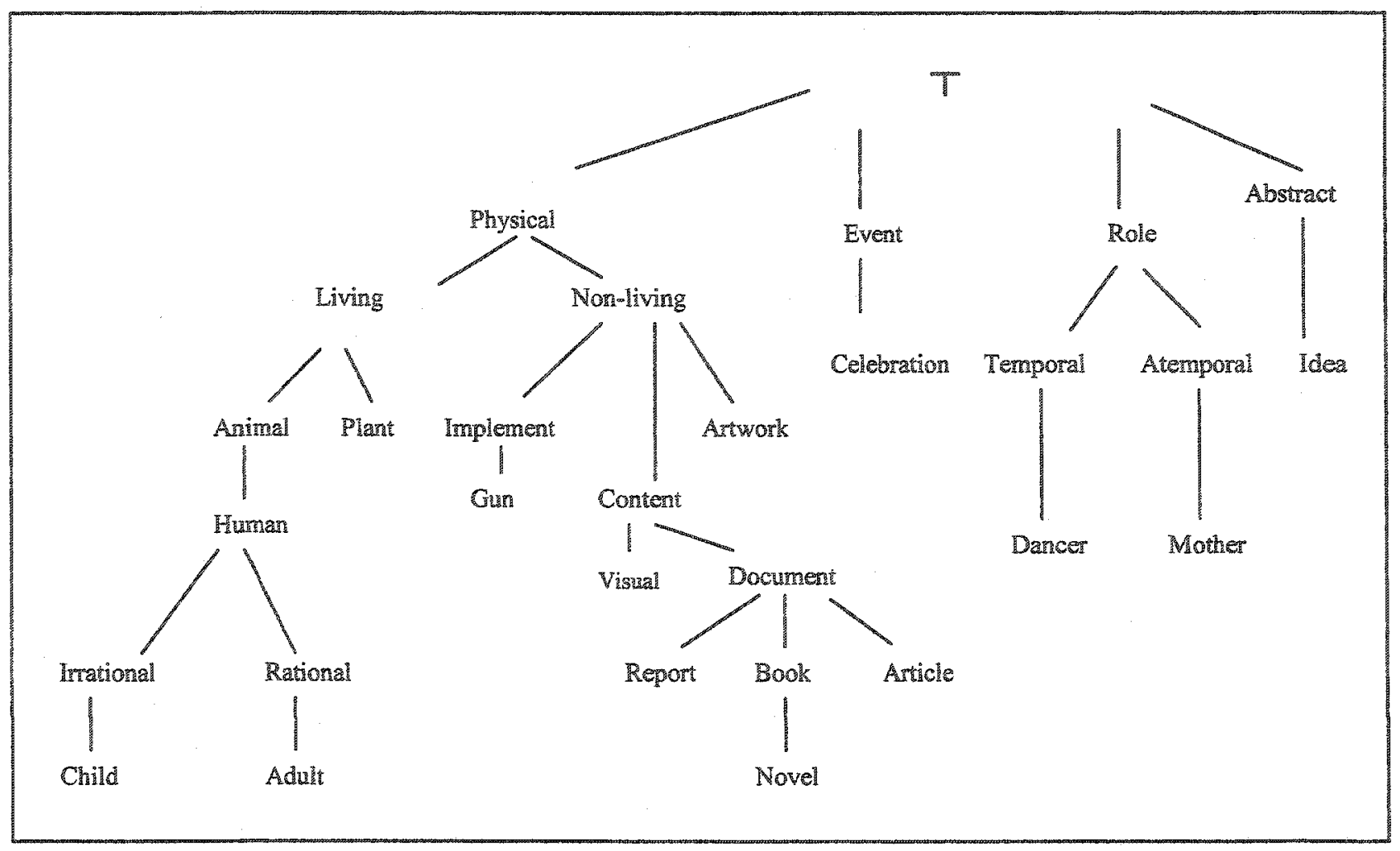

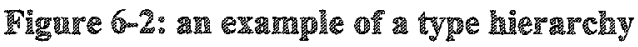

This is a rather simple type hierarchy. A full-fledged type system can certainly be more complicated than this. For instance, given the vocabulary offered by the taxonomy of Figure 6-2 we cannot talk about realms of studies such as physics, philosophy, etc. This is because the ontology in its current form is not committed to the existing of such entities. However, the type hierarchy in Figure 6-2 serves as an example to demonstrate how typing can be an asset in the semantic process. For example, if, given the ontological representation of Figure 6-2, the query "Canadian book" is put to a search engine the response should turn up answers that include book and novels on/by Canadians. This is because, according to Figure 6-2, a novel is a book. 
To illustrate how ontologies can help in resolving word sensemambigutities, consider the polysemous adjective 'good' as in the expressions good man, good dog, good gum, and good child. In these expressions 'good' has different senses, i.e. as a modifier for ethics, behaviour, and pertomance. Good in good gun certainly is not meant to describe the gun's ethics. Rather it is meant to describe the gun's perfomance. In terms of the ontology in Figure 6-2, this is because a 'gun' is not a rational thing. Good in good man has this sense, since a man is an adult, a rational human being. Finally, since children and dogs are less rational beings, 'good' is not meant to describe the morality of a dog or a child. Rather good in good child and good dog has the sense of describing the behaviour as being in accordance to the norms, relative to children or dogs.

A good ontological design should make the ontology open-ended. This allows the inclusion of new types when the need arises. For instance, since in modem life documents are not limited to paper media, the inclusion of other forms of media should be possible- $6 . g$. the Visual type in Figure 6-2.

In the hierarchy of Figure $6-2$, Role is treated as a type, rather than a relation. In other words roles are reified and can be quantified over. Thus, roles are reated as types in their own right. However, as illustrated in Figure 6-2, Role type is not linked to regular types such as Human. This is because roles are ontologically different from ordinary types. This distinction can be traced back to the philosophy of Pierce who described regular types and role types as having, respectively, "firstness" and "secondness". On this conception, the type "Human" has firstness, since it can exist independently, while "Surgeon" does not.

\subsection{Type Hierarchy Assumed in This Work}

In this work, we assume a simple type hierarchy for the purpose of computing the meaning of adjective-noun combinations. Such a herarchy is depicted in Figure 6-3. As shown in Figure 6-3, the distinction between kinds and roles (see, Sowa (1984, 2000), Steimann (2000), and Guarino (1992)) is taken into consideration. In this view, the kind or type of an entity cannot change as long as the entity exists, but it can play many roles 
at the same point of time--i.e. have different role types in iss life span. So, what Siegel (1976) describes as a reference is roughly a role played by the kind-the referent. In this Work we adopt the kind/role aistinction rather than Siegel's reference/referent distinction. This is because the former is more informative and easily accommodated in a type hierarchy, while the latter is too general. Thus, for instance, "Human" is of natural kind type, a subtype of kind, while "student" is a role.

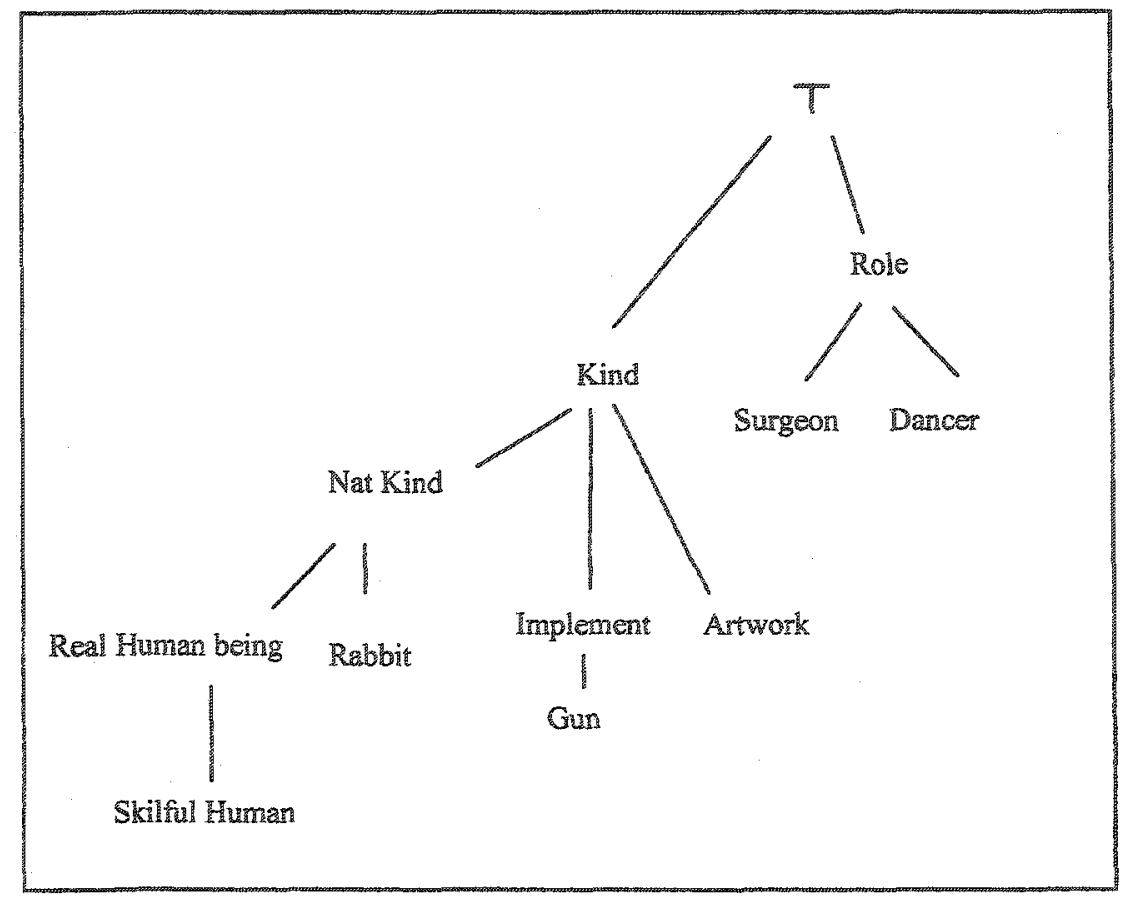

Figure 6-3: kind/role distinction 


\section{Chapter 7 \\ DETAILE DESCRIPTION OF THE FIRST PROPOSED APPROACH AND EXAMPLES: THE SUBSECTIVE VERSION}

Kamp (1975) defines a privative adjective as one for which, given an adjective $A$ and noun $\mathrm{N}$, the claim ' $\mathrm{No} A \mathrm{~N}$ is an $\mathrm{N}$ ' is necessarily true. The question that arises from this conclusion is what is the AN? If a fake gun is not a gun, what it is? This chapter is an attempt to answer this question.

In addition, in this chapter we provide a uniform semantic treatment of adjectives that is subsective.

\subsection{Characteristics of the New Approach}

In this work, we present a semantic approach to privative adjectives. This approach is:

- Compositional.

- General-i.e. provides uniform semantic treatment to adjectives.

- Set-theoretic.

By being set-theoretic, this approach is unique in that it doesn't resort to higher-order logics in generalizing adjectival phrases to be functions from intension to intension-as is commonly held, see the literature review earlier.

\subsection{Privalives: alfferent perspective}

\subsubsection{Missing Properties}

It has been proposed (e.g. Franks (1995), Franks et al(1989), and Franks (1989)) that privative adjectives deprive the noun they combine with from an essential property. As a result, the object denoted by the compound no longer falls under the noun's extension. This is illustrated in Table 7-1, in the case of the adjective 'fake', and Table 7-2 for other privative adjectives 


\begin{tabular}{|c|c|}
\hline Adijestive Phressa & 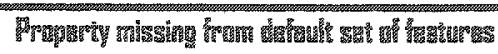 \\
\hline Fake gun & Function \\
\hline Fake painting & Originality/Content \\
\hline Fake statue & Originality \\
\hline Fake bracelet & Substance \\
\hline Fake smile & Sincerity \\
\hline Fake watch & Function \\
\hline Fake surgeon & Qualifications/expertise \\
\hline Fake fur & Substance \\
\hline Fake perfume & Substance/originality \\
\hline
\end{tabular}

Table 7-1: missing properties

According to Table 7 1 , a fake gun is not a gun because it does not function as a gune.g. it doesn't fire bullets in an appropriate way as a regular gun does. In all other aspects, a fake gun is just like a regular one. Similarly, a fake surgeon is not a surgeon maybe for lacking qualifications /expertise. Conceived as such, a fake surgeon is not capable of executing the duties of a real surgeon. Fake painting, on the other hand, is ambiguous. A painting could be a fake for two reasons: fake per se, maybe because it is a print, or fake because it is a replica. On the latter reading, the phrase fake painting is usually a short for fake painting of such an artist or an era. In the latter reading, what is of concern is the originality of the artwork. For instance, a painting might be a fake because it is not a Picasso (painting) or it does not belong to the renaissance era as claimed. Similar arguments apply to the combinations fake bracelet, and fake smile.

\subsubsection{Fake guns Are Guns}

Language is inherently generative. With its, rather limited, stock of linguistic items it is capable of expressing novel concepts by means of combining existing linguistic items. In some cases, however, and because of the dynamic nature of concepts, new referents may fall under an already existing concept. For example, in number theory, a number used to denote a natural number. With the conception of negative numbers, the concept "number" encompasses both negative and positive numbers. This process continued (and may continue) to include different kinds of numbers. This is because there is so much in common between the entities or mathematical objects we now call numbers. 
In everyday language this process, we argue, is generally in use-consider, for instance the category "bird", as much studied and illustrated in prototype theory and defoult logics with regard to the property of "ffying"-and specifically with regard to privative-noun combinations. A fake gun and a real gun have many properties in common-similarly, an artificial heart and a real heart. In some cases, the distinction between an instance of the denotation of a default-noun combination and that of a privative-noun combination is hard to tell, or requires domain knowledge, e.g. artificial light versus natural ight, Table 7-2-if there is a difference, indeed. If it were for things denoted by a privative-noun combination not to fall under the extension denoted by the noun, there might have been a dedicated lexeme-interestingly, even the word robot (i.e. a single linguist item) is originally chosen by the Czech playwright Karl Copek (1890-1938) as a more suitable term for "artificial workers" in his play Rossum's Universal Robots'. Of course, this is not to claim that a concept must be denoted by a single lexeme. What is meant, however, is that the frequent use of a concept is usually reflected in language by being represented by a single linguistic symbol, as is the case with common nouns. Therefore, in answering the question of what is a fake gun, we argue it is a gun, provided that fake and real guns are subsumed by the tem 'gun'。

\begin{tabular}{ll}
\hline Adjective Phrase & Property missing from the default sat features \\
\hline Artificial heart & e.g. not llesh-and-blood \\
\hline Artificial flower & e.g. doesin't grow \\
\hline Artificial light & e.g. Source \\
\hline Former senator & e.g. temporal continuance \\
\hline False teeth & e.g. not naturally grown \\
\hline Cloned sheep & e.g. not naturally bred \\
\hline Virtual reality & e.g. exists visually only \\
\hline Imitation leather & e.g. genuineness \\
\hline Wooden lion & e.g. "make-ness"-physical and non-living \\
\hline
\end{tabular}

Tabue 7-2: raissing groperthes, continued

7 See, htto://capel.misto.cz/english/interesting.htral for a translation of an article by the author of the play in the Lidove noviny, 24.12.1933 
The notion of augmenting the concept, or equally the extension, denoted by the noun in an adjective-noun combination, is linguistically supported. In language, it is noticed that all privative adjectives have antonyms/contrasts, e.g. intensifiers. Privatives such as fake, artificial, and false have antonyms/contrast, respectively, real/geruine, natural, and true. It seems that there is a strong pairing between privatives and their (intensifier) counterparts to the extent that the use of the privative antonym is meaningless, if possible indeed, in isolation with its counterpart. The intensifier is usually implicit. Most of the time it is considered default or redundant when there is no ambiguity. The compound real fur is deemed necessary only when there is fake fur in the vicinity.

Partee (2001) reaches the conclusion that privative adjectives are subsective based on work done by other researchers (e.g., see, Nowak (2000)) on the "Noun Phrase-split phenomena" in Polish, which reveals the absence of the privative adjective class in Polish. That is, the presence of the privative class of adjectives is an idiosyncrasy of some languages and English is one of them.

In short, intensifier/privative seem to be (semantically) intimately related. If viewed as functions, they can be thought of as functions and their respective inverse functions. Altematively, they can be viewed as set partitions of the set $N$, which represents the denotation of the noun an intensifier/privative pair combines with. The latter view is adopted in the approach proposed in this section.

In our view, both "regular" adjectives such as 'red", 'angry', or 'skilful' and privative adjectives such as 'fake" or 'former' have one thing in common. They both pick out or further constrain the domain denoted by the noun of the compound. They differ in the means of going about doing it: regular adjectives by highlighting some property or properties of the noun, while privative adjectives by "masking" some property or properties of the noun. 


\section{Privatue Compounds}

Privative compounds do not ensue from privative adjectives only. Some kind of intersective adjectives lead to such an effect. Consider the examples in $(7-1)$.
a) Stone lion
b) Stuffed tiger
c) Wooden man
d) Auto teller

All compounds in (7-1) are privative caused by intersective adjectives. Apart from their figurative meanings, the compounds in (7-1) do not denote what their respective nouns do; a lion that is stone is not a lion, likewise, a wooden man is not a man and a wood. There are two possible approaches to accommodate privative compounds within a unified approach to adjective-noun combinations. These are privative compounds as an operation of typecasting or as consequence of augmentation of nouns' denotations. We will deal with these approaches in turn in the following subsections.

\subsubsection{Privative compounds: a typecasting operation}

The adjectives in (7-1) can be looked at as special intersectives. They are connected with the nature of the thing denoted by the noun. They differ from other intersective adjectives, such as colour adjectives, in that they indicate an essential property without which the thing denoted by the noun would not come to existence. Consider the examples in (7-2).
a) cold-blooded insect versus
red insect
b) flesh-and-blood teller versus
tall teller

It seems that properties indicated by adjectives such as 'red' and 'tall' are accidental, while properties such as "flesh-and-blood" are essential, at least in the actual world. The 
latter case is reflected in language by the absence of single lexical items indicating those properties. In ract, because the property "llesh-and-blood" is essential to animals, it cannot be used as distinguishing property among instances of a certain class. If this is so, what is an expression such as wooden mon supposed to convey?

We believe the purpose of expressions such as stone lion is typecasting/type-declaring. This procedure is similar to typecasting in programming languages. Consider (7-3).

$$
\begin{aligned}
& \text { ineger } x . \\
& \text { real } \quad y \\
& y:=0.3333 *(\text { real } x
\end{aligned}
$$

The construct "real) $x^{99}$ makes it possible that whatever value denoted by " $\mathrm{x}$ " is now expected to behave the same as those values of type real, although its original type was integer. This operation is to be contrasted with describing $x$ as being less than one (i.e. $\mathrm{x}<1$ ), which is analogous to describing an insect as being red (i.e. red insect).

Bearing the analogy of numbers in programming languages in mind, we can say that natural-language expressions such as stone lion undergo a similar process. This can be illustrated as follows. A lion is, evolutionarily or "Godly", defined as of type "flesh-andblood". This is the type of lion that speakers and hearers of language have in mind. When the expression stone lion is uttered, an entity or object of type stone results. It behaves much as a stone, i.e. being inanimate, rather than its original type, i.e. animate. One may conclude that there are some intersective adjectives that can function as type denoting when combined with certain types of nouns.

This observation can be generalized to animate, and probably to natural kinds. In (7-4) We notice two things. First, since tables are essentially inanimate, the compound wooden table is not considered privative, as is wooden man. This is because tables are "typically" but not essentially made of wood. Consequently, second, the adjectives "wooden", 'metallic', and "plastic' are used as distinguishing adjectives. 

a) Wooden table
b) Metallic table
c) Plastic table

As far as the semantics is concemed, privative compounds can be treated as subsectives. Intersective adjectives denote things as nouns do. This is in contrast to other adjectives that acquire this abiity only when combined with a noun, i.e. relative adjectives. The denotation of the compound red apple, for instance, is a subset of both the set of red things and the set of apples. In the case of ype-denoting adjectives as in wooden man, the intersection operation does not go both ways. Rather, the denotation of the expression wooden mon is a subset of the predicate denoted by wooden, but not that denoted by "real man". Here, subsectiveness goes in the opposite direction-in contrast to that of expressions such as rightul politicion.

Finally, some constructs in natural language are better explained as type-casting. Consider $(7-5-a)$.
a) That gun is a good nutcracker.
b) *That man is a good lion.
c) That man is good swimmer.

At a first glance, (7-5-a) might be thought of as a gun in the role of a nutcracker. In (n-5a) the underlying type is Implement (i.e. gun and mutcracker are both Implement, specifically Arteracts). Analogously, in (7-5-b), the underlying types are Nat. Kind. However, we do not nomally consider $(7-5 . b)$ as expressing the idea that a man is in the lion role. Therefore, $(7-5-a)$ cannot be considered as expressing the idea that there is a gun in a nutcracker role.

Swimmer in $(7-5-0)$ is a real role since there is no genus called "swimmer". In other words, we cannot identify something solely as a swimmer, i.e. without the event of 
swimming. On other hand, a nutcracker is a mutcracker even if we do not see it crack nuts; or, even if it has never cracked and will never crack a nut.

\subsubsection{Privative Compounds: a subsective compounding}

An altemative approach to privative compounds emerges naturally once noun augmentation is adopted.

Since adjectives in privative compounds are intersective and do not necessarily have antonyms/contrasts, as is the case in privative adjectives, an augmentation of common nouns based on the respective (intersective) adjectives is, at least, linguistically implausible. That is, the adjectives in the compounds stone lion and stuffed tiger, for example, have no clear antonyms/contrasts. However, we argue, augmenting concepts, as shown in the previous subsection, can accommodate cases connected with privative compounds. We demonstrate this by using the compounds stone lion and auto teller.

We can think of the denotations of 'lion' and 'teller' as containing, respectively, real/fake lions and naturallartificial tellers. On this conception, the denotation of stone lion is a subset of fake lion. This makes the expression stone lion, by transitivity of the subset operation, subsective. Similarly, the denotation of the expression awto teller is a subset of artificial tellers. Consequently, the denotation of auto teller is a subset of the denotation of the noun "teller".

This treatment might appear as if the compounds auto tellew and stone lion were considered synonyms with, respectively, artificial teller and fake lon. However, this is not necessarily the case. All that is argued for is that an auto teller is definitely not a natural (e.g. of flesh-and-blood) teller and a stone lion is definitely not a real lion. Consequently, an auto teller is an artificial thing and stone lion is a fake lion, since it is inanimate. 


\subsection{A Uniform Subsective Approach to Adjective-noun Combinations}

In this chapter, we argue for a generalized treatment of adjectives that adheres to the view that adjectival nominals are subsective. This view is a challenge to the commonlyaccepted wisdom that, generally, adjectives can semantically be accounted for only as functions from intension to intension or properties to properties. The commonly-accepted wisdom renders a set-theoretic approach to a general treatment of adjectives out of the question. However, as argued above, once the extension of a common noun is augmented, to include fake-real, former-current, artificial-natural, etc., a generalized solution to adjective-noun combinations within set theory is attainable.

The "subsectiveness" nature of adjectives can be demonstrated as follows. First, intersective compounds such as red rose are the simplest case where the denotation of the combination is a member of the denotations of both 'red' and 'rose'. The denotation of the compound can also be seen as a subset of the denotation of the noun 'rose'. That is, all intersectives are subsectives. Thus, intersectives are special case of subsectives, much like a square is a special case of a rectangle where all sides are equal. Similarly, in subsective adjectives such as veteran dancer the denotation of the compound is a subset of the denotation of the noun 'dancer'. Also, a privative compound such as stuffed tiger can be treated subsectively, given our assumption that 'tiger' denotes all tigers, real or not. Finally, with the augmentation of noun extension to include fake/real, artificialinatural, etc, a subsective reading of the privative combination is possible. Consequently, the denotation of the expression fake gun is a subset of the denotation of gun.

Thus, nouns such as gun, we argue, denote supersets. This superset includes all things denoted by a privative adjective and its intensifier counterpart. With this conception in mind, a sample of privative-noun combination is illustrated in Table 7-3. 


\begin{tabular}{|c|c|c|c|}
\hline Adjective Phrpeses & Supersegt & Typer & Ambigupus \\
\hline Fake gun & Fake-real/original & Implement & $\sqrt{ }$ \\
\hline Fake painting & Fake-original/-real & Artwork & $\sqrt{1}$ \\
\hline Fake statue & Fake-original/-real & Artwork & J \\
\hline Fake bracelet & Fake-real/-original & Omament & t \\
\hline Fake smile & Fake-real & Gesture & $\mathrm{X}$ \\
\hline Fake watch & Fake-real/original & Implement & $\sqrt{ }$ \\
\hline Fake surgeon & Fake-real & Role & $X$ \\
\hline Fake fur & Fake-real (or genuine) & Ornament & $\sqrt{ }$ \\
\hline Former actor & Former-current & Role & $\mathrm{X}$ \\
\hline Artificial heart & Artificial-natural & Implement & $\mathrm{X}$ \\
\hline Virtual book & Virtual-actual & Content & $\mathrm{X}$ \\
\hline Stone lion & Fake-real & Kind & $\mathrm{X}$ \\
\hline
\end{tabular}

T2:

The column "type" indicates the type a denotation of a noun belongs to. For example, a statue is of type artwork. Thus, we expect the treatment of this particular instance, i.e. of statue, is to be generalized to all things categorized as Artwork. This argument applies to all other nouns in Table 7-3. Different types may require different treatments: e.g. in fake statue the properties in question could be the originality/content of the statue, while in a fake watch the properties in questions could be functionality/originality.

The column "Ambiguous" indicates whether the respective compound is ambiguous or not. For example, the compounds fake bracelet and fake watch can be ambiguous. The former can mean "a bracelet that is fake for not being of the purported substance (e.g. diamond)", or it can mean " a bracelet that is fake for not being of the purported brand, manufacture, era, etc.". Similarly, the expression fake watch can mean "something that looks like a watch but in fact is not" or it can, also, means that "a real watch that is fake for not being of certain brand, for instance". Disambiguation can be done via linguistic or pragmatic contexts.

Also, in the course of providing uniform semantics for adjectives, we attempt to accommodate problematic issues connected with adjectives. These are "double adjectives", an issue raised and termed "doublet" by Siegel, such as 'skilful'. 


\subsection{Summary of Assumptions}

The arguments above lead us to the following assumptions:

1. Common nowns denote real/fake, natural/artificial, currentformer, etc. thingswhere appropriate-and are categorized according to their types. For example, the term 'president' denotes fomer/current, real/fake, naturalartificial, etc presidents.

2. Adjectives assume the following hierarchy:

- Intersective, e.g. "red" as in "red car".

- Subsective:

a. Pure, e.g. "veteran" as in "veteran manager"

b. Double, e.g. "beautiful" as in "beautiful dancer"

c. Privative, e.g "counterfeit" as in "counterfeit money"

3. Denotations are sets, represented diagrammatically, as Ven-like diagrams: for example, the set of people can be represented as an oval:

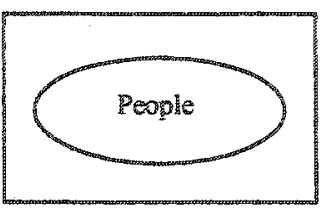

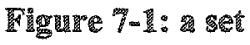

Also, types and properties are represented as boxes:

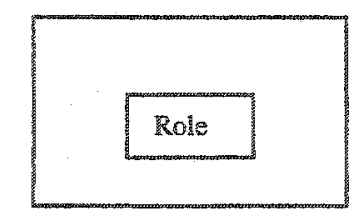

Figure 7-2: 2 agnelprepperty

Entries in this box, include, other types such as Artwork and Implement. For example, a set of people playing the student role is diagrammatically represented as in Figure 7-3: 


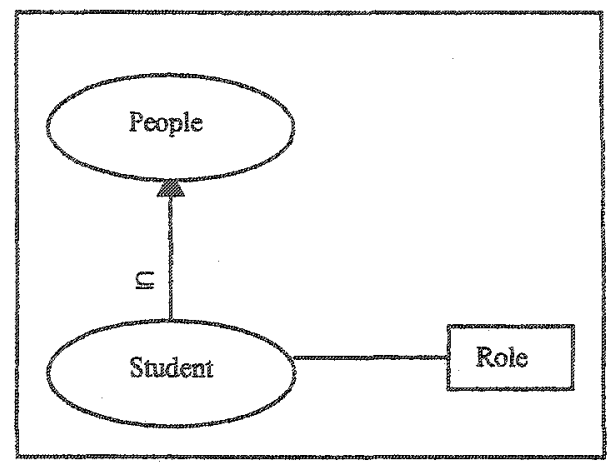

Tigure 7-3: a set of people

4. A meta-function Type 0 with common nouns as its domain and types of common noun denotations as its range. For example, given the phrase clever student, Type ('student') would yield PEOPLE.

\subsection{The Semantics of an One-Adjective-One-Moun Combination}

For the purpose of this work, we distinguish four types that a noun's denotation may belong to. These are natural kind, role, implement, and artwork. This is important since a compound interpretation may be sensitive not only to the adjective's type-Siegel's view (see, section 4.2)-but also sensitive to the noun's type, too-Larson's view (see, section 4.8). These types are part of an ontology we present here. The proposed ontology plays a key role in interpreting adjectival compounds.

\subsubsection{Intersectives}

Intersectives are the most restricted of all adjectives. They are distinguished from other adjectives by being independent from the noun they combine with. For this reason, they are sometimes called absolute adjectives. A phrase such as red car can diagrammatically be represented as in Figure 7-4. 


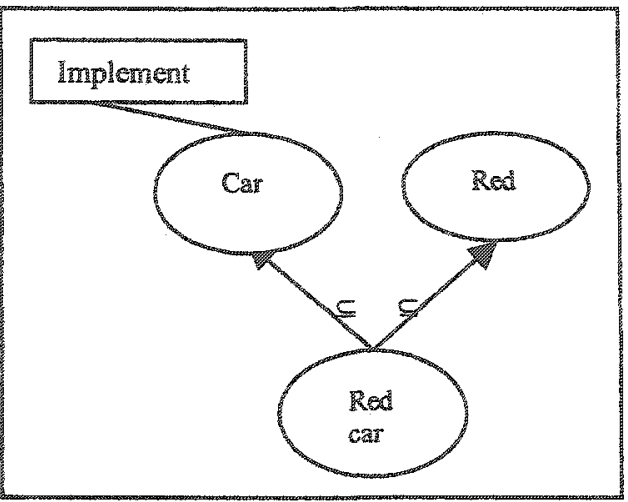

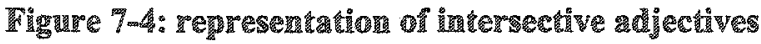

Thus, red car is a subset of both Car and Red sets, regardless of the type the car things belong to. That is,

$$
\| \text { red car }\|\subseteq\| \text { car } \| \text { \& } \| \mathrm{red} \text { carl } \subseteq\|\mathrm{red}\|
$$

The first conjunct is of interest to us since it shows the subsective reading of the compound. The second conjunct provides extra information, but it doesn't undermine the previous fact in any way.

\subsubsection{Subsectives}

Subsective adjectives can be "pure subsective" or doublet. The semantics of pure subsectives is straightforward, as shown below with the adjective "veteran".

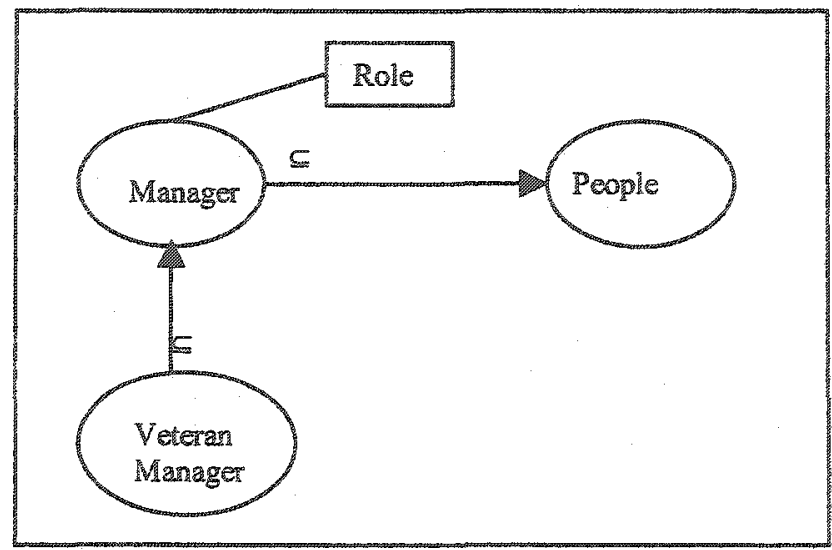

Tigure " 7-5: Pure subsective adjectives: reference-modifyimg 
In this case $\|$ veteran manager\| $\subseteq \|$ manager $\|$

Examples of other pure subsectives are 'rightrul", "chief", "utter', 'consummate', and 'initial'; and, profession adjectives such as electrical (e.g. engineer), medical (e.g. doctor) rural (e.g. policeman), criminal (e.g. lawyer), etc.

On the other hand, doublets can have two different readings: intersective and the nomal subsective reading. This is the view held by authors such as Siegel (1976). Consider the examples in $(7-6)$.
a) John is a clever student
b) John is a skilul surgeon
c) John is a good doctor
d) John is an industrious CEO
e) John is an old friend

Each of the sentences in (7-6) admits two readings. (7-6-a) can mean "John is a clever man"-the intersective reading or, alternatively, it can mean "John is clever qua student"-i.e. he goes cleverly about doing his studies. Similarly, (7-6-c) can mean "John is a good man" or "John is good as a doctor". This ambiguity disappears if the noun indicates a "type" instead of a "role" in the predication position as in $(7-7)$.
a) John is a clever man
b) John is a skilful man
c) John is a good man
d) John is an industrious man
e) John is an old man

The readings in (7-7) are understood to be intersectives only. A possible representation of double adjectives is presented in Figure $7-6$, for the compound clever surgeon. In this 
approach, the double adjectives is further mphasized and "pushed" to the lexicon or taken as such during semantic interpretation. Thus, double adjectives would have two lexical items corresponding to their respective senses. For example, 'clever' would have, say, "clever-1' and 'clever-2'. The former is the referent or kind modifying and the latter is the reference or role modifying. If we take adjectives as functions, then intersective adjectives have in their domain kind-indicating nouns, while pure subsectives have roleindicating nouns in their domain.

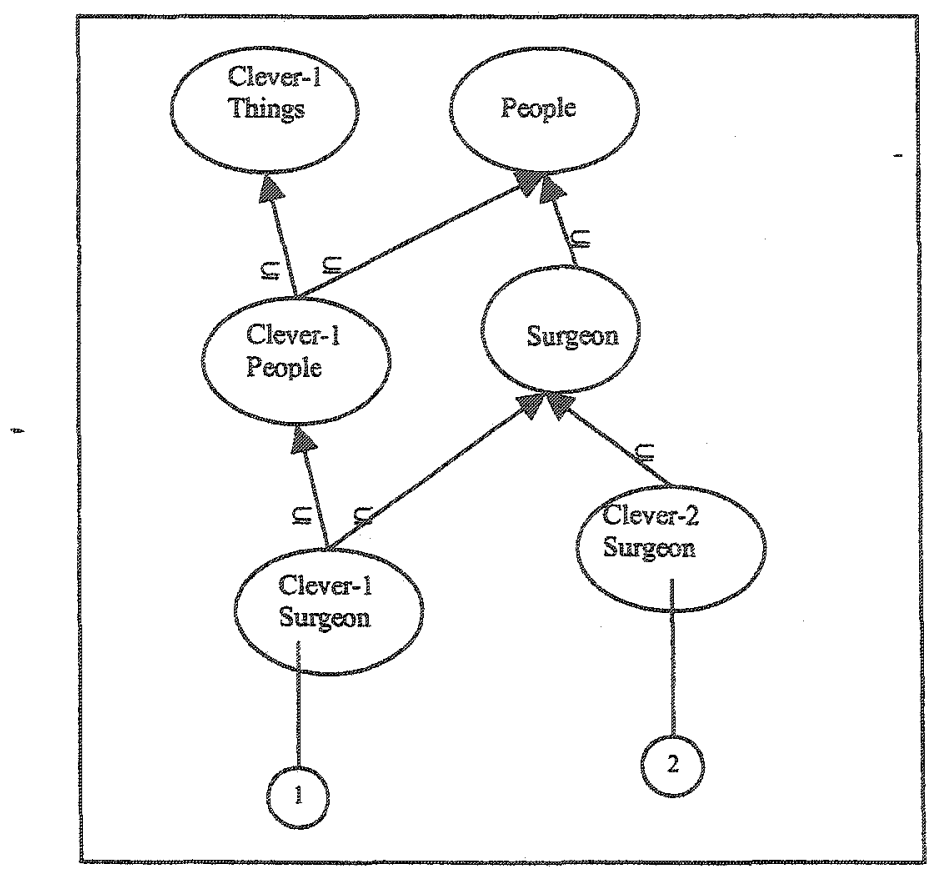

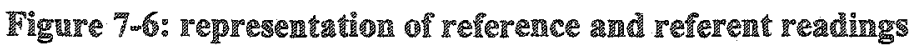

In Figure 76 , the numbers (1), and (2), respectively, indicate the intersective and subsective readings. Reading (1), as indicated by the set Clever-1 Surgeon, states that an individual is a surgeon who is generally clever, i.e. not necessarily clever at surgery. Clever-2 Surgeon, on the other hand, represents people who are clever at surgery, and not necessarily clever in general.

The representation of the double 'clever' in Figure $7-6$ prevents wrong inferences that ensue from the confusion of the two senses of double adjectives. For the kind-modifying (i.e. role-modifying) sense of 'clever', 'clever-2', is always represented as a subset. In other words, it cannot undergo any intersection operation, as does the sense 'skilful-1'. 
In some cases, the linguistic context helps disambiguate the readings of double adjectives, as illustrated in $(7-8)$.
a) John is a skiful man
e) John is a skilful-1 man
b) That musician is a good surgeon
1) That musician is a good-2 surgeon
c) That singer is good
g) That singer is good-1/good-2

The sentence $(7-8-a)$ is unambiguous. This is because skifful modifies man, which is not a role. In such a case, it is understood that the general sense of 'skilful', i.e. 'skilful-1', is what the reading selects. Thus, $(7-8-a)$ is equivalent to $(7-8-e)$. Similarly, $(7 \times-8-b)$, although the referent of that plays the roles of a musician and that of a surgeon, good modifies surgeon. This reading is expressed in (7-8-1). The sentences (7-8-a) and (7-8-b) are to be contrasted with sentence $(7-8-c)$, which is ambiguous and context-dependent. For it could mean that the referent of that is morally good ('good-1") or good as dancer ('good-2') or in any other role not explicitly mentioned in the sentence.

The context can influence attributive reading, too. von Vintel and Heim (1999) cite the following example (the emphasis is ours): "For our checker team, we need at least one lutist who is good at that game. Well, I do not think there is a single good autist in the orchestra, but there is an excellent violinist."

Orher don intelligent, old, true, etc.

\subsubsection{Privatives}

As disscused in section 7.2, augmentation of a noun's denotation is centeral to the semantic treatment of privatives. In this subsection, we will demonstrate how the semantics of privative adjectives is accounted for. In most of the examples studied, we will be using the adjective 'rake", since it poses a challenge to semantic interpreation resluting from the ambinguity of the compounds containing it. Our frst example is the 
compound fake painting. When questioning whether a painting per se, i.e. irrelevent of the painter, is fake or real, is is uambiguious. This is illustrated in Figure $7-7$.

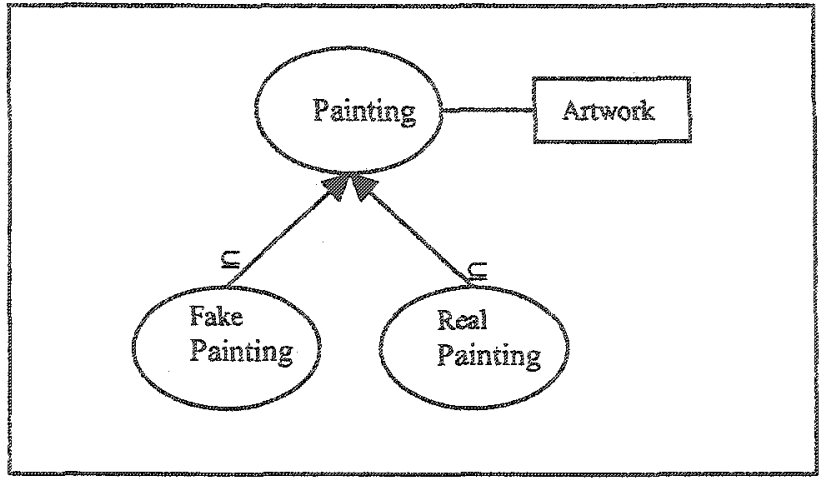

Tigure 7-7\% representation of folke paind ting

Most of the time when the phrase fake painting is uttered, speakers and hearers have a particular painter in mind to whom the painting is purported to belong. So fake painting is usually a short for, say, foke Rembrandt painting or even to fake Rembrande. This explicit phrase can diagrammatically be represented as in Figure 7-8.

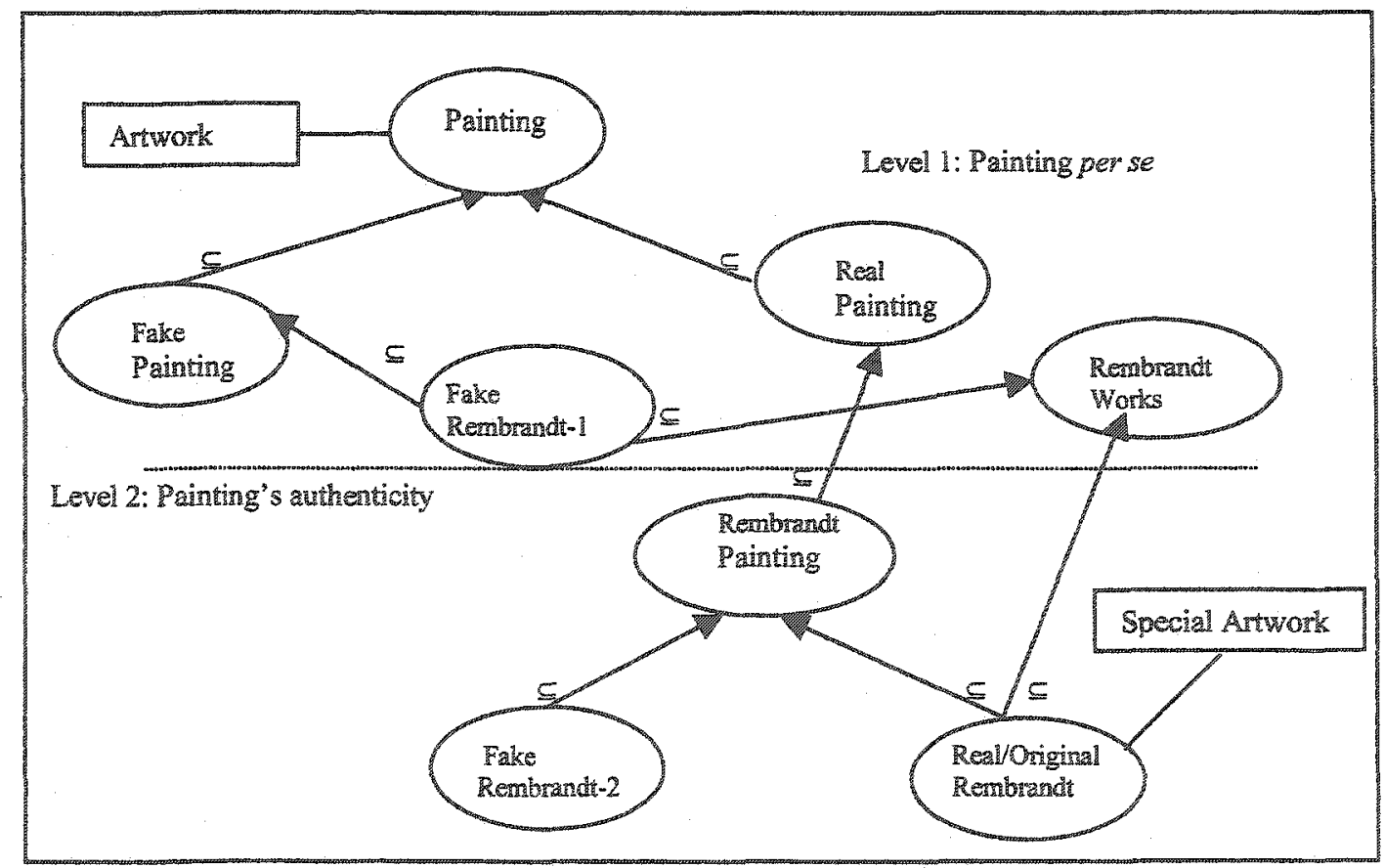

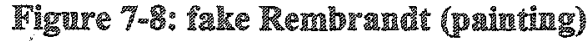

Thus, as shown in the diagram, afake Rembrondt painting is ambiguous. It might mean a painting that is not painted by Rembrand-fake has narrow scope-or could mean fake as a painting and consequently as Rembrand's. Also, there is a possibility that some 
work actually done by Rembrand as a painting, but at a closer look it mus out it is fake-say, a print rather than a painting. This latter possibility is represented by the set Fake Rambrandt-1, Figure 7-8. If the work is really a painting but it is questionable with regard to its originality or authenticity, it will end up either Fake Renbrandt-real painting but not painted by Rembrand-or original Rembrandt sets, when authenticity is confirmed.

One can even go further hown more levels-in addition to levels 1 and 2 in Figure 7.8. A painting might be a real one, a real Rembrandt but still fake from another perspective. For instance, if someone who is not familiar cnough with Rembrandt's work might assert the painting to be not a Rembrandt on the grounds that it was done by the very young Rembrandt, that is, fake (the adul or the fomous) Rembrandt.

Nouns of type Implement can also assume a structure similar to that of Artwork. For, example, consider the phrase Fake gun and its representation in Figure 7.9.

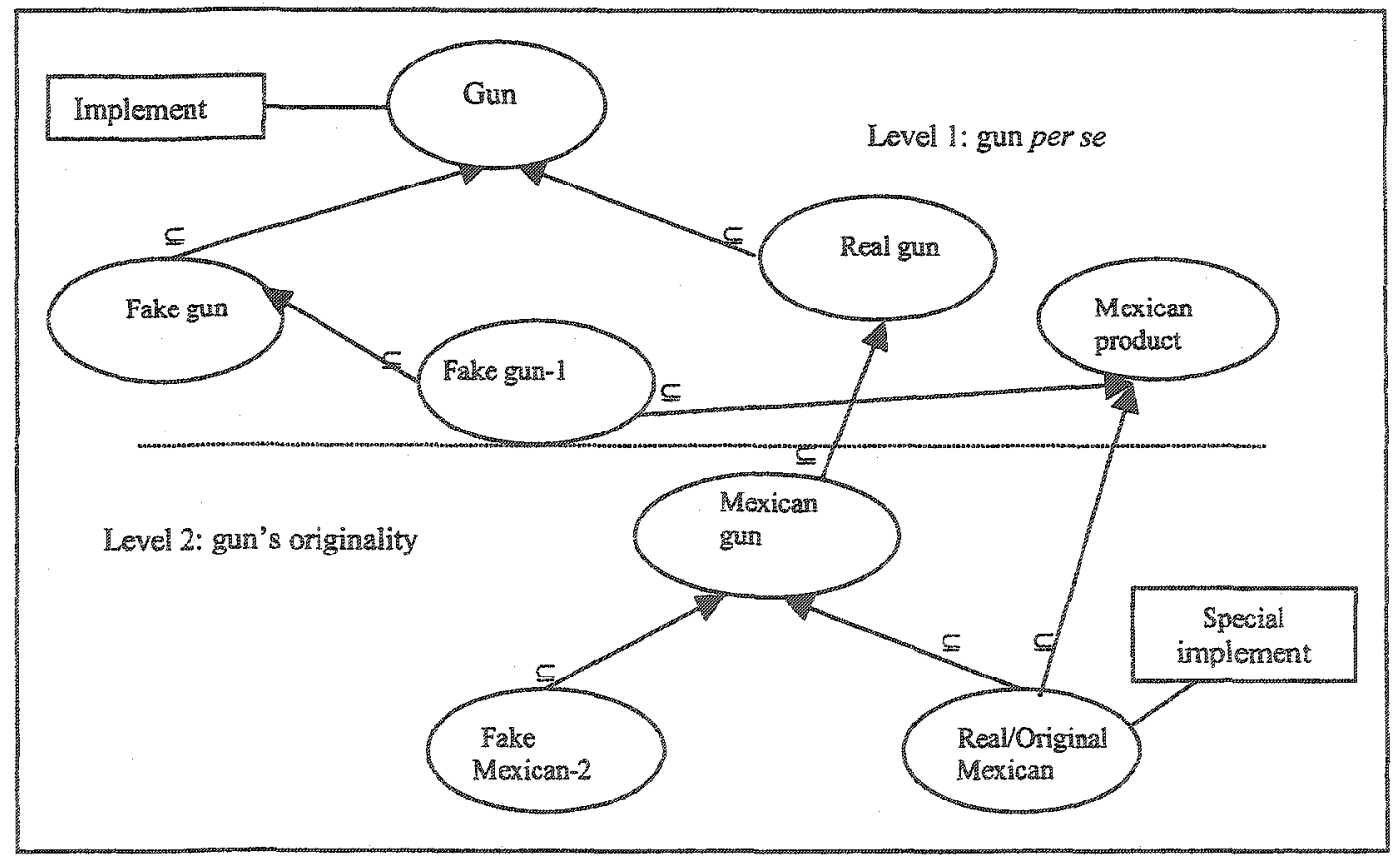

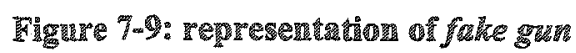

This representation is very similar to that of fake painting in Figure 7-8: fake gun, at level 1 , asserts that the gun in mind is functionally fake; and, in the elliptic form it asserts the 
gun's "fakeness" as Mexican. In the latter case the phrase fake gun can be a short for fake Mexican gun. As with the phrase fake paining, one can go at least one more level down the structure in Figure $7-9$ by means of the phrase foke 19 th century Mexican gun, i.e. fake only withespect to a specific era.

However, there is one difference between the semantics of fake gun and fake painting: one might have a replica gun or a replica watch but not a replica painting (to some extent), for instance. This is due to the fact that artworks are more valuable for their uniqueness. This distinction comes from the definitions of Artwork and Implement. However, uniqueness is not a sole property of Artwork. Consider the literal meaning of the phrases fake holy grail or a fake Cleopatra tub. Here, tubs and grails are usually of not much value and can be replicated, but they acquire value and uniqueness when they are related some events or individuals.

Finally, it is worth mentioning that the representations of the phrases such as fake (Rembrandt) paining and fake (Mexican) gun do not preclude disjoint readings, Figure 78 and 7-9. The referent of the phrase fake Rembrond painting could belong to the set of fake (i.e. not real) painting and to the set of things purported to be Rembrandr's (but in fact they are not). The Figure 7.8 presents a certain level of abstraction. For instance, the set Rembrand Works of Figure $7-8$ contains rake and real work that belong to Rembrandt. To get the inclusive reading of foke Rembrandt painting (i.e. as being lake as a painting and as work does not belong to Rembrandt), we need to split the set Rembrandt Works into two sets-fake and real-and obtain the desired reading.

\subsubsection{Privative Compounds}

Based on the analysis of privative compounds, see section 7.3 .1 , we will consider the phrase wooden mon. The semantics of this phrase can be represented as in Figure 17-10. 


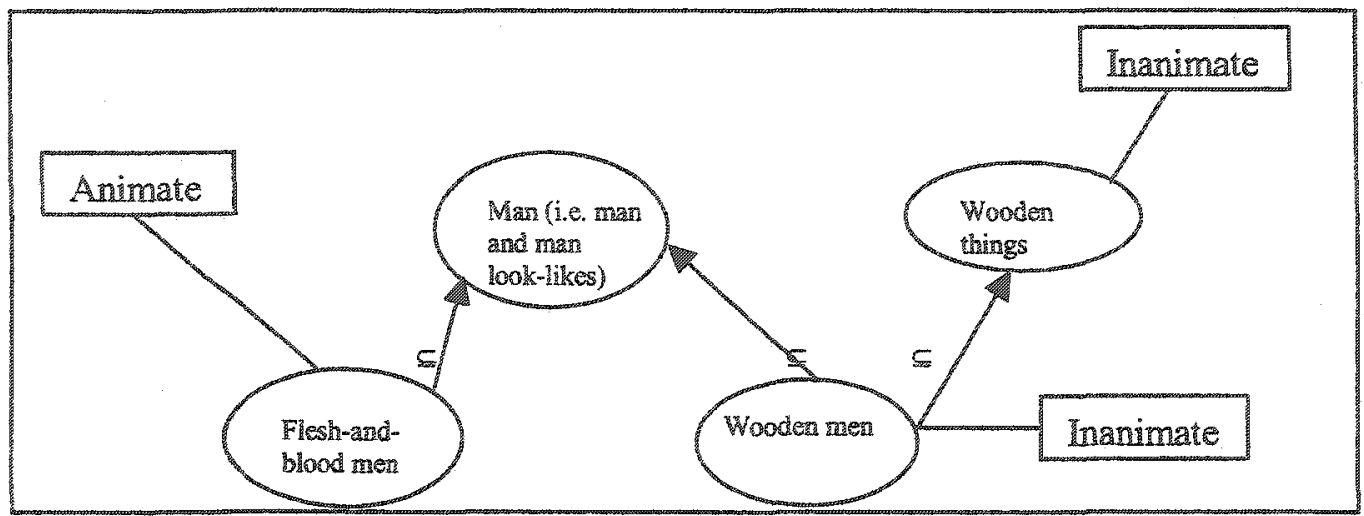

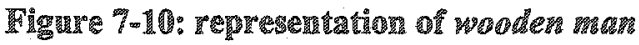

As mentioned in section 7.3 , type-denoting intersectives are only sensitive to some types, e.g. animates. Wooden chair and stone statue are still intersective. However, the compounds of wooden choir and stone chair are also subsets of their respective nouns. In figure 7-10 Wooden Men is subset of Wooden Things, hence the subsective reading. That is,

$\|$ wooden man $\|\subseteq\|$ wooden $\|$

A representation based on the analysis of subsection 7.3 .2 might look like Figure $7-11$.

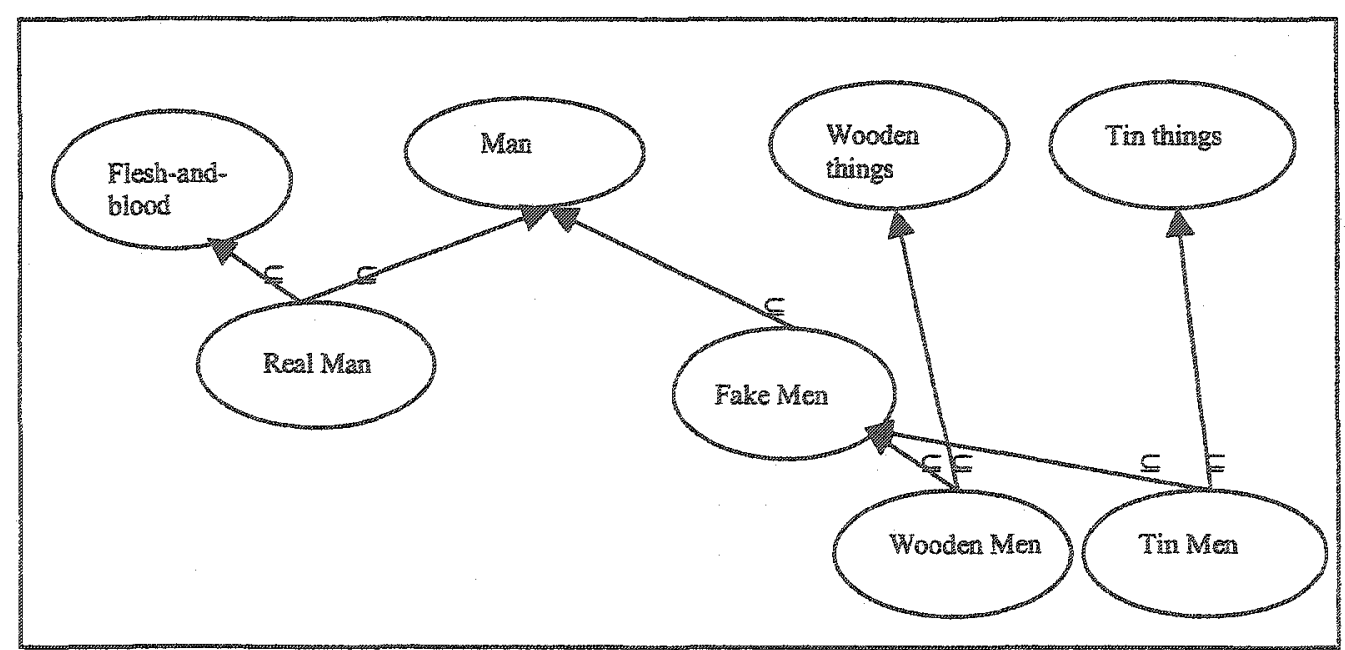

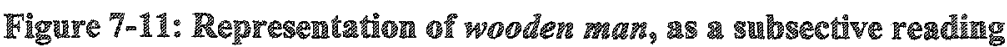


In Figure 7.11 , it is clear that a subsective reading can be obtained. This is expressed in the following set operation:

$$
\| \text { wooden man }\|\subseteq\| \text { fake man }\|\subseteq\| \text { man } \|
$$

\subsubsection{Summary of Discussion}

The discussion in the previous subsection can be summarized by means of Table 7-4. In Table 7.4, types of different nouns are matched up against all kinds of adjectives. The result of this match-up is the identification of the respective semantic operations indicated as entries in the table.

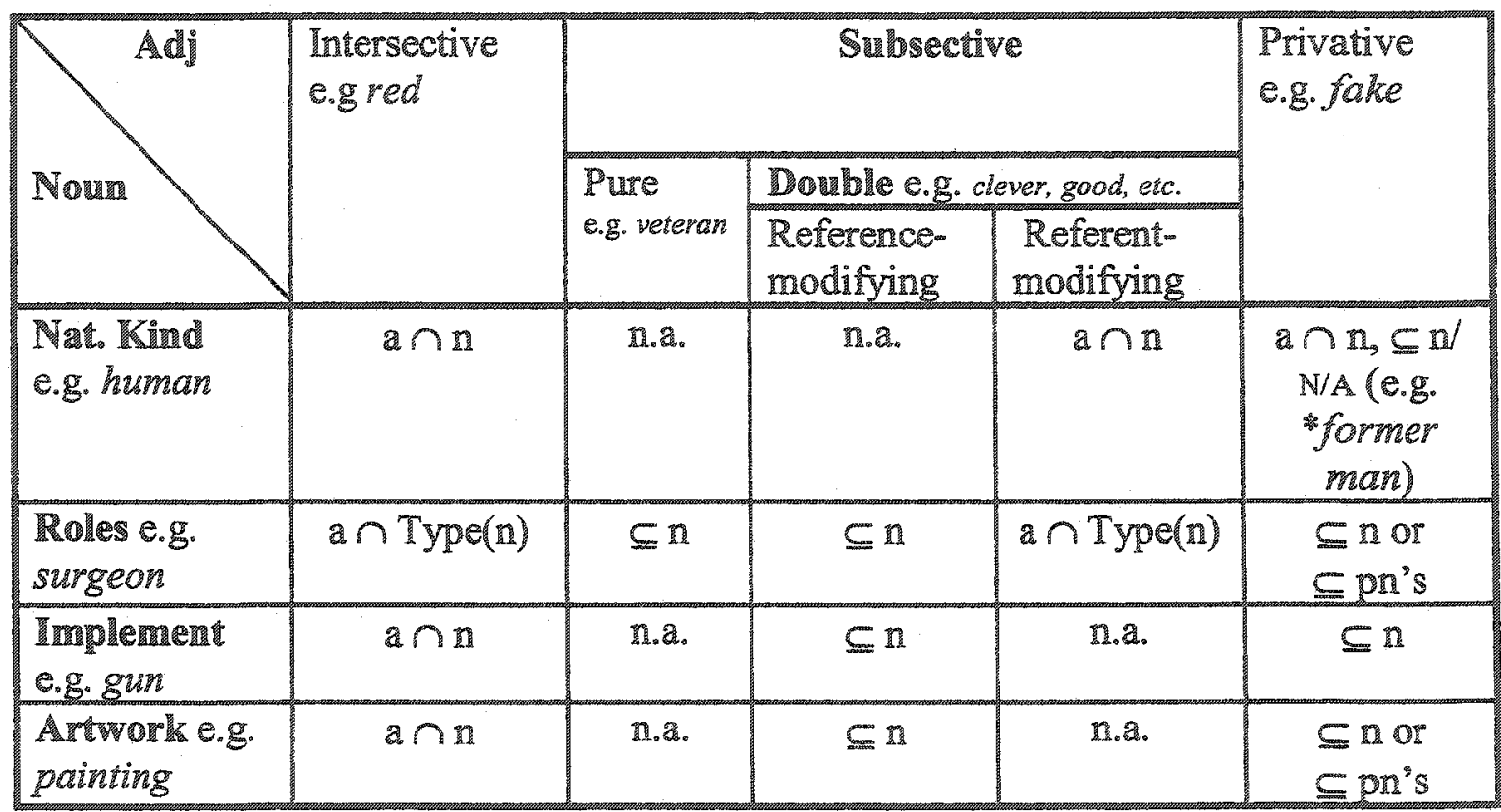

Table 7-4: summary of semmatic operations on adjectival compounds

Where ' $a$ ' and ' $n$ ' represent adjective and noun, respectively. Also, in Table $7-4$, the meta-function Type is used to get the type of a referent from its reference. This is necessary in the treatment of "double adjectives" to get both reference- and referentmodifying readings.

Some of the operations are ambiguous. This is indicated in Table $7-4$ by: (1) multiple entries in the table, as in the case of the subsective adjectives and Role types; and, (2) by 
the connective 'or'. In the latter case, for example, a fake gun can mean two things: a gun per se is fake or it is rake with regard to certain brand, e.g. Pake Mexican gun. Fake painting also is ambiguous, as pointed ont in subsection 7.6.3. However, this ambiguity stems from using the short form of the expression rather that the long form, i.e. fake painting as short form for fake Rembrand painting or fake gun as a shor form for fake Mexican gun.

Table 7.4 serves as a rough approximation. In chapter 9 , we furcher elaborate on Table 7. 4 so that idiosyncrasies of different compounds are taken into consideration. For example, although both 'skilful' and 'good' are classified as double adjective, they differ in their semantic behaviour with regard to some common noun types. 
There is a restriction on the order of adjectives in English as well as all other languages that have "adjective" in their syntactic categories (see, Dixon (1982, p24), Quirk et al (1985), Frawley (1992), and Shaw and Hatzivassiloglou (1999)). Thus, for example, the compound beautiful short curved new red German racing car is acceptable in English, while the compound red curved short beautiful new racing German car is not-though, it passes the grammaticality test. Adjective ordering, thus, is semantically motivated: adjectives are categorized in semantic classes according to some rigid criteria. For example, Quirk and Greenbaum(1973, p 404) suggest the order general> age> colour> participle> provenances noun $>$ denominal, while Dixon (1982) proposes the order value $>$ dimension $>$ physical property $>$ speed $>$ human propensity $>$ age $>$ colour.

The literature, as Raskin and Nirenburg (1995) note, does not include relative adjectives, where privatives are subclass of, in proposals connected with adjective ordering. However, there is a general agreement, e.g. Kamp (1975) and Frawely (1992), that intensional adjectives precede extensional ones, when they sequentially combine to modify a common noun head. Accordingly, in this chapter, we will only discus the cases where privative adjectives are at the leftmost position in the multiple adjective compounds.

In addition, we, in line with our analysis, assume that common nouns, intersective adjective, and subsective adjectives-relative to the denotation of the noun they combine with-denote sets. The elements of such sets can be-where appropriate-fake/real, current/former, etc. For example, the set Student can be represented as in Figure 8-1. 


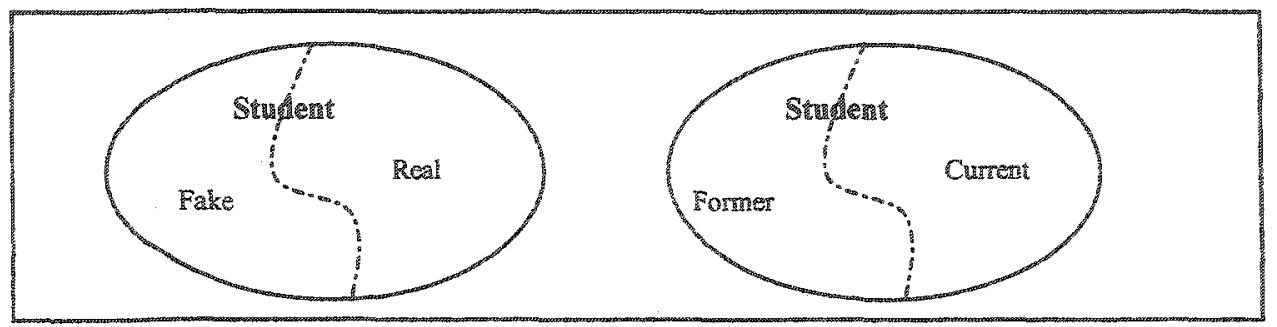

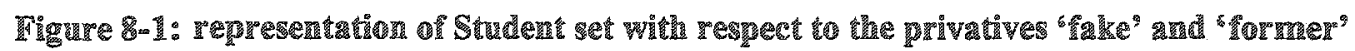

A similar representation can be provided for intersective adjectives such as 'red' with regard to "fake".

\subsection{Privative-intersective Combination}

The first example we will consider is (8-1). In this example, we have a privative and an intersective adjective that modify the noun man, which is of type natural kind.

fake red man

This combination has the following possible (semantic) representation-two possibilities, as depicted in Figure $8-2$.

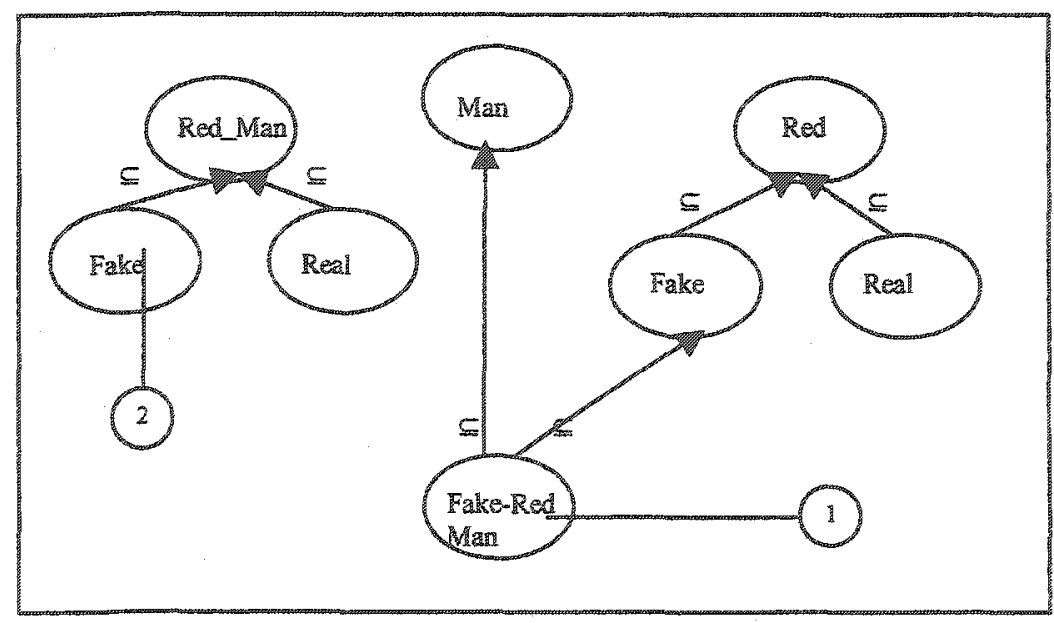

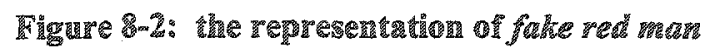


The two possible readings are depicted in Figure 8-2: (1), where fake has narrow scope, and (2), where foke has wide scope over the adjective phrase red mon. A similar representation can be shown for nouns of type Implement, e.g. fake red gum, and those of type Artwork, e.g. fake red pointing. This is because the adjective 'red' is a referentmodifying adjective.

It should be noted that the set Red_Man does not represent the set intersection of Red and Man; rather, it is a representation of the denotation of the idea or thought of "red man".

\subsection{Privative-Subsectives Combination}

For the privative-subsective combination, we use the privative 'fake' and the pure subsective "veteran'. The adjectival phrase involving these adjectives is illustrated by example $(8-2)$.

(8-2)

Fake veteran manager

The possible readings of (8-2) are diagrammatically represented in Figure (8-3).

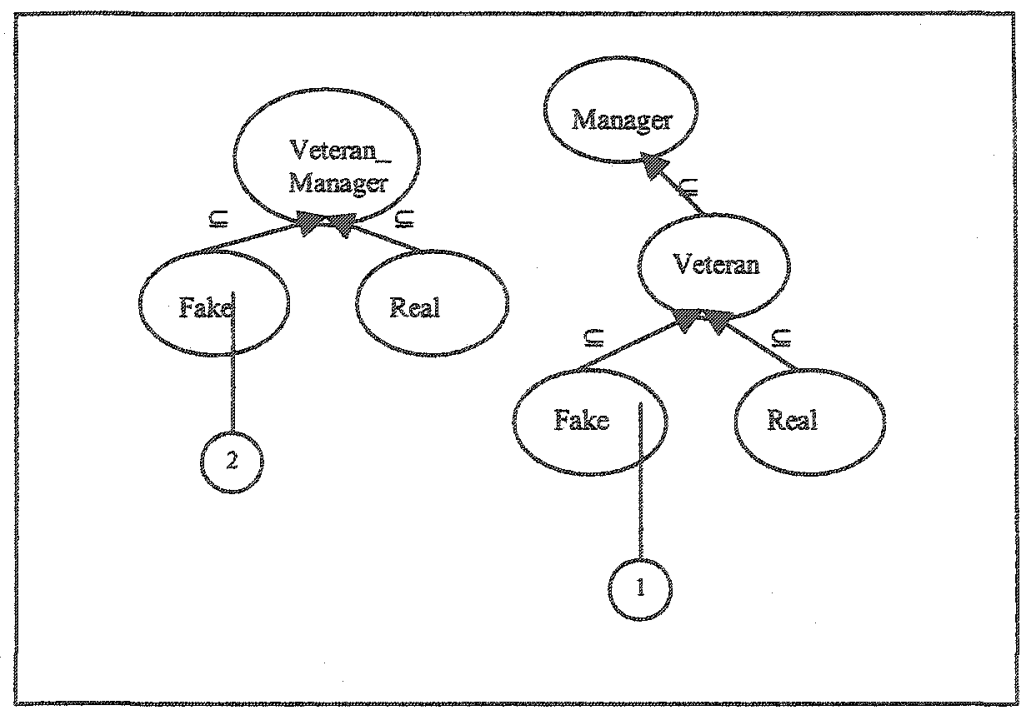

Wigure 8-3: represeatation of fra 
In Figure 8-3, the numbers (1) and (2), respectively, represent the narrow and wide readings of the adjective fake.

Double adjectives are similar to pure subsective. However, the intersective reading must be taken into consideration. This can be demonstrated by using the adjective "skilful", as in $(8-3)$.

fake shintui surgeon

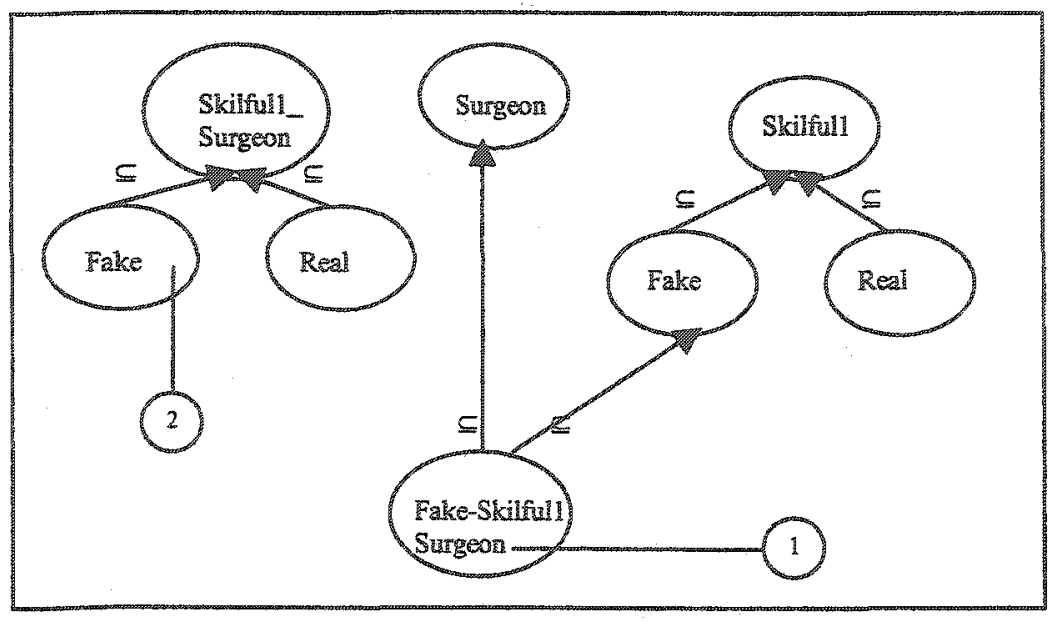

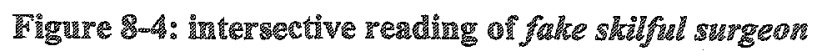

Figure 8-4 depicts the general sense of 'skilful'. In the figure, the absolute sense of 'skilful' is indicated as 'skilfull'. The two possible readings are indicated in the figure as (1), the narrow-scope of skilful, and (2), the wide-scope of skilful. 


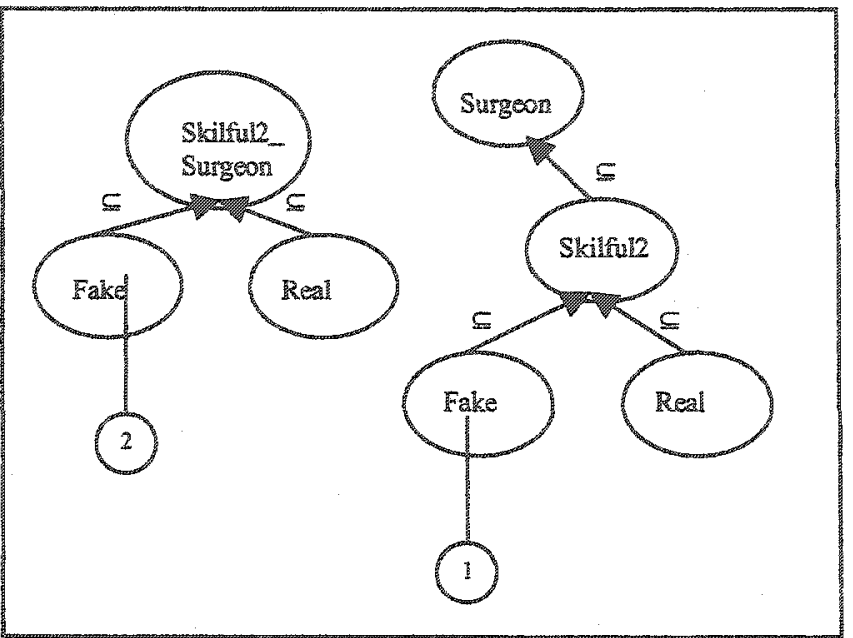

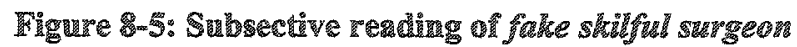

Figure 8-5 shows the two readings of the kind-modifying (i.e. reference-modifying) sense of 'skilful'. The narrow-scope and wide-scope readings are indicated, respectively, (1) and (2).

\subsection{Privative-privative combinations}

Since privatives are now considered subsectives, their semantic behaviour is not much different from that of the other subsectives, e.g. "veteran'. Consider example (8-4) and its representation in Figure 8-6.

former fake actor

Here, again, we have two possible readings. These readings correspond to the narrowscope, labeled (1) in Figure 8-6, and wide-scope reading, labeled (2) in Figure 8-6, of 'former'. 


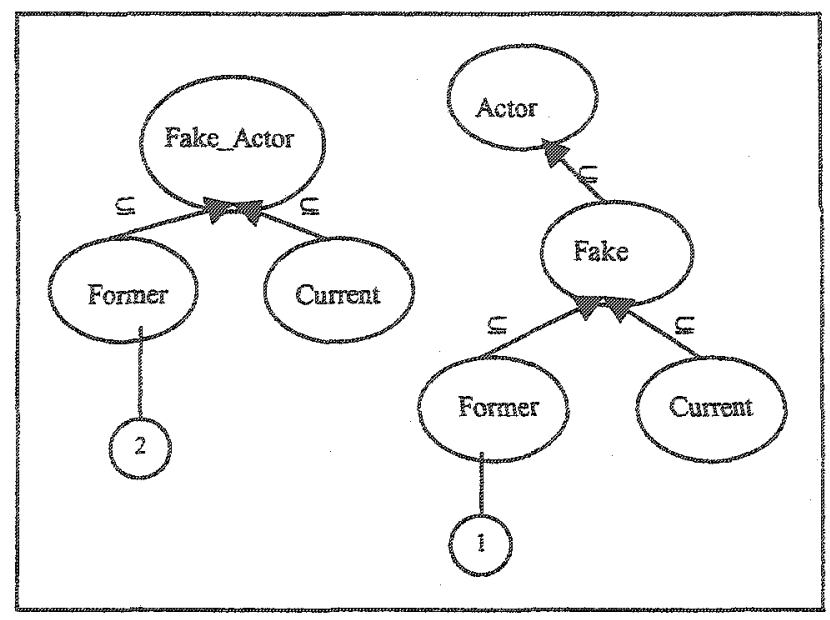

Wigure 8.6: representation of former frace actor

If we reverse the adjectives of example $(8-4)$ to get $(8-5)$, we still have the same pattern, as shown in Figure 8.7.

(8-5)

fake fomer actor

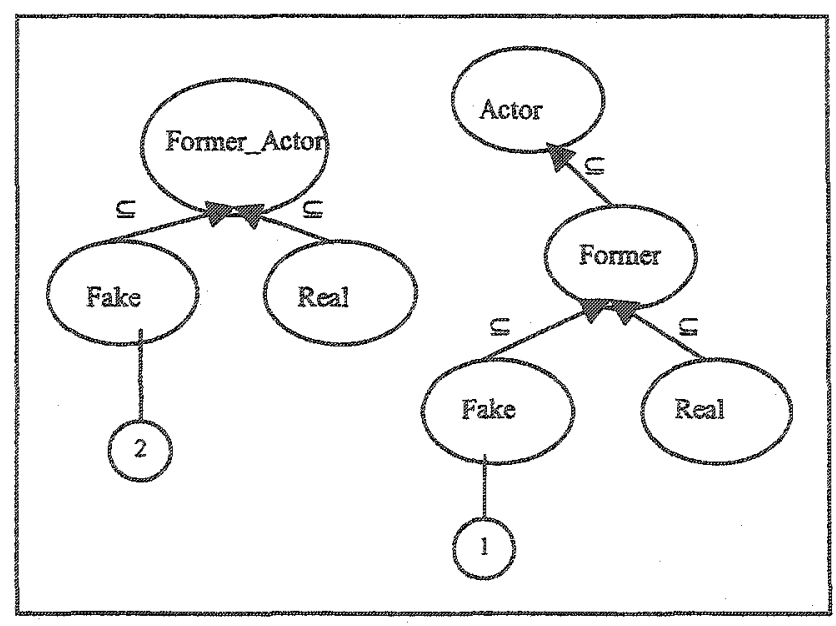

Figure 8. $\%$ \% representation of foke former actor

The numbers (1) and (2) in Figure $8-7$ indicate, respectively, narrow-scope and widescope effect of the adjective 'fake". 
In this chapter, we present an algorithm for computing the semantics of adjectival phrases. The algorithm is based on the analysis in the previous two chapters. The algorithm is implemented as a Miranda program. We will dub this routine API, Adjectival Phrase Interpreter.

\title{
9.1. Adjectival Phrase Interpreter (API): building the lexicon and mapping lexemes to sets
}

\begin{abstract}
API's lexicon is rather limited. It only contains adjectives and nouns-common and proper. However, this serves our purpose in treating adjective-noun combinations. Initially, the lexicon recognizes the following types of adjectives: intersective, subsective, and privative. Eventually, adjectives will be either intersective or subsective. Nouns are entered to the lexicon along with their respective types. For example, 'gun' would have the type Implement entered along with it.
\end{abstract}

In line with our analysis, privative adjectives are considered subsective. However, in order for them to be at equal footing with regular subsective, API must do some extra work. Once an input containing a privative adjective is entered, API does two things:

1. If not already created, it creates a set denoting the noun, i.e. the superset; and,

2. It creates two subsets of the noun's denotation, the superset.

For example, the input artificial heart would trigger the creation, if it does not exist, of the super set Heart and its constituent subsets Artificial-Heart and Natural-heart. 


\section{2 implementation Strategy}

Our ontology assumes the existence of four types: Natural Kind, Role, Implement, and Artwork. Although each adjective-noun combination has, with the exception of complete synonymy, a uniquely computed meaning, adjectives are similar in their range of applicability to nouns. Our strategy is to abstract away from the idiosyncrasies of meanings of adjective-noun combinations and focus on their applicability. We want to take advantage of this observation in order to save time and effort in coding the program as well as improving program maintainability. This can be achieved by grouping adjectives that are similar in their range of applicability. Then, those similar adjectives receive the same implementation framework. To further clarify what we mean consider Table 9-1.

\begin{tabular}{|c|c|c|c|c|c|c|c|}
\hline \multicolumn{5}{|c|}{ Intersective readings } & \multicolumn{3}{|c|}{ Subsective readings } \\
\hline & $\begin{array}{l}\text { Good } \\
\text { (Moralisy) }\end{array}$ & $\begin{array}{l}\text { Large } \\
\text { (Dimension) }\end{array}$ & $\begin{array}{l}\text { Reautiond } \\
\text { (Pingsical appeal) }\end{array}$ & $\begin{array}{l}\text { Skilliful } \\
\text { (Gemeral) }\end{array}$ & $\begin{array}{l}\text { Good } \\
\text { Perhormancel }\end{array}$ & $\begin{array}{l}\text { Tormer } \\
\text { Former relles) }\end{array}$ & 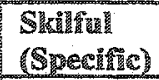 \\
\hline 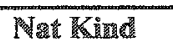 & $\sqrt{2}$ & $\sqrt{ }$ & $\sqrt{2}$ & $\sqrt{ }$ & $\mathrm{X}$ & $X$ & $X$ \\
\hline Role & $\sqrt{ }$ & $\sqrt{ }$ & $\sqrt{ }$ & $\mathrm{X}$ & $\sqrt{ }$ & $\sqrt{ }$ & $\sqrt{ }$ \\
\hline 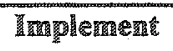 & $\bar{X}$ & $\sqrt{ }$ & $\sqrt{ }$ & $X$ & $\sqrt{ }$ & $\bar{X}$ & $X$ \\
\hline Astwor & $X$ & $\sqrt{ }$ & $\sqrt{ }$ & $\mathrm{X}$ & $\sqrt{ }$ & $\bar{x}$ & $\bar{X}$ \\
\hline
\end{tabular}

Table 9-1: Abstracting implementation details

In Table 9-1, for instance, the adjectives 'former' and 'skilful', in their subsective sense, can have similar implementations. Thus, they are going to be in the same implementation category, with other adjectives, if any, that behave in a similar way.

Since, according to our analysis, adjectives can be intersective, subsective or both, we reduce the columns of table 9-1 to just two columns, as in Table 9-2-in the case of the adjective 'good'. It should be clear that Table 9-2 expresses the observation that 'good', in its predicative sense, is applicable to all types except those of type Implement and Artwork. Along with 'good', adjectives such as 'bad' might roughly share the same implementation. 


$\|$ good $\|=$\begin{tabular}{|l|c|c|}
\hline & Intersective & Subsective \\
\hline Nat. Kind & $\sqrt{ }$ & $\mathrm{X}$ \\
\hline Role & $\sqrt{ }$ & $\sqrt{ }$ \\
\hline Implement & $\mathrm{X}$ & $\sqrt{ }$ \\
\hline Arwork & $\mathrm{X}$ & $\sqrt{ }$ \\
\hline
\end{tabular}

Table 9-2: applicability patem of 'good'

The adjective 'beautiful' can have the following pattern.

$\|$ beautioul $\|=$\begin{tabular}{|l|c|c|}
\hline & Intersective & Subsective \\
\hline Nat. Kind & $\sqrt{ }$ & $X$ \\
\hline Role & $\sqrt{ }$ & $\sqrt{ }$ \\
\hline Implement & $\sqrt{ }$ & $\sqrt{ }$ \\
\hline Artwork & $\sqrt{ }$ & $\sqrt{ }$ \\
\hline
\end{tabular}

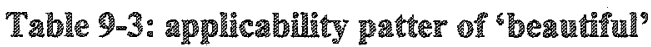

The adjectives 'old' and 'new' may fall in the same implementation category as 'beautiful'.

It should be noticed that although 'good' and 'beautiful' are classified as double adjectives their semantic representations differ. This is depicted in tables 9-2 and 9-3.

A pure intersective adjective such as 'red' can have the applicability pattern that is shown in Table $9-4$.

$\|$ red $\|=$\begin{tabular}{|l|c|c|}
\hline & Intersective & Subsective \\
\hline Nat. Kind & $\downarrow$ & $\mathrm{X}$ \\
\hline Role & $\checkmark$ & $\mathrm{X}$ \\
\hline Implement & $\checkmark$ & $\mathrm{X}$ \\
\hline Artwork & $\checkmark$ & $\mathrm{X}$ \\
\hline
\end{tabular}

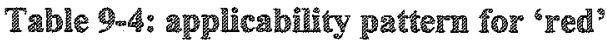

As shown in Table 9-4, 'red' is applicable to the four types. Since 'red' is a 'pure' intersective adjective, it cannot be used subsectively. 
"Ted" is to be contrasted with the "pure" subsective adjective such as "veteran'. The latter's applicability pattern is depicted in Table 9.5.

\begin{tabular}{|c|c|c|c|}
\hline \multirow{5}{*}{ I veteran || = } & & Intersective & Subsective \\
\hline & Nat. Kind & $X$ & $X$ \\
\hline & Role & $X$ & $\sqrt{1}$ \\
\hline & Implement & $X$ & $\mathrm{X}$ \\
\hline & Antwork & $X$ & $\bar{X}$ \\
\hline
\end{tabular}

Table 9-5: applicability patterm 10\% "Yeteran'

From table 9-1, it is evident that, given the four types we assumed, there are 256 (i.e.16X16) possible pattems. In fact, the number of pattems is less than 256 since the pattem in Table 9.6 cannot conceivably occur.

\begin{tabular}{|l|c|c|}
\hline & Intersective & Subsective \\
\hline Nat. Kind & $\mathrm{X}$ & $\mathrm{X}$ \\
\hline Role & $\mathrm{X}$ & $\mathrm{X}$ \\
\hline Implement & $\mathrm{X}$ & $\mathrm{X}$ \\
\hline Artwork & $\mathrm{X}$ & $\mathrm{X}$ \\
\hline
\end{tabular}

Table 9-9: the impossible patterm

Other possible patterns are reported in Appendix $B$.

\subsection{Coding and Data Representation}

API coding is straightorward. All that we need is populated sets-some might be empty-and the definition of operations over these sets. The operations are subset, intersection, and union.

The sample program assumes a domain of entities that include the following:

mant, man2, man3 represented, respectively, by symbols $m 1, m 2, m 3$

spadel, spade 2, spade3 represented, respectively, by symbols $s p 1, s p 2, s p 3$

Then, for example, we can define the following sets, based on the above domain:

$$
\begin{aligned}
& \text { set_of man }=\left[m 1, m 2, m_{3}, m 4\right] \\
& \text { sel_of_spade }=[\mathrm{sp1}, \mathrm{sp2}, \mathrm{sp3}]
\end{aligned}
$$


set_of_surgeon $=[\mathrm{m} / \mathrm{m}, \mathrm{m}, \mathrm{m}$ ]

set of_large $=[m 1, m 4$, spl] if we assume that 'large' is not vague

Since subsective readings are enumerated, not computed, they are also defined as part of the database hierarchy. For example, the set that represents the denotation of the phrase good surgeon-good as a surgeon, the subsective reading-is as follows: Hooper

$$
\text { set_of_good_as_surgeon }=[\mathrm{m} 3, \mathrm{~m} 4]
$$

However, the intersective readings are generated from the database, e.g. large man.

\subsection{A Review of the Source Code}

In this subsection we present a documentation of the essential parts of the source code.

Creating the database is created as a set hierarchy. It includes four common nouns. These are: 'man', 'surgeon', 'musician', and 'spade'. The database is illustrated in Figure 9-1.

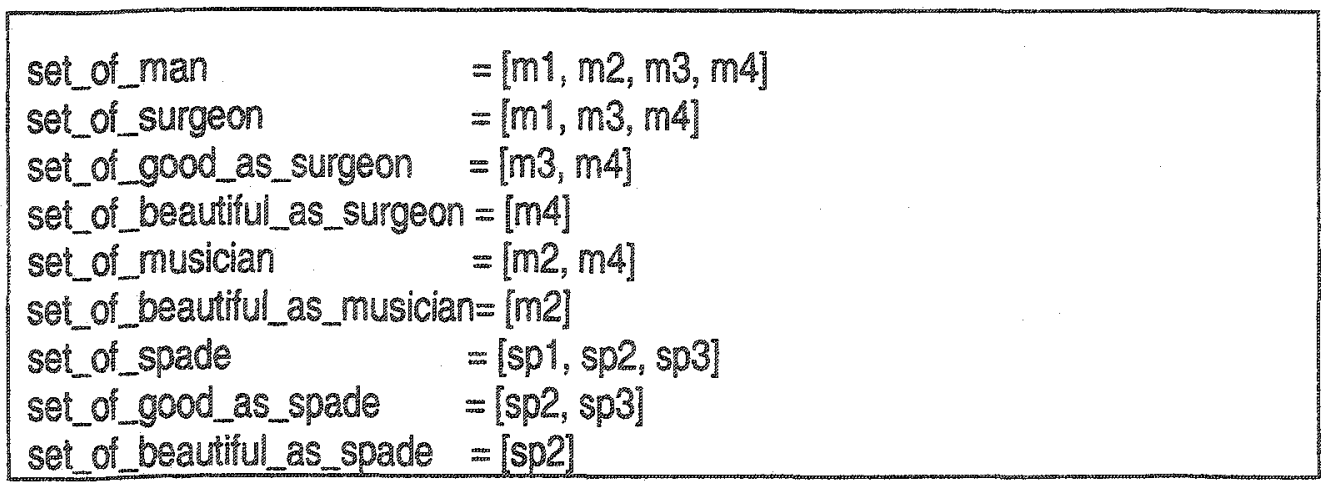

Tigure 9.1:2 5napshot of A

As shown in Figure $9-1$, for example, the subsective reading beautiful surgeon is represented as the set set_of_beautiful_as_surgeon; given the current states of affairs, it contains the member ' $\mathrm{m} 4^{9}$ " 
Operations on Sets. API defines three set operations. These are union, intersection, and subset. The respective Miranda definition of these operations is shown in Figure 9-2.

$$
\begin{aligned}
& \text { unitest }=s+(t-s) \\
& \begin{aligned}
& \text { intersec } s t=s-(s-t) \\
& \text { subset } s !=\text { True, it }(s-n)=0 \\
&=\text { False, othewise }
\end{aligned}
\end{aligned}
$$

Figngre 9-2: the comiling of set operation

Meaning Representation. Meaning of words is represented in tems of sets. Each meaning consists of a triple: a word, a type and a set. Representation of the common nouns 'man', 'spade', 'surgeon', and 'musician' is shown in Figure 9-3.

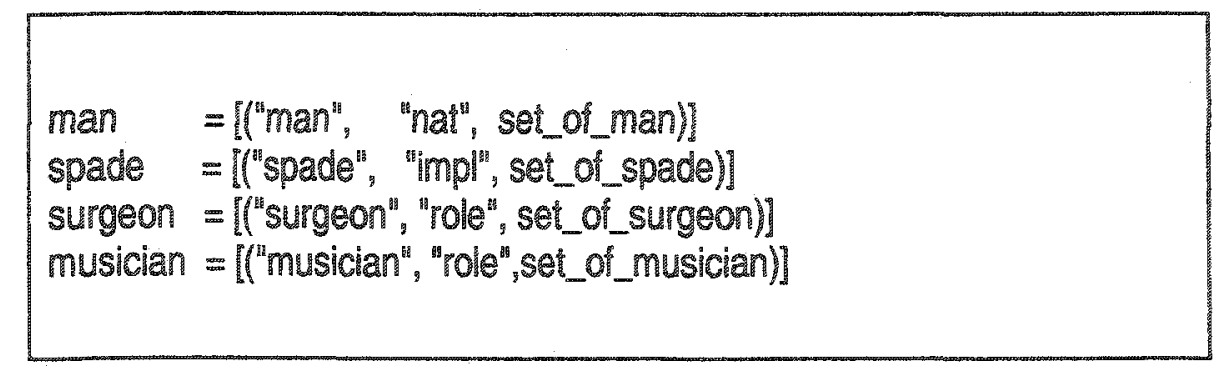

Tigughe -3:

It should be noted that word meaning is represented as a list. This is important in order to accommodate ambiguity.

Subsective Readiangs. Since subsective readings are non-computable, a utility function, get_set, is used to retrieve sets denoting the subsective reading by means of strings identifiers. 


$$
\begin{aligned}
& \text { get_set "good_as_surgeon" = set_of good_as_surgeon } \\
& \text { get_set "good_as_spade" = setoĺoood_as_spade } \\
& \text { get_set "beautitulas_surgeon" = set_or_beautitu_as_surgeon } \\
& \text { get_set "beautifulas_musician" = set_of_beautiful_as_musician } \\
& \text { get_set "beautifulas_spade" = setof beautiful_as_spade } \\
& \text { get_se" "good_as visually_beautiful_surgeon" } \\
& \text { =set_of_good_as_visually_beauitul_surgeon } \\
& \text { get_set "good_as_beautifu_as_surgeon" } \\
& \text { get_set any }=[] \\
& \text { =set_of_good_as_beautitul_as_surgeon }
\end{aligned}
$$

Figure 9-4: represemtation of subsective readings

This utility function is shown in Figure $9-4$ in the case of the subsective readings good as surgeon, good as spade, beoutiful surgeon, beautiful musicion, beautiful spade, good as beautiful (physically beautiful) surgeon, and good as beautiful strgeon.

Intersective Ad jechives. The meaning of adjectives is described as "operators" on the meaning of nouns such that the result in some cases depends on the rype of the noun. This is shown in Figure 9-5 in the case of the adjective 'large".

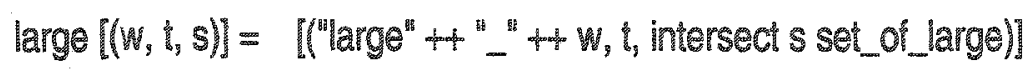

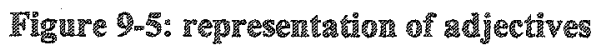

Note that in Figure 9-5 the adjective 'large' is intersective; we curther assume, for simplicity, that it is not vague.

Donle Adjectives. Double adjectives have wwo different representations: one for the intersective reading and the other for the subsective one.

API implements the double adjectives 'good' and 'beautiful'. Figure $9-6$ shows the implementation of 'good'. 


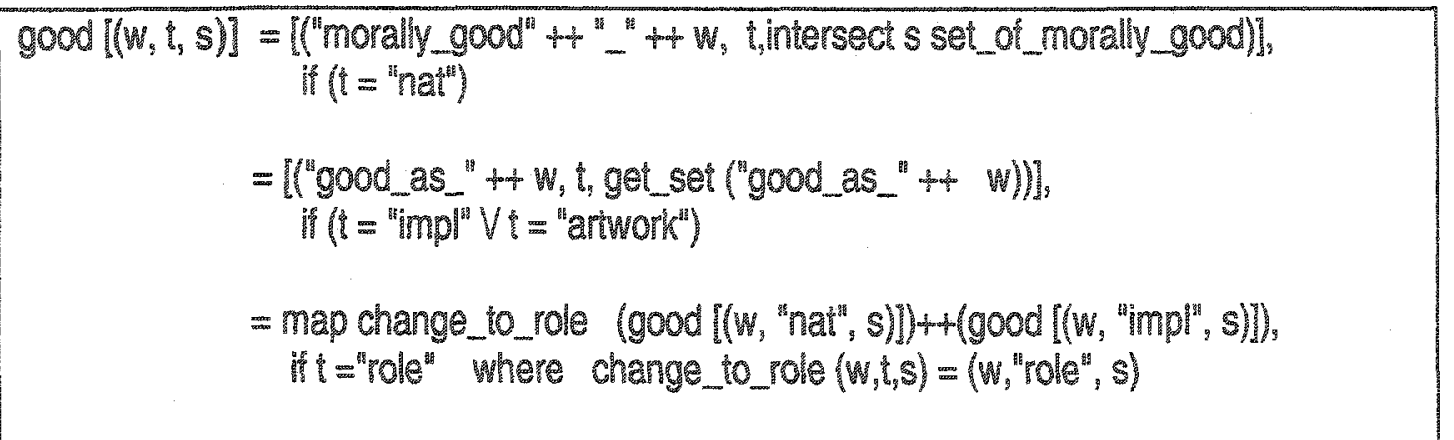

Figure 9-6: defingingy the adjective 'good"

It should be noted that the meaning of 'good' is a function of the type of the noun it combines with. If the noun is Nat Kind or Role then the reading is intersective (as well as subsective, in the case of Role). For all other types, the reading is subsective; in this case, we need to identify the subsective set.

Although 'beautiful' is a double adjective as 'good' is, its applicability patten differs from that of 'good'. This difference is evident from the tables 9-2 and 9-3. The Miranda code that defines 'beautiful' is shown in Figure 9-7.

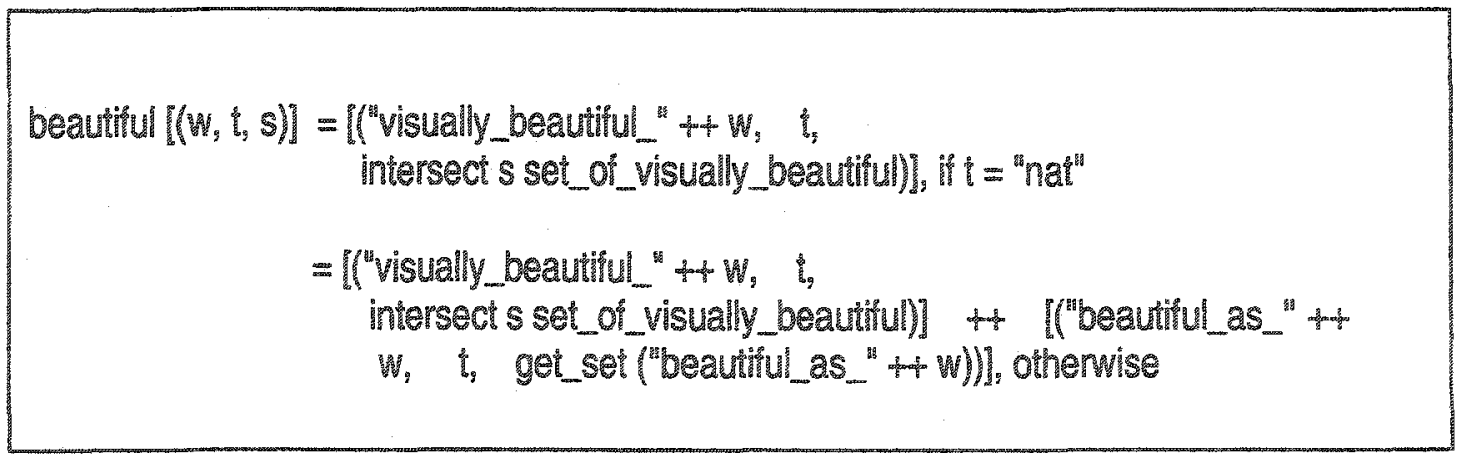

Figure 9.7: ㄱe

Figure $9-7$ shows the code that accommodates the two possible reading of 'beautiful': the intersective reading (pertaining physica beauty), and the subsective reading (describing how actions are performed). 
Once 'good" and 'beautiful' are defined, it is possible to abstract their implementation out and use them as "blueprints" to define similar adjectives. Abstraction is illustrated below in the case of the adjectives 'large' and 'small'.

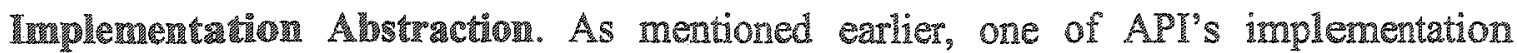
strategies is to avoid implementation repetition. This is done by allowing different adjectives that have similar semantic applicability pattems to share a similar piece of code. This is shown in Figure $9-8$ in the case of the adjective 'small', which shares a similar semantic patern with 'large'.

(1) make_intersective_I aw as $[(w, t, s)]=$

(2) [aw+" $+w$ in inersect sas)]

(3) small = make_intersecive_f "small" set_of_small

(4) visually_beauthul = make_inersective_1 "visually_beautiful" sat_of_visually_beautiful

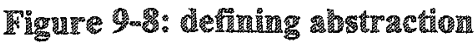

Lines (1) and (2) of Figure 9-8 define abstraction of 'large'; based on this definition, the adjective 'small' is defined, line (3) of Figure 9.8. Finally, line (4) of Figure 9.8 defines hyphenated adjectives that are purely intersectives. 
In the previous three chapters we have argued that the denotation of an adjective-noun combinations is a subset of the denotation of the noun. The preceding chapter provided an implementation of this approach.

In this chapter, we provide an analysis to the subsective approach mainly in terms of the implementation results obtained by running the sample program, API.

\subsection{Argument on Compositionality}

We argue that the subsective approach is compositional. This is because the meaning of the adjectival compound is a function of its parts, namely a subset of the noun. Formally, this can be shown as follows. Let an be a node in a parsing tree dominating the nodes adj and noun. Then the meaning of an is defined as follows:

$$
\|a n\|=F(\|a d j\|, \| \text { roun } \|)
$$

where \|noun\| is a set and \|adj\| is a function if adj is subsective, otherwise, \|adj\| is a set. $F$ and its composite function $g$ are defined as follows:

$$
F= \begin{cases}g: \| \text { noum }\|\rightarrow\| n o u n \| & \text { if } a d j \text { is subsective } \\ \|a d j\| \cap \| \text { noun } \| & \text { if } \text { adj is intersective }\end{cases}
$$

In either case, the value of $F$ is always a subset of the noun of the compound, i.e. noun. The function $F$ applies to all adjective-noun combinations. Since Miranda is a functional 
programming 1 anguage, the mapping of the function $F$ into a Miranda program is straightorward, as shown in the previous chapter.

\subsection{Argument on mierence Correctness}

In showing that the subsective approach warrants valid inferences only, we will be using sample outputs from the API program.

At the time of posing queries to API, its database has the following contents:

$$
\begin{aligned}
& \text { set_of_man } \\
& \text { setof moraly good } \\
& =\left[m 1, m_{2}, m_{3}, m_{4}\right] \\
& \text { set_of_surgeon } \\
& \text { set_of_good_as_surgeon } \\
& \text { set_of_beautitul_as_surgeon } \\
& =[m 1, m 2] \\
& =\left[\mathrm{ml}, \mathrm{ms}_{3}, \mathrm{~m} 4\right] \\
& =[m 3, m 4] \\
& =[m 4] \\
& \text { set_of musician } \\
& \text { set_of_beautiful_as.musician } \\
& =[m 2, m 4] \\
& \text { sei_of_spade } \\
& \text { set_of_good_as_spade } \\
& \text { sel_of_beautilul_as_spade } \\
& \text { set_of_visually_beautiul = } \left.\mathrm{m}_{2}, \mathrm{~m}^{3}, \mathrm{spl}\right] \\
& \text { setof_large }=[\mathrm{m} / \mathrm{m}, \mathrm{spl}] \\
& \begin{array}{ll}
\text { set_of_large } & =[\mathrm{m} 1, \mathrm{m4}, \mathrm{sp} 1] \\
\text { se__of_small } & =\left[\mathrm{m}_{2}, \mathrm{m3}, \mathrm{sp2}, \mathrm{sp} 3\right]
\end{array} \\
& \text { set_of_good_as_visually_beautiu__surgeon }=[\mathrm{m} 3] \\
& \text { set_of_good_as_beauiful_as_surgeon = }[\mathrm{m} 4] \\
& =[5 p 1, s p 2, s p 3] \\
& =[\mathrm{sp} 2, \mathrm{sp} 3] \\
& =\text { [sp2] }
\end{aligned}
$$

\subsubsection{Case l: single adjective and a head noun}

Following are some queries and API's responses:

Queryl: good man

Reply: [(

Explanation: there is only one response since the expression good man is unambiguous. Good here is intersective. There are two entities "manl" and "man2" in the intersection of the sets set_of morally_good and set_oi_man.

Query2: good surgeon 


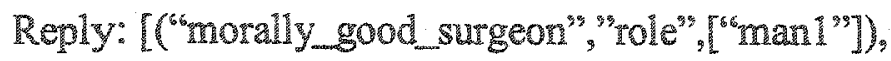
("good_as_surgeon", "role", ["man3", "man4"])]

Explanation: good in good surgeon has two possible meanings: morally good (intersective), and good as a surgeon (subsective).

Query3: beautiful man

Reply: [("visually_beautiful_man","nat",["man2","man3"])]

Explanation: here again the query is unambiguous. Because man is of type Nat. Kind, visually becutiful is of concern.

Query4: beautiful spade

Reply: [("visually_beautiful_spade", "impl",["spadel"]), ("beautiful_as_spade","impl",["spade2"])]

Explanation: API generates two responses to the query beautiful spade since 'beautiful' is a double adjective. This is consistent with the intuition that a spade can be physically beautiful-the intersective reading -or can be beautiful (e.g. handy) as a spade-the subsective reading. In terms of API's database, as shown above, there are two instances of spade, "spadel" denoted by "sp1" and "spade2" denoted by "sp2". The former is beautiful as spade, and the latter is visually beautiful.

Query5: beautiful surgeon

Reply: [("visually_beautiful_surgeon","role",["man]","man3"]), ("beautiful_as_surgeon", "role",["man4"])]

Explanation: here, 'beautiful 'is a double adjective and 'surgeon' is a role. Thus, 'beautiful' is ambiguous. This ambiguity is reflected in the two responses produced by Query5.

Query6: good spade

Reply: [("good_as_spade", "impl",["spade2", "spade 3"])] 
Explanation: the response to query 7 reflects the idea that the compound good spade is subsective. This is to be contrasted with queryh where "beauty", contrary to "goodness", is a property shared by many things.

\subsubsection{Case ll: consecutive adjectives and a head noun}

In the following query samples, we use parentheses to indicate the wide-scope reading of the respective adjectives.

Query7: large (good man)

Reply: [("large_morally_good_man", "nat", ["manl"])]

Explanation: here large is intersective. It modifies 'man'. In other words, the compound large good man is equivalent to lorge, good man. The result indicates the common element, "man1", among the three involved sets.

Query 8: good (large man)

Reply: [(morally_good large man", "nat", ["man1"])]

Explanation: the adjective good is understood to be intersective in this compound. For 'man' is of type Nat. Kind. This makes Query2 equivalent to Query1, that is, set intersection involving the three sets.

Query9: large (good surgeon)

Reply: [("large_morally_good_surgeon", "role", ["man1"]), ("large_good_as_surgeon", "impl",["man4"])]

Explanation: here, the compound is ambiguous. The ambiguity stems rom the adjective good and the noun surgeon. In its intersective reading, good yields the same result as in

Queryl and Query2. In the other subsective reading of good and because large is intersective, the resulting list indicates a set intersection involving the sets set_of_large and set_of_good_as_surgeon. 
Query 10: large (beautiful surgeon)

[("Iarge_visually_beautiful_surgeon", "role", [] ,

("large_beautiful_as_surgeon"," "role", ["man4"]D]

Explanation: in this expression, beatiful is ambiguous; in its intersective sense and according to API's current database, there is no common element between the sets set_of_large, set_of_visually_beautifu, and set_of_surgeon.

Query 11: good (beautiful surgeon)

Reply: [("morally_good_visually_beautiful_surgeon","role",[]),

("good_as_visually_beautiful_surgeon", "impl",["man3"]),

("morally_good_beautifu_as_surgeon", "role", []),

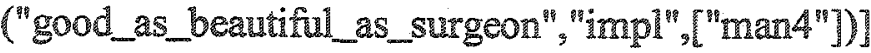

Explanation: here, since both good and beautiful, when modifying a noun of type role, are ambiguous, four possible answers are expected. In its intersective reading, good (i.e. morally good) has no common element(s) with the sets denoting (both visually beautiful and beautiful_as) becutiful things, and surgeon. This resuls in empty sets-lists in terms of the Miranda program. The other two readings yield non-empty sets. This is because the sets set_of_good_as_visually_beautiul_surgeon and set_ol_good_as_beautiul_as_surgeon have, respectively, the elements "man3" and "man4".

Note that the program API composes the names of result sets, e.g. "good_as_visualy_beautiul_surgeon" and "good_as_beautifu_as_surgeon". For intersective cases this "name" is only used to help the user understand the output. However, for subsective cases, the composed name (e.g. "Se_of_good_as_beautiul_as_surgeon") is used to identify the "subsective" set from the database and, as such, is part of the function $g$ from section 10.1 .

\subsubsection{Case II: Validation of Inerence correchess}

In this subsection, we show that API does not license wrong inferences. To proof this case, consider the following arguments, in the form of queries to API and their answers. 
Query: beautiful surgeon

Reply: [("visually_beautiful_surgeon" "role" "r.man1" "man3"]),

("beautiful_as_surgeon", "role", ["man4"])]

This means, among other things, "mant" is beautiful as a surgeon".

Query: musician

Reply: [(musician" "role", [man2" "man4"])]

This means "'man4" is a musician".

Query: beautiful musician

Reply: [("visually_beautiful_musician", "role", "man2"]),

("beautifu_as_musician", "role", ["man2"])]

This means, among other things, "man2' is beiatiful as a musician". Thus, "man4" is not listed in this reply. Therefore, "man4" is not beautiful as a musician.

Further, consider the following argument:

Query: spade

Reply: [("Spade", "impl",["spadel" "spade2", "spade 3"])]

This means, among other things, "spadel' is a spade".

Query: visually_beautiful spade

Reply: [("visually_beautiful_spade", impl", ["spadel"])]

This means, "spadel is (physically) beautifu".

Query: beautiful as_spade spade

Reply: [ ("beautifuL_as_spade", "impl", ["spade2"])]

This means, "Spade2 is beautiful as a spade". Since "spadel" is not included in this answer, "it is concluded that "spadel" is not beautiful as a spade-although it is a visually beautiful spade".

Thus, these arguments show that no invalid inferences have been drawn. This shows the approach is sound in its treatment of adjectives-noun combination. 


\subsection{Shortcomings}

The Subsective approach to the semantics of adjective-noun combinations has two weaknesses. First, it recognizes two classes of adjectives. This division is reflected in the implementation of the program, API. API performs, as we have seen earlier, computation of meaning only in the case of set intersection operation. That is, when the adjectives involved have intersective readings. Otherwise, it just performs subset picking-outs.

Second, also related to the first, coding subsective readings as well as wide-scope readings such as those in Query 13 as part of the database hierarchy is not a neat way of doing computation. 
Chapter 11 DETAILED DESCRIPTION OF THE SECOND PROPOSED APPROACH AND EXAMPLES: THE INTERSECTIVE VERSION

So far, we have been arguing for a uniform treatment of adjective-noun combinations that is subsective. This is based on the conventional approach that says adjectives and nouns have the same internal representation.

In this chapter, we argue that since adjectives and nouns are different, their respective representation should be different as well. Once this difference is taken into account, adjectives are shown to be semantically systematic in their behaviour and all of them can be treated intersectively.

\section{I Motivation}

In section 3.3, we quoted Jespersen (1929). This quote is repeated below:

On the whole, substantives are more special than adjectives, they are applicable to fewer objects than adjectives, in the parlance of logicians, the extension of a substantive is less, and its intension is greater than that of an adjective.

The difference between adjectives and common nouns has also been expressed by Strawson (see, Guarino (1998) as that between sortal and nonsortal predicates. Strawson states that a sortal predicate, "supplies a principle for distinguishing and counting individual particulars which it collects", while a nonsortal predicate "supplies such a principle only for particulars already distinguished, or distinguishable, in accordance with some antecedent principle or method".

We believe, bearing Jespersen's and Strawson's observations in mind, that representing common nouns on a par with adjectives is "forcing" a behaviour on adjectives that is not 
in their nature. This behaviour manifests itself in the intersection failure of sets representing adjectives and sets representing common nouns, which leads to the conclusion that adjectives must be of complex nature.

We argue that it is possible to represent all adjectives as sets, and yet capture their idiosyncrasies. This can be done by considering sets representing adjectives as having typed objects as their members. A schema for an adjective-representing set may look like the following:

(11-1)

Set_name =\{member: ype $\}$ : type?

where typel is a non-propery type and ype2 property lype

For example, clever pet, clever man, and clever police dog in the sentences John is a clever man, Fido is a clever pet, and Fido is a clever police dog can be represented as follows:

Clever=f: human, f: pet, i:: policedog\}: clever where $\|$ John $=\mathrm{j}$, and $\|$ Fidol $=$ ?

This representation of the adjective 'clever' captures the intuition that although "f" and "f" are members of the set Clever, both are clever in their own way. John is clever as a man while Fido is clever as a dog. What they have in common is "cleverness". This is reflected by ascribing the type "clever" to the set containing them.

This representation of adjectives makes it possible for an object to have more than one occurrence in adjective-representing sets, as done with "f: pet" and "f: policedog" in the set Clever.

Common nouns may have the following representation schema:

(11

Set_name = member: type\}: type 
where ype is a non-property type

The representation of (11-2) is different from that of (11-1) in that the members' type is the same as the set's type. The representation of (11-2) servers two purposes: 1$)$ it makes the internal structure of common nouns similar to that of adjectives (i.e. "meraber: type" pattern); and, 2) it eliminates the co-extension problem. Regarding the latter point, if for example, as is the case in the actual world, the set of cordate contains the same elenents as those in the set of renate, according to $(11-2)$, the two sets are not equal. Hence, they do not mean the same thing.

\subsection{Equality of typed Sets}

Since sets now contain typed elements, set operations must take the type of set members into consideration. This can easily be accommodated as follows:

The elements $x_{1}$ and $x_{2}$ are equal iff $x_{1}$ and $x_{2}$ are the one and the same and both of the same type

We, also, require members of adjectives that are considered (by and large) independent, i.e. denote irrespective of the type of the noun they combine with, be given the most generic type " $T$ ". This type has the lowest precedence amongst types. It is the superype of every type in the type hierarchy.

\subsection{Examples Using the New Approach}

This section contains examples using the new approach. The examples cover different kinds of adjective-noun combinations.

\section{3 .1 intersectives}

Argument example:

Maria is a vegetarian dancer 
Maria is a singer

Therefore, Maria is a vegetarian singer (valid)

Set representation:

$$
\begin{aligned}
\text { Human } & =\{m: \text { human, } . . .\}: \text { human } \\
\text { Dancer } & =\{m: \text { dancer }, . . .\}: \text { dancer } \\
\text { Singer } & =\{m: \text { singer, } . . .\}: \text { singer } \\
\text { Vegetarian } & =\{m: T ; . . .\} \text { vegetarian } \quad \text { where } \| \text { Maria } \|=m
\end{aligned}
$$

Inference example:

$f m \in$ (Vegetarian $\cap$ Singer )

Expected answer: True

Reason: type " $T$ "is a neutral type. Is is overidden by all other types.

\subsubsection{Subsectives}

Example argument:

a)

$$
\begin{aligned}
& \text { Maria is skiful dancer } \\
& \text { Maria is a singer }
\end{aligned}
$$

Therefore, Maria is a skilful singer (invalid)

(Here, we still distinguish two senses of 'skilful', i.e. the role-modifying and the kindmodifying. However, we can use one set only)

Set representation:

Dancer $=[$ m: dancer $;. .]:$. dancer 
Singer= $[m:$ singer,... $]$ : singer

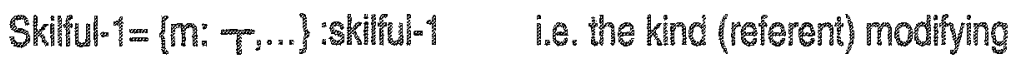

Skilul-2 = m: dancer,... lskilhul-2 l.s. the role(reterence) modifying

Inference example:

$f m \in($ Skillful $-2 \cap$ Singer)

Expected answer: False

Reason: the member "m: singer" is not in the intersection because of type mismatch. That is, the element "m: dancer" of the set Skilful-2 does not match any member of the set Singer whose members are of type singer.

b)

We add sentences (I) and (II) to the database in (a):

D) Maria is a skillful woman

II) Maria is a Politician

Therefore, Maria is a skilful politician (Invalid)

After adding the previous two pieces of data, the following sets will be updated/created:

Human = \{m: human:... $\}$ : human

Skillu-1 = Im: T,...\}: skilul 1

Politician $=\{$ m: politician,..$]$ : politician

Inference example:

$f \mathrm{~m} \in$ (Skilful-2 $\cap$ Policician)

Expected answer: False

$f m \in$ (Skilful-1 $\cap$ Politician) 
Expected answer: true

Notice that (Skilful-2 $\cap$ Policician) and (Skilful-1 $\cap$ Politician) generate different answers. This is because the former states that whatever in the intersection is skiful as a politician, while the latter states that the intersection includes those individuals who are politicians and generally skilled, 1.e. not necessarily skilled as politicians.

\subsubsection{Pure Subsective}

Example argument:

John is a guitarist

John is a veteran musician

Therefore, John is a veteran guitarist (invalid)

Guitarist $=$ J: guitarist,...$\}:$ guitarist

Musician = j: musician, ... J: musician

Veteran $=\{j$ : musician\}: veteran $\quad$ Where $\|$ wohn $\|=$ I

From this representation, it is clear that the statement John is a veteran guitarist cannot be affirmed. This is because "j" is not in the intersection of Veteran and Guitarist.

\subsubsection{Privative}

Argument example, one:

Maria is a fomer leacher

Maria is a programmer

Therefore, Maria is a former programmer (Invalid)

Set representation: 


$$
\begin{aligned}
& \text { Human }=\{m: \text { Human,... }\}: \text { Human } \\
& \text { Teacher }=\{m: \text { teachar,... }\} \text { : teacher } \\
& \text { Fomer }=\{m: \text { teacher,... }\} \text { :omer } \\
& \text { Programmer }=\{m: \text { programmer, ... }\} \text { : programmer }
\end{aligned}
$$

Inference examples:

$f \mathrm{~m} \in$ (Former $\cap$ Programmer)

Expected answer: false

$\leftarrow \mathrm{m} \in$ (Fomer $\cap$ Puman)

Expected answer: false

Argument example, two:

Maria is a fake surgeon

Maria is an actor

Therefore, Maria is a fake actor (Invalid)

Set representation:

$$
\begin{aligned}
\text { Surgeon } & =\{m: \text { surgeon, }, . .\}: \text { surgeon } \\
\text { Actor } & =\{m: \text { actor,... }: \text { actor } \\
\text { Fake } & =\{m: \text { surgeon, } . . .\}: \text { fake } \\
\text { Human } & =\{m: \text { human,... }: \text { human }
\end{aligned}
$$

Inference example:

fme (Faken Actor)

Expected answer: false

p me (Fake ก Human)

Expected answer: false 
Note: here we should add the set Current, in (a), and Real, in (b) or be able to infer them.

\section{3 .5 Prvative but extensional Adjectives}

Example adjective: "artificial"

Example inference:

Robots is an artificial man

Robot5 is a worker

Therefore, Robots is an artificial worker (valid)

Set representation:

Human $=\{15:$ human,$\ldots\}:$ human

Woker $=\{15:$ worker, ... : worker

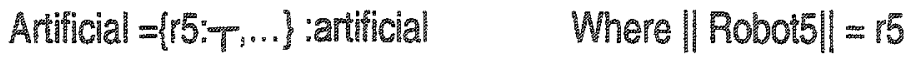

Inference example:

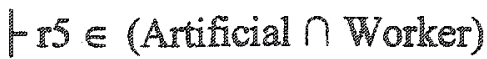

Expected answer: true

F (Arthial $\cap$ Worker $) \subseteq$ Worker

Expected answer: True

$\mid($ Artificial $\cap H$ Huan $) \subseteq$ Human

Expected answer: True

Reason: type "T" is the neutral type. It is overridden by all types 


\subsection{Muttiple-adjectives-one-head-noun Combinations}

In the previous section, we presented an intersective treatment of adjective-noun combinations. In this section, we extend this treatment to include adjectival phrases with multiple adjectives and a head noun.

\subsubsection{An Analysis}

Providing an intersective account for expressions with multiple adjectives and a head noun is a more challenging task than single-adjective-noun combinations. This is because an adjective in a combination can have different scopes. To illustrate, consider examples $(11-3)$.
a) Oceania is a deep blue ocean
b) Companies favour intelligent, aggressive people
c) Jane is an attractive blond woman

In (11-3-a), deep may have wide scope, i.e. modifies blue ocean, or narrow-scope, i.e. modifies blue. (11-3-b) is not ambiguous, because of the comma. (11-3-c) is ambiguous, due to wide and narrow scope readings.

An at-face-value, set-theoretic representation for the examples in (11-3) is not possible, with the exception of example (11-3-b). This is due to the associative law of set theory, stated below:

$$
\forall \text { Sets } A, B \text {, and } C \quad A \cap(B \cap C)=(A \cap B) \cap C
$$

Thus, for instance, mapping examples (11-3) to set intersections would fail to capture the different possible readings. In particular, consider the wide-scope reading of attractive in (11-3-c). This reading can be expressed as follows: 
(11-4)

Jane is an [atroctive [blond woman]]

And, the set-theoretic representation of the adjectival phrase might look something like this:

(11直-5)

Atractive $\cap$ (Blond $\cap$ Woman)

However, this representation does not capture the intended meaning. That is, attractive in (11-4) modifies the expression blond woman as a whole. In other words, for someone who utters (11-4), blond is essential to the extent that if the denotation of Jane were not blond, the utterance (11-4) might not have taken place.

\subsubsection{A Solution}

In order to accommodate adjective phrases, we need to do two things. First, expand our ontology to include properties-assuming that adjectives denote properties. This will enable us to form new property types from the more basic ones. Second, we need a rigorous typing system, whereby every set has a type. The typing system we are proposing shortly will enable us to generate new types from the basic ones.

The type system must correspond to the grammar's production rules. Grammar rules for adjective phrases might look like the following:

(11-6)

$$
\begin{aligned}
& \mathrm{AP}::=\mathrm{AN} \\
& \mathrm{N}::=\mathrm{AN} \mid \mathrm{man} \text { |woman |man |dancer| surgeon|... } \\
& \mathrm{A}::=\text { good | red |attractivel fragrant|... }
\end{aligned}
$$


The rules in (11-6) will recursively generate adjective phrases such as good man, fragrant red roses, etc. The grammar in (1-6) generates adjectives phrases by means of a string concatenation function. A typing system should paralle the grammar and be able to recursively define new types from exiting ones. Such a system is inductively defined as follows:

$($ (1)

a) The basic types are the nodes of the taxonomy of Figure 11-1, e.g. Nat Kind, Kind, Properties, role, Implement, and T.

b) If $a$ is a property type and $b$ is a basic type, then $a: b$ is a type

c) If $a$ and $b$ are property types then $a \cdot b$ is a property type

d) If $a$ is a type and $b$ is a non-property type, then $a: b$ is a type.

e) Nothing else is a type.

(11-7-a) states the basic types assumed. In a full-fledged system, the set of admissible basic types must be larger than this. However, this set suffices to denonstrate our approach.

(11-7-b) states that the first basic type of a resulting set is a property type. This is because here we are only treating adjective phrases-not noun-noun combinations, for example. $(11-7-c)$ generates property types. This is necessary for dealing with narrow-scope readings, i.e. when an adjective modifies another adjective and both modify a noun or an adjective phrase. Both $(11-7-b)$ and $(11-7-d)$ ensure that the resulting type is that of the head noun.

Our taxonomy of chapter 6 , with Property type included, is repeated below, as Figure 11 1. 


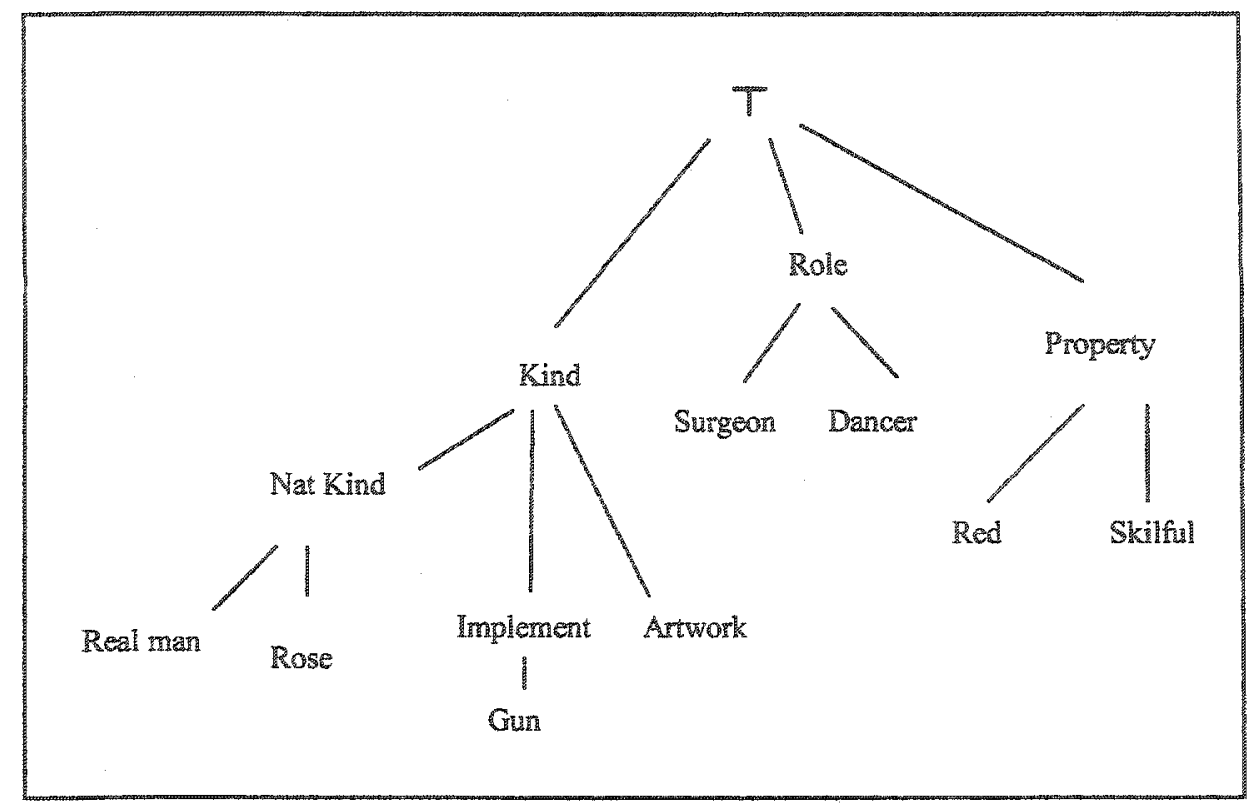

Figure 11-1: a

With the typing rules of $(11-7)$ in mind, the representation of the adjective phrase in (114) is as follows, $\|$ Jane $\|=w$ :

$$
\begin{aligned}
& \text { Blond }=\{w: \text { w }, . . .\} \text { blond } \\
& \text { Woman }=\text { W: woman,...] woman } \\
& \text { Blond } n \text { Woman }=\text { \{w: blond: woman }, . . \text { f blond: woman } \\
& \text { Atractive }=\{w: \text { blond: woman, ... }\} \text { :attractive }
\end{aligned}
$$$$
\text { Atractive } n \text { (Blond nWoman) = \{w: attractive: blond: woman, ... \}: attractive: blond: woman }
$$$$
\text { The syntactic-semantic steps that led to the above representation are shown below. }
$$

Atractive blond woman

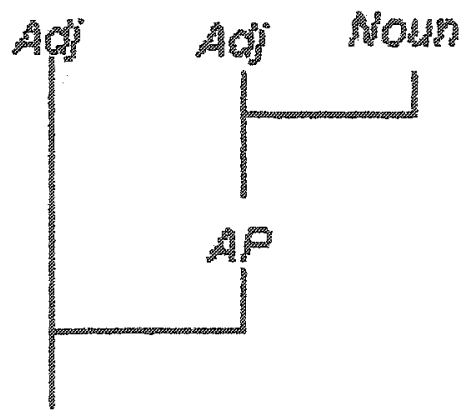

AP
Atroctue nblond nwomm

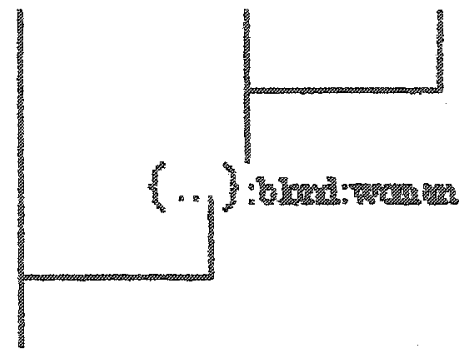

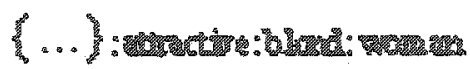

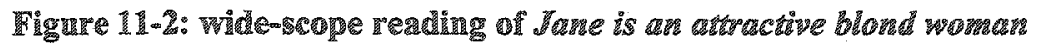


It should be noticed that from reading $(11-4)$ the following can be deduced:

Jane is blond

Jane is a woman

But not necessarily,

Jane is atractive

This reflects the intuition that the sentence Jane is an attractive (blond woman) expresses a different proposition from that expressed by the sentence Jane is an attractive, blond woman. The latter reading would result in the inclusion of the element "w: woman" in the set Atractive.

Finally, narrow-scope readings are computed differently. The narrow scope-reading of an (attroctive blond) woman is attributing "attractive-blond-ness" to the denotation of Jane. Such a reading is depicted in Figure 11-3

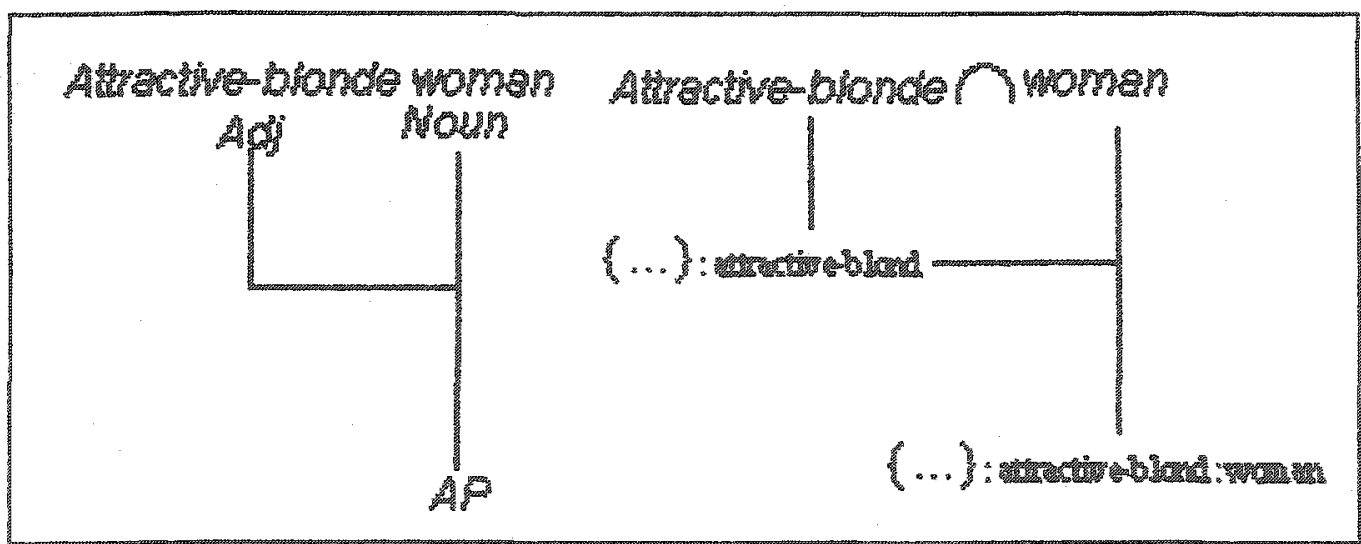

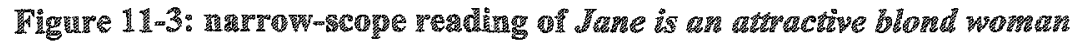

Notice that the set Attractive-blond is of type "attractive-blond". This results from applying the type comation rule of $(11-7-c)$. The set representation of the narrow-scope reading is as follows: 


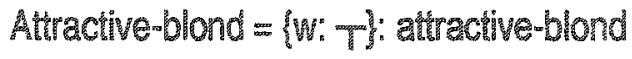 \\ Woman $=\{$ woman $\}:$ woman \\ Atractive-blond $n$ Woman = w: attactive-blond: woman\}: attractive-blond: woman
}

Thus, our semantic interpreter will have two or more different syntactic trees as input, each of which is treated differently semantically.

\title{
11.4.3 More Examoles
}

In this sub-section, we will further carry on applying the new approach to different kinds of adjective phrases.

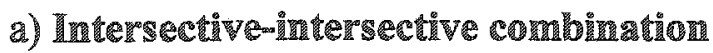

Example adjectives: 'deep', 'blue'

Sentence:

Oceania is a deep blue ocean

Possible readings:

[Deep blue] ocean-m-(1) i.e. narrow scope reading of deep

Deep [blue ocean] - (2) i.e. wide scope reading of deep

Deep, blue ocean-m-(3)

The narrow-scope reading, reading (1) is represented as follows:

Deep-blue $=\{0:$ tr $\}$ deep-blue

$$
\text { Ocean }=\text { fo: ocean: ocean }
$$

Deep-blue nocean = jo: deep-blue: oceanj: deep-bive: ocean

$$
\text { Where } \| \text { Oceanial }=0
$$


This representation results in an adjective-nown combination construction. It is intersective and casily computed.

Target reading ${ }^{8}$ : Oceania is a deep (blue ocean)

Set representation:

$$
\begin{aligned}
\text { Deep } & =10: \text { blue: ocean } \text { deep } \\
\text { Blue } & =\{0: \text { T: blue } \\
\text { ocean } & =\{0: \text { ocean }\}: \text { ccean }
\end{aligned}
$$

Computing the meaning

Step 1:

Blue $n$ Ocean = 0 : blue: ocean $\}_{\text {blue: ocean }}$

Step2:

Deep $\cap$ (Blue $\cap$ Ocean) =\{o: deep: blue: ocean\}: deep: blue: ocean

Finally, reading (2) is a short form for the following 3 readings:

Oceania is a deep ocean

Oceania is a blue ocean

Each of these readings is a simple adjective-noun combination.

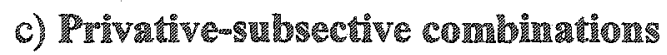

Example:

Maria is a fake skilful dancer

Since 'skilful' is a double adjective, we assume its two senses are 'skiful-1' and 'skilful$2^{\prime}$. The fomer is the general sense kind-modifying (or referent-modifying) and the latter

\footnotetext{
${ }^{8}$ The readings deep, blue ocean and deep (bhe ocean) might be equivalent. However, it might turn out that only blue oceans are deep. Either way, the example here is a means of illustration.
} 
the role-modifying (or reference-modifying). Thus, the phrase skilful-1 dancer would describe someone or something who/which is a dancer and generally skilful-even if their dancing is awkward. On the other hand, the phrase skiful-2 dancer would describe someone or something who/which dances skilfully.

Because 'skilful' is double adjective, the phrase fake skiful dancer will have six possible readings:

1. [ake skilnul-2] dancer

2. fake [skilful-2 dancer]

3. [rake skifin-1] dancer

4. fake [skilful-1 dancer]

5. Cake, skilful-2 dancer

6. fake, skilful-1 dancer

If Maria is the one who is described by reading (1) then she is a dancer but fakes being skilul at dancing. Reading (1) can be represented as follows:

$$
\text { Dancer }=\{\text { : dancer }, . . .]: \text { dancer }
$$

Fake-Skilul-2 = \{m: dancer, g gílake-skilhul-2

Fake-Skilul-2 nDancer Im: fake-skiltul-2dancerł: fake-skiliul-2: dancer

where $m=\|$ Marial

In reading (2) fake has a wide scope. It modifies the whole sub-phrase skilfu-2 dancer. Reading (2) will have the following representation:

Fake $=\{m:$ skillul-2: dancer, i $:$ Pake

Dancer = im: dancer, ... j: dancer

Skiliul-2 = m: dancer\}: skillul-2

Skilful-2 $\cap$ Dancer = Im: skilul-2: dancer: skilul-2: dancer

Fake n(Skilful-2 n Dancer) = Im: fake: skilul-2: dancer): fake: skillul-2: dancer where $\mathrm{m}=\|\mathrm{Maria}\|$ 
As is clear from the representation, Maria is a dancer, and she dances skifully. However, her skilful dancing (in some respect) is lake.

Reading (3) describes Maria as a dancer who fakes being generally skilü. This reading can have the following representation:

$$
\text { Dancer = Im: dancer, }, \text { a }]: \text { dancer }
$$

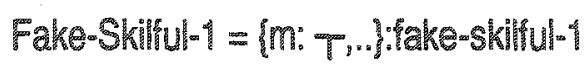

Fake-Skiful-1 nDancer = Im: fake-skilul $1:$ dancerl: fake-skilful-1: dancer

where $=\|$ Marial

Reading (4) is similar to reading (2) but with the sense 'skilful-1' of 'skillul'. This reading has the following representation:

Fake $=\{m:$ skillum $1:$ dancer,$\ldots .):$. take

Skilul-1 =\{m: T\}: skillul-1

Dancer =\{m: dancer $\}$ : dancer

Skilful- I n Dancer =\{m: skilful-1: dancer $\}:$ skillul-1: dancer

Fake ก (Skilful-1 ก Dancer) =[m: Pake: skilful-1: dancer]: fake: skilul-1: dancer where $\mathrm{m}=\|$ Marial

The remaining two readings can have, respectively, the following representations: Reading (5):

Fake $=$ Im: dancer, ... l: iake

Skilul-2 = [m: dancer] : skilul-2

Dancer $=\{m:$ dancer $\}:$ dancer

Fake n Dancer= \{m: fake: dancer): take: dancer

Skilhul-2 $\cap$ Dancer = \{m: skilul-2: dancer\}: skiltul-2: dancer

where $\mathrm{m}=$ "Mariall

Reading (5) describes Maria as a fake dancer who dances skilfully. 
是eading (6):

$$
\begin{aligned}
& \text { Fake }=\{m \text { dancer, } . . . j \text { lake } \\
& \text { Skilhul-1 = \{m: T): skiltul-1 } \\
& \text { Dancer }=\{m: \text { dancer\}: dancer } \\
& \text { Fake } \cap \text { Dancer = \{m: \{ake: dancer }\} \text { : \{ake: dancer } \\
& \text { where }=\| \text { Marial } \\
& \text { Skilul-1 } n \text { Dancer = } \text { Im: skilfu- } 1: \text { dancer\}: skilul-1: dancer }
\end{aligned}
$$

Reading (6) describes Maria as a fake dancer who is generally skilled.

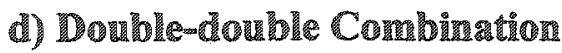

Example adjectives: 'beautiful' and 'good'.

Sentence: Maria is a good beautiful surgeon

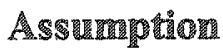

The respective senses of 'beautiful' and 'good' are 'beautifulVis', for the intersective reading "visually beautiful", and 'beautifulAt", for the subsective reading "beautiful at doing/performing"; and, "goodGn', fort the intersective reading "generally good/morally good" and goodAt for the subsective reading "good at doing/performing".
\end{abstract}

There are 10 possible readings. These are:

1. [GoodAt beautifulVis] surgeon

2. [GoodAt beautifulat] surgeon

3. GoodAt beautifulat surgeon]

4. GoodAt [beautifulVis surgeon]

5. [GoodGn beautifuVis] surgeon

6. [GoodGn beautifulAt] surgeon

7. GoodGn [beautifulAt surgeon]

8. GoodGn [beautifulin surgeon]

9. GoodAt, beautifulAt surgeon 
10. GoodGn, beatifulvis surgeon

Of course, some of these combinations are implausible or at best debatable. Generally, the senses 'goodAt' and beatifulAt apply only to roles-in this particular example to 'surgeon'; the sense 'goodCin' and 'beautifulVis' apply only to kinds (or referent).

Below we provide set representations of some of the readings. In all the representations that follow we assume $\|$ Marian $=m$

Reading (2): [GoodAt beautifulAt] surgeon

Here the senses 'goodAt' and 'beautifulAt' will form a new property of type s'goodAtbeautifulAt". In tum, this new hyphenated adjective modifies surgeon:

Surgeon=m: surgeon: surgeon

GoodAtobautulAt=:m:surgeon:goodAt-beautiulAt

GoodA-beautiulAt nSurgeon = Im: goodAi-beauifuAt:surgeon \}:goodAt-beauthulAt:surgeon

Reading (3): GoodAt [beautifulAt surgeon]

Here goodAt modifies the adjective phrase beautifulAt surgeon. This reading can be represented as follows:

$$
\begin{aligned}
& \text { Surgeon= Im: surgeon]: surgeon } \\
& \text { Beautifula = Im: surgeonj:beautivuA! }
\end{aligned}
$$

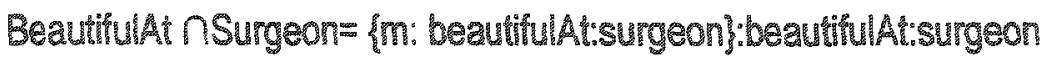

$$
\begin{aligned}
& \text { CoodAl= Im:beuthuAt: surgeon:goodAt }
\end{aligned}
$$$$
\text { GoodA! } \cap \text { (BeaudiulAt } \cap \text { Surgeon) = (m:goodAt:beautifulAtsurgeon): goodAt:beautifuAt:surgeon }
$$

Reading (9): GoodAt, beautifulAt surgeon

This reading is equivalent to the following

GoodAt surgeon i.e. performs surgery in a good way 
BeautifulAt surgeon i.e performs surgery beautifully

GoodAt = Im: Surgeon:GoodA?

BeauthulA:= m: surgeon:beaunuth

BeautifulA ก Surgeon=\{m: beautrulat:surgeon?:beautifulA: surgeon

GoodAt nSurgeon=\{m: goodAt: surgeon]: goodAt: surgeon

\subsection{Scalar Adjectives and the Case of Vagueness}

Syntactically Scalar (other terms are "relative" and "measure") adjectives can be in the attributive position- e.g. tall in John is a tall man- or in the predicative position-as in John is tall. Scalar adjectives behave strangely with regard to the inference process. Consider the adjective 'tall' in the following inference:

John is a basketball-player

John is a tall man

John is a tall basketball-player

(invalid inference)

This wrong inference does not mean that the adjective 'tall' is subsective. Such a conclusion would mean that 'tall' is intensional, which is not true". For the property of being tall is not a part of the intension of "basketball-player". Rather, it is a property of John's. This is to be contrasted by the sentence John is an established bashetball player.

However, if the data in (11-8) is changed to that of (11.9) the conclusion is still not necessarily invalid.

(11-9)

John is a tall basketball player

${ }^{9}$ Some authors consider scalar adjectives intensional. 
John is a man

John is a tall man

For we may later come to know the fact that John is not tall - he might be handicapped or a dwarf. Here the "tallness" factor relative to some stereotypical context is not informative.

Generally speaking, the use of scalar adjectives is very subjective. One person, for example, might think models are typically tall and slim, while others may not share him/her this belief.

The issue of vagueness, in general, and vagueness of adjectives, in particular, is a thomy one. It is a well-known problem in many fields such as philosophy, cognitive science, and linguistics. Theories such as "supervaluation" and "fuzzy logic" try to account for this problem. To show the depth of this issue, we here quote Russell (1945):

We are told that, since 6 is greater thot 4 but less then 12, 6 is both great and small, which is a contradiction. Again, Socrates is now taller than Theaetetus, who is a youth not yet full grown; but in a few years Socrates will be shorter than Theaetetus. Therefore Socrotes is both tall and short. The idea of a relational proposition seems to have puzzled Plato, as it did most of the great philosophers down to Hegel (inclusive).

What makes scalar adjectives hard to deal with is that they are also sensitive to context, as discussed in subsections 4.2 and 4.7.

Here, we are not concemed with providing a "cure-all" solution to vague constructs. Rather, within the contexts of adjective-noun combinations, we are in pursuit of a rather modest ambition that will enable us to eliminate undesired inferences such as those in (11-8) and (11-9). For this goal, the adjective representation we presented in this chapter 
can help in blocking such wrong inferences. In this representation, the set Tall will look something like the following:

$$
\text { Tall }=\{: \text { human, } j: \text { basketball_player }\}: \text { tall where } \| \text { John } \|=j
$$

In some constructs, the class to which an object belongs is not even mentioned. Consider examples $(11-10)$.

(11-10)
a) it is high
b) itis tall

In such cases, we have to rely on the context to provide us with the type of things denoted by it. 


\subsection{Analysis of the Intersective Approach}

\subsubsection{Summary of Intersective Approach}

This chapter has been about providing a uniform semantic treatment of adjective-noun combinations. This was achieved by using types. We have shown that this approach can easily be extended to handle mutiple-adjective phrases. We have also pointed out that the inconsistency of inferences involving adjectives results from insisting on representing all adjectives in a way similar to that of common nouns, intransitive verbs, or absolute adjectives, despite their ontological differences. This led to the conventional concusion that adjectives are inherently complex. In our approach, the difference is captured by ascribing a uniform type to all members of the sets representing the denotations of common nouns, while adjective-representing sets may contain heterogeneous types.

Central to this unifom treatment of adjective phrases is our analysis that privative adjectives are no different from other role-modifying (or reference-modifying) adjectives, the so-called subsective adjectives.

An important by-product of this approach is the elimination of the co-extension problem without resorting to the notion of possible worlds. Thus, even in the case where all singers are dancers and all dancers are singers, the two sets are not equal-i.e. they do not mean the same thing. This can be shown as follows:

(11貫)

$$
\text { Singer = d: singer }{ }_{n .} \text { \% Dancer }=\{\text { : dancer, ... }
$$

A similar argument was put forward by Larson (see section 4.8 ) based on McConnellGinet's work that failures of substitutivity are better explained not by considering alternative situations where individuals have a different property; rather, failure of 
substitutivity can better be explained by ".. assessing an added dimension in the given situation", McConnell-Ginet (1982). That dimension, according to McConnell-Ginet and Larson, is events.

We attained a similar result by considering types. As denonstrated in this chapter, using types we were even able to express complex expressions involving multiple adjectives. Farther, Larson had to "extend" the semantic of the variable $e$, (see section 4.8 ) to range over states in addition to events. Furthermore, Larson's approach seems to work well with adjectives that can be paraphrased as adverbs, e.g. 'beautiful' as 'beautifully' and 'former' as 'formerly'. However, there are some constructs that cannot easily, if at all, be adverbially paraphrased.

Finally, representations such as those of (11-11) might seem to have solved a problem and created another: it would not allow us to enquire about those individuals who are both singers and dancers. However, we still can get the intersection of arbitrary sets by "elevating" them to the nearest common type (in the case of singer and dancer this would be artist) or the type " $T$ ". In either case, the intersection becomes permissible once both sets are of the same, higher type.

\subsubsection{The Intersective Approach versus the Subsective approach}

The subsective approach is characterized by its simplicity of representation. In this approach, set semantics remains as simple as in nave set theory.

However, with the apparent simplicity come some shortcomings. in the subsective approach, computation is possible with intersective readings only. Nevertheless, the buk of adjectives in Engish, for example, are non-intersective. For this reason, the subsective approach requires that subsective and some consecutive adjectives in a compound be part of the database hierarchy. 
Finally and nost importantly, admitting adjectives to be of wo classes contradicts the conventional view of "adjective" as a single (syntactic) group, and it is weak argument for compositionality. This case is to be contrasted with the case of the intersective approach, where the compound is a function (i.e. a set intersection) of its constituents. This result omphasizes the "unity" of adjectives. If this result is proved to be correct, it will be one of the arguments that demonstrate that natural language is systematic.

The disadvantage of the intersective approach lies in its use of types. The use of types complicates set semantics. Set operations must take type into consideration. Nonetheless, we believe since the intersective approach has a more expressive power than the subsective the complexity is natural. This is analogous to Proposition and Predicate Calculi. The fomer is simple yet lacks expressiveness, while the latter is more complicated yet expressively powerful. 


\subsection{Conclusion}

We have presented two generalized approaches to the semantics of adjectivenoun combinations. The first approach treats adjectives as subsectives. The second approach treats them as intersectives.

Both approaches were possible when the class of adjectives conventionally known as "privative" is considered to be subsective. In this view common nouns such as 'gun' are argued to have fake and real guns in their denotations. Both approaches make use of a. type hierarchy. However, the intersective approach makes extensive use of types.

In both approaches, compositionality is maintained, more elegantly in the intersective approach. This is because for each syntactic rule there is a semantic rule and the meaning of a complex expression (adjective phrase) is a systematic function of its parts.

It is the conclusion of this work that adjectives are more systematic in their behaviour than originally thought and can be treated within set theory.

\subsection{Future Work}

The current work only dealt with adjective-noun combinations proper. Future research can proceed in three directions: 1) completion of the treatment of all cases pertaining to adjective-noun combinations, 2) treament of other adjectival constructs; and, 3) treatment of all cases of compound nominals. 
As for the first point, we mentioned that this work does not cover constructs containing adjectives such as "possible', and 'potential. We hinted that modal logic is a good candidate to underake this task. If this view is correct, then the challenge is in integrating the modal approach with one of the approaches proposed here.

The second point pertains to other constucts where adjectives may occur, as demonstrated in the following examples:

a) That is Cinderella's old dress.

b) It is certain that taking philosophy courses is a good choice.

(a) is connected with possessive foms. The sentence (a) is ambiguous since it can either be talking about the dress as being old in the absolute sense or old with respect to Cinderella possessing it. In (b), the adjective 'certain' modifies a proposition. In other words, what certain modifies is an abstract entity.

The third point pertains to general modification of nouns by adjectives, other nouns, or a combination of both, e.g., information retrieval system or computer book sale. It is known that such constructs rely heavily on world knowledge. This has led many researchers to believe that an ontology is the first step towards a solution to this problem.

In all cases, the important issue of vague concepts and context-dependency must be taken into consideration. In this work we have been, to some extent, under the assumption that predicates pick out referents within succinct boundaries. In reality this cannot be true, as Kamp and Partee (1995, p129) put it, "probably almost every predicate is both vague and context-dependent to some degree". Similar views are expressed in Varzi (2001). Therefore, vagueness and contextedependency must be taken seriously in order to produce competent NL systems. 
Allen, J. (1995) Natural Language Understanding. The Benjamin/Cummings Publishing Company, Inc.

Bachimont, B. (2001) Translated from: Bruno Bachimont "Modélisation linguistique et modélisation logique des ontologies: l'apport de l'ontologie formelle." In Proceedings of IC 2001, pp 349-368 Plate-forme AFIA, Grenoble 25-28 juin 2001

Booch, G. (1994) Objet-Oriented Analysis and Design with Applications. AddisonWesley.

Bell, D. (1996) The Formation of Concepts and the Structure of Thoughts. In Philosophy and Phenomenological Research

Bouchard, D. (2002) Adjectives, Number and Interfaces: Why Languages Vary. In North-Holland Linguistic Series: Linguistic Variations, 61.

Brown, C. (Winter 2002 Edition) Narrow Mental Content. In The Stanford Encyclopedia of Philosophy, Edward N. Zalta (ed.).

Carnap, Rudolf (1942) Introduction to Semanitics. Cambridge: Harvard University Press

Carnap, Rudolf (1956) Meaning and Necessity: A Study in Semantics and Modal Logic. Chicago: University of Chicago Press.

Chalmers, D. (2001) The Foundations of Two-Dimensional Semantics. In In The TwoDimensionalist Framework: Foundations and Applications, ed. M. Garcia-Carpintero and J. Macià (Oxford: 2004)

Chalmers, D. (2002) Philosophy of Mind: Classical and Contemporary Readings. Published by Oxford University.

Chierchia, G. and McConnell-Ginet, S.(1990) Meaning and Grammar: An Introduction to Semantics. Cambridge, MA, The MIT Press.

Dowty, D., Wall, R. and Peters, S. (1981) Introduction to Montague Semantics. D. Reidel Publishing Company, Dordrecht, Boston, Lancasert, Tokyo.

Dirven, R. and Vespoor, M. (1998) Cognitive Exploration of Language and Linguistics. John Benjamins.

Davidson, D. (1967) The logical form of action sentences. Reprinted in Essays on Actions and Events. Oxford: Oxford University Press 
Dixon, R. W. (1982) Where Have All the Adjectives Gone? In: R. M. W.Dixon, Where Have All the Adjectives Gone? And Other essays in Semantics and Syntax. BerlinAmsterdam-new York: Mouton, pp 1-62.

Franks, B. (1995). Sense generation: A "Quasi-Classical" approach to concepts and concept combination. Cognitive Science, 19, 441-505

Franks, B. (1989). Concept Combination: Towards an Account of Privatives. In G.Dunbar, B.Franks, \& T.Myers, (eds.), Papers from the 1989 Edinburgh Round Table on the Mental Lexicon. Edinburgh: Edinburgh University, Centre for Cognitive Science.

Friedman, J. Moran, D. B., and Waren, D. S., (1978) Explicit finite intensional models for PTQ. In: American Joumal for Computational Linguistics, microfiche 74, 1978, pp. $3-22$

Frost, R and Boulos, P. (2002) An Efficient Compositional Semantics for NaturalLanguage Database Queries with Arbitrarily-Nested Quantification and Negation. Springer-Verlag Heidelberg Volume 2338/2002

Frawley, W. (1992) Linguistic Semantics. Hillsdale, N.J.: Erlbaum.

Givon, T. (1984) Syntax: A Functional/Typological Introduction. Vols. I and I, John Benjamins,

Gruber, T.R. (1993). Toward Principles for the Design of Ontologies Used for Knowledge Sharing, In Foma Ontology in Conceptual Analysis and Knowledge Representation, edited by Nicola Guarino and Roberto Poli, Kluwer Academic Publishers

Guarino, N. and Welty, C. (2000) Towards a methodology for ontologybased model engineering. In Proceedings of ECOOP-2000 Workshop on Model Engineering. Cannes, France. Available from http:/www.ladseb.pd.cnr.it/infor/ontology/Papers/OntologyPapers. Html

Guarino N. (1997) Understanding, Building and Using Ontologies. In A Commentary to Using Explicit Ontologies in KBS Development, by van Heijst, Schreiber, and Wielinga. International Joumal of Human and Computer Studies vol. 46 n. 2/3, pp. 293-310.

Guarino N., Giaretta P. (1995) Ontologies and Knowledge Bases: Towards a Teminological Clarification. In N.J. L. Mars (ed.), Towards Very Large Knowledge Bases, IOS Press.

Guarino N. (1992) Concepts, Atributes, and Arbitrary Relations: Some Linguistic and Ontological Criteria for Structuring Knowledge Bases. In Data and Knowledge Engineering 8: 249-261. 
Hausser, R.(2000) The Four Basic Ontologies of Semantic Interpretation. (The Tenth European - Japanese Conference on Information Modelling and Knowledge bases May 8-11 2000. Hotelli Riekoninna, Saariselkä, Lapland, Finland.

Heim, I. And Kratzer, A. (1997) Semantics in Generative Grammar. MPG Books, Bodmin, Comwall. UK

Hirst, G. (1988) Semantic interpretation and ambiguity. In Artificial Intelligence (An Intemational Joumal) Vol 34 PP $131-177$.

Hirst, G. (1987) Semantic Interpretation and the Resolution of Ambiguity. Cambridge University Press.

Isabelle, P. (1984) Another look at nominal compounds. In The Proceedings of the $10^{\text {th }}$ International Conference on Computational Linguistics. Stanford, USA 1984.

Janssen, T.M.V. (1997) The Principle of Compositionality of Meaning. In Handbook of Logic and Language, The MIT Press, North-Holland (1997).

Kamp H. (1975) Two theories about adjectives. In E. L. Keenan (ed), Formal semantics for natural languages, Cambridge, UK.

Kamp, H. and Partee P.H., (1995) Prototype theory and compositionality. Cognition 57 pp 129-191

Pustejovsky, J(1995) The Generative Lexicon, Massachusetts Institute of Technology Press.

Lahav, R. (1989). Against compositionality: the case of adjectives. In Philosophical studies, 57

Larson, R.K (2002) The grammar of intensionality. In: Preyer, G. (ed.) On Logical Form. Oxford University Press.

Larson, RK. (1998) Events and modification in nominals. In: D Strolovitch and A. Lawson (eds.) Proceedings from Semantics and Linguistic Theory (SALT) VIII. Comell University. Ithaca. NY.

Larson, R.K. (1995) Olga is a beautiful dancer, Winter Meetings of The Linguistic Society of America, New Orleans, 5-8 de Janeiro.

Levi, J. N. (1978) The syntax and semantics of complex nominals. New York: Academic Press. 
Lehnert, W. G. (1988). The analysis of nominal compounds. In Umberto Eco, Marco Santambrogio, Patrizia Violi (eds.), Meaning and mental representation. Bloomington and Indianapolis, $\mathbb{N}$ : Indiana University Press, $155-180$.

Lewis, D. (1970) General Semantics. Synthese, 22:18-67.

Lyons, J.(1977) Semantics, 2 volumes. Cambridge University Press, London \& New York

Martin-Lof, P., (1975) An intuitionistic theory of types: Predicative part. In: Logic Colloguizm 73, PP 73-118. North-Holland.

Mizoguchi, M. and Mitsuru Kkeda, M. (1997) Towards Ontology Engineering In Proceedings of The Joint 1997 Pacific Asian Conference on Expert systems / Singapore Intemational Conference on Intelligent Systems, pp. 259-266, 1997.

McConnell-Ginet, S. (1982) Adverbs and Logical Form, in Language 58: 144-84.

Maurel, J.(1993). Des adjectifs de relation en Latin. Information grammaticale 58, pp. 23-26.

Montague, R. (1970). English as a Formal Language. In Linguaggi nella Società e hella Tecnica, ed. Bruno Visentini et al., 189-224. Milan: Edizioni di Comunità. Reprintedin Montague 1974, 188-221

Nordstrom, B., and Smith, J. (1984) Propositions and specification of programs in Martin-lof s type theory, BIT 24 PP 288-301

Partee, B. H. (2001) Privative adjectives: subsective plus coercion. To appear in T.E. Zimmermann, ed. Studies in Presupposition. Available at: htp://wwwunix.oit.umass.edu/ partee/

Partee, B., Meulen, A., Wall, R. (1990) Mathematical Methods in Linguistics. Kluwer Academic Publishers, Dordrecht, The Netherlands.

Partee, B. H, with Hendriks, H.LW. (1997) Montague Grammar. In Handbook of Logic and Language. Elsevier Science.

Parsons, T. (1995) Thematic Relations and Arguments. In: Linguistic Inquiry, Volume 26 Number 4 Fall 1995.

Partee,B.H., Meulen, A. ter, and Wall, R.E. (1990) Mathematical Methods in Linguistics. Kuwer, Dordrecht, The Netherlands. 
Peregrin, J. language and its models: is model theory a theory of semantics?

Nordic Journal of Philosophical Logic, Vol 2, No. 1 pp.1-22 (1997)

Peters, 1. and Peters, W. (2000) The Treatment of Adjectives in SIMPLE: Theoretical Observations. The $2^{\text {nd }}$ International Conference on Language Resources \& Evaluation. LREC2000), Athens, Greece

Platts, M. (1979) Ways of Meaning: An Introduction to a Philosophy of Language. Boston: Routledge.

Pustejovsky, J. (1995) The Generative Lexicon. Cambridge, Mass.: MIT Press Quirk, R., Greenbaum, S., Leech, G. and Svarvik, J. (1985) A Comprehensive Grammar of the English Language. Longman.

Quirk, R. and Greenbaum, S. (1973). A University Grammar of English Longman, Harlow.

Raskin, V. and Nirenburg, S. (1995) Lexical Semantics of Adjectives. A microtheory of Adjectival meaning, in: MCCS-95-288, Las chuces, N.M. New Mexico State Universiry.

Rey, G. (1983) Concepts and Stereotypes. Cognition, 15:237-262.

Russell, B. (1945) A History of Westem Philosophy, New York: Simon and Schuster; London: George Allen \& Unwin, 1946.

Shaw, and Hatzivassiloglow, V. (1999) Ordering among Premodifiers. In Proceeding of $37^{\text {th }}$ ACL, Maryland, PP135-143.

Siegel, M. Capturing the adjective. Unpublished PhD dissertation. University of Massachusets at Amherst. (1976)

Smith, E. E. (1988) Concepts and Thought. In R.J. Stemberg and E.E. Smith (ed), The Psychology of Human Thought. Cambridge University Press.

Sowa, J. F. (2000) Ontology, Metadata, and Semiotics. Proceedings of ICCS'2000 in Damstadt, Germany, on August 14, 2000. Published in B. Ganter \& G. W. Mineau, eds., Conceptual Structures: Logical, Linguistic, and Computational Issues, Lecture Notes in Al

Sowa, J. F. (1999) Knowledge Representation: Logical, Philosophical, and Computational Foundations. Brooks Cole Publishing Co., Pacific Grove.

Sowa, J. F. (1984) Conceptual Structures: Information Processing in Mind and Machine, Addison-Wesley.

Sowa, J. F. Guided Tour of Ontology; John F. Sowa 
http:/www.jsowa.com/ontology/guided.htm

Steimann, F. (2000) On the representation of roles in object-oriented and conceptual modeling Data \& Knowledge Engineering 35 83-107.

Svenonius, P. (1994) The structural location of the attributive adjective. In E. Duncan, D. Farkas, and P. Spaelti (eds.), The Proceedings of the Twelfh West Coast Conference on Formal Linguistics, pp. 439-454. CSLI, Stanford, Ca.

Thompson, S. (1991) Type Theory and Functional Programming. Addison-Wesley.

Tumer, R. (1992) Properties, Propositions and semantic theory. In Rosner, $M$ and Johanson, $\mathbb{R}$ (Edt) Computational Linguistics and Formal Semantics. Cambridge University Press.

Uschold, M., and Gruninger, M. (1996). Ontologies: Principles, Methods and Applications. The Knowledge Engineering Review, V.11, N.2, 1996. Available Intemet: http:/citeseer.nj.nec.comms/20_streitz.pdf.v6DC

von Fintel, K., Heim, I. (1999) More on Lousy Teachers and Beautiful Dancers. Topics in Semantics, spring 1999. Available at:

http:/web.mit.edu/fintel/www/adjectives.notes.pdf

Varzi, A. C. (2001) Vagueness, Logic, and Ontology. In: The Dialogue. Yearbooks for Philosophical Hermeneutics, pp 135-154.

Wheeler S.C. (1972) Attributives and their Modifiers. In Nous, Vol. V1, No. 4, pp.310334.

Winograd, T. (1972) Understanding Natural Language. Academic Press, Harcourt Brace Jovanovich, San Diego, New York.

Woods, W .A. (1981) Procedural Semantics as a Theory of Meaning. In computational aspects of linguist structure and discourse setring Joshi, I. Sag, and Webber, B. Cambridge University Press.

Woods, W. A. (1968) Procedural senantics for a question-answering machine. AFIPS Conference Proceedings (33) $457-471$.

Woods, W. A. (1967) Semantics for a Question-Answering Syster . Garland Publishing, New York.

Zadrozny, W. (2000) Minimum Description Length and Compositionality. In Computing Meaning, Bunt, H.and Muskens, R. (Eds.) Vol.1. Kluwer 1999. pp.113-128 
Zadrozny, W. (1994) From compositional to systematic semantics. In Linguistics and Philosop y $(17): 329-342$.

Zadrozny, W (1992). On Compositional Semantics. In Proceeding of COLNNG-92, Nantes, France. 


\section{Appendix A: ADJECTIVE LISTING ${ }^{10}$}

\begin{tabular}{|c|c|c|}
\hline & $\begin{array}{l}\text { mache posin } \\
\text { Prenterive }\end{array}$ & menomina \\
\hline aboveboard & $\sqrt{ }$ & \\
\hline afloat & $\sqrt{1}$ & \\
\hline agape & $\sqrt{ }$ & \\
\hline aged & $\sqrt{ }$ & $\sqrt{ }$ \\
\hline agog & $\sqrt{ }$ & \\
\hline akimbo & $\sqrt{ }$ & \\
\hline alive & $\sqrt{ }$ & \\
\hline angey & $\sqrt{ }$ & $\sqrt{ }$ \\
\hline asleep & $\sqrt{ }$ & \\
\hline asunder & $\sqrt{ }$ & \\
\hline averse & $\sqrt{ }$ & \\
\hline available & $\sqrt{ }$ & $\sqrt{ }$ \\
\hline camivorous & $\sqrt{ }$ & $\sqrt{ }$ \\
\hline documentary & $\sqrt{ }$ & $\sqrt{ }$ \\
\hline drunk & $\sqrt{ }$ & $\sqrt{ }$ \\
\hline four-legged & $\sqrt{ }$ & $\sqrt{ }$ \\
\hline ill & $\sqrt{ }$ & $\sqrt{1}$ \\
\hline infinite & $\sqrt{ }$ & $\sqrt{ }$ \\
\hline loath & $\sqrt{ }$ & \\
\hline mutual & $\sqrt{ }$ & $\sqrt{ }$ \\
\hline nearby & $\sqrt{1}$ & $\sqrt{ }$ \\
\hline nude & $\sqrt{1}$ & $\sqrt{ }$ \\
\hline pacifist & $\sqrt{ }$ & $\sqrt{ }$ \\
\hline parallel & $\sqrt{ }$ & $\sqrt{ }$ \\
\hline prone & $\sqrt{ }$ & \\
\hline rancid & $\sqrt{ }$ & $\sqrt{ }$ \\
\hline redolent & $\sqrt{ }$ & \\
\hline remiss & $\sqrt{ }$ & \\
\hline ifie & $\sqrt{ }$ & \\
\hline sick & $\sqrt{ }$ & $\sqrt{ }$ \\
\hline sober & $\sqrt{ }$ & $\sqrt{ }$ \\
\hline speckled & $\sqrt{ }$ & $\sqrt{1}$ \\
\hline touched & $\sqrt{ }$ & \\
\hline unused & $\sqrt{2}$ & $\sqrt{ }$ \\
\hline vegetarian & $\sqrt{ }$ & $\sqrt{ }$ \\
\hline winged & $\sqrt{ }$ & $\sqrt{ }$ \\
\hline \multicolumn{3}{|c|}{ 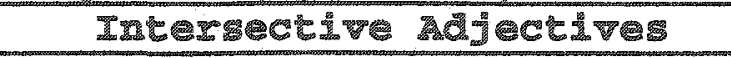 } \\
\hline
\end{tabular}

\begin{tabular}{|c|c|c|}
\hline & $\begin{array}{l}\text { tactic Position } \\
\text { predicative }\end{array}$ & - reponivar \\
\hline large & $\sqrt{1}$ & $\sqrt{ }$ \\
\hline light & $\sqrt{2}$ & $\sqrt{ }$ \\
\hline Iittle & $\sqrt{ }$ & $\sqrt{2}$ \\
\hline Small & $\sqrt{1}$ & $\sqrt{2}$ \\
\hline heavy & $\sqrt{ }$ & $\sqrt{ }$ \\
\hline tall & $\sqrt{ }$ & $\sqrt{ }$ \\
\hline healthy & $\sqrt{ }$ & $\sqrt{ }$ \\
\hline naughty & $\sqrt{1}$ & $\sqrt{ }$ \\
\hline short & $\sqrt{ }$ & $\sqrt{ }$ \\
\hline fat & $\sqrt{1}$ & $\sqrt{ }$ \\
\hline bald & $\sqrt{ }$ & $\sqrt{ }$ \\
\hline \multicolumn{3}{|c|}{$\begin{array}{c}\text { Scalar Intergectwe } \\
\text { adjecturas } \\
\end{array}$} \\
\hline
\end{tabular}

${ }^{10}$ The bulk of adjectives listed in this appendix comes from Siegel (1967). 


\begin{tabular}{|c|c|c|}
\hline sym & 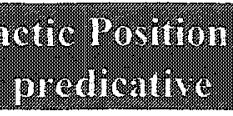 & prenominal \\
\hline actual & & $\sqrt{ }$ \\
\hline blithering & & $\sqrt{1}$ \\
\hline bottom & & $\sqrt{1}$ \\
\hline chief & & $\sqrt{ }$ \\
\hline consummate & & $\sqrt{ }$ \\
\hline distinguished & & $\sqrt{ }$ \\
\hline electrical & & v \\
\hline forcible & & $\sqrt{ }$ \\
\hline initial & & $\sqrt{ }$ \\
\hline inveterate & & $\sqrt{ }$ \\
\hline main & & $\sqrt{ }$ \\
\hline mechanical & & $\sqrt{1}$ \\
\hline mere & & $\sqrt{ }$ \\
\hline middle & & $\sqrt{ }$ \\
\hline ostensible & & $\sqrt{ }$ \\
\hline principal & & $\sqrt{ }$ \\
\hline prize & & $\sqrt{ }$ \\
\hline rightful & & $\sqrt{ }$ \\
\hline sheer & & $\sqrt{1}$ \\
\hline staunch & & $\sqrt{2}$ \\
\hline temporary & & $\sqrt{ }$ \\
\hline top & & $\sqrt{ }$ \\
\hline ultimate & & $\sqrt{ }$ \\
\hline utter & & $\sqrt{1}$ \\
\hline veritable & & $\sqrt{1}$ \\
\hline veteran & & $\sqrt{2}$ \\
\hline Widcat & & $\sqrt{1}$ \\
\hline \multicolumn{3}{|c|}{ Pure subsective Adjectives } \\
\hline
\end{tabular}

\begin{tabular}{|c|c|c|}
\hline & 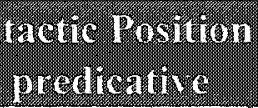 & menninal \\
\hline apostate & & $\sqrt{1}$ \\
\hline artificial & $\sqrt{3}$ & $\sqrt{ }$ \\
\hline bogus & & $\sqrt{ }$ \\
\hline false & $\sqrt{1}$ & $\sqrt{ }$ \\
\hline forged & & $\sqrt{1}$ \\
\hline Former & & $\sqrt{ }$ \\
\hline Fctitious & & $\sqrt{ }$ \\
\hline virual & $\sqrt{1}$ & $\sqrt{ }$ \\
\hline makeshif & & $\sqrt{1}$ \\
\hline \multicolumn{3}{|c|}{ 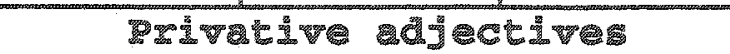 } \\
\hline
\end{tabular}




\begin{tabular}{|c|c|c|}
\hline & $\begin{array}{l}\text { Sy piacie Pos } \\
\text { unedicalve }\end{array}$ & nom \\
\hline artificial & $\sqrt{1}$ & $\sqrt{ }$ \\
\hline bad & $\sqrt{ }$ & $\sqrt{1}$ \\
\hline beautiful & $\sqrt{ }$ & $\sqrt{ }$ \\
\hline careful & $\sqrt{ }$ & $\sqrt{ }$ \\
\hline cheap & $\sqrt{1}$ & $\sqrt{ }$ \\
\hline clean & $\sqrt{ }$ & $\sqrt{1}$ \\
\hline clever & $\sqrt{1}$ & $\sqrt{1}$ \\
\hline complaint & $\sqrt{ }$ & $\sqrt{ }$ \\
\hline confused & $\sqrt{1}$ & $\sqrt{ }$ \\
\hline copious & $\sqrt{ }$ & $\sqrt{ }$ \\
\hline crazy & $\sqrt{1}$ & $\sqrt{ }$ \\
\hline customary & $\sqrt{ }$ & $\sqrt{ }$ \\
\hline deep & $\sqrt{ }$ & $\sqrt{3}$ \\
\hline dependable & $\sqrt{ }$ & $\sqrt{ }$ \\
\hline dificult & $\sqrt{ }$ & $\sqrt{ }$ \\
\hline diligent & $\sqrt{1}$ & $\sqrt{1}$ \\
\hline easy & $\sqrt{1}$ & $\sqrt{1}$ \\
\hline famous & $\sqrt{1}$ & $\sqrt{1}$ \\
\hline favourite & $\sqrt{ }$ & $\sqrt{ }$ \\
\hline final & $\sqrt{2}$ & $\sqrt{ }$ \\
\hline firm & $\sqrt{ }$ & $\sqrt{ }$ \\
\hline friendly & $\sqrt{ }$ & $\sqrt{ }$ \\
\hline good & $\sqrt{ }$ & $\sqrt{ }$ \\
\hline great & $\sqrt{1}$ & $\sqrt{ }$ \\
\hline handy & $\sqrt{ }$ & $\sqrt{ }$ \\
\hline intelligent & $\sqrt{ }$ & $\sqrt{1}$ \\
\hline intentional & $\sqrt{ }$ & $\sqrt{ }$ \\
\hline local & $\sqrt{1}$ & $\sqrt{ }$ \\
\hline navigable & $\sqrt{1}$ & $\sqrt{1}$ \\
\hline new & $\sqrt{ }$ & $\sqrt{1}$ \\
\hline normal & $\sqrt{1}$ & $\sqrt{2}$ \\
\hline old & $\sqrt{1}$ & $\sqrt{ }$ \\
\hline original & 1 & $\sqrt{ }$ \\
\hline profound & $\sqrt{ }$ & $\sqrt{1}$ \\
\hline \multicolumn{3}{|c|}{ Double advectures } \\
\hline
\end{tabular}

\begin{tabular}{|c|c|c|}
\hline & $\begin{array}{l}\text { Syutactic Pos } \\
\text { predicatine }\end{array}$ & prenomina \\
\hline public & $\sqrt{ }$ & $\sqrt{2}$ \\
\hline radical & $\sqrt{1}$ & $\sqrt{1}$ \\
\hline ready & $\sqrt{ }$ & $\sqrt{ }$ \\
\hline regular & $\sqrt{ }$ & $\sqrt{1}$ \\
\hline representative & $\sqrt{ }$ & $\sqrt{1}$ \\
\hline responsible & $\sqrt{ }$ & $\sqrt{1}$ \\
\hline skilful & $\sqrt{1}$ & $\sqrt{1}$ \\
\hline sorry & $\sqrt{1}$ & $\sqrt{ }$ \\
\hline zealous & $\sqrt{ }$ & $\sqrt{ }$ \\
\hline old & $\sqrt{ }$ & $\sqrt{ }$ \\
\hline ariginal & $\sqrt{2}$ & $\sqrt{ }$ \\
\hline profound & $\sqrt{1}$ & $\sqrt{1}$ \\
\hline public & $\sqrt{ }$ & $\sqrt{ }$ \\
\hline radical & $\sqrt{ }$ & $\sqrt{1}$ \\
\hline rare & $\sqrt{ }$ & $\sqrt{ }$ \\
\hline ready & $\sqrt{ }$ & $\sqrt{ }$ \\
\hline regular & $\sqrt{1}$ & $\sqrt{ }$ \\
\hline representative & $\sqrt{2}$ & $\sqrt{ }$ \\
\hline responsible & $\sqrt{ }$ & $\sqrt{1}$ \\
\hline skilful & $\sqrt{ }$ & $\sqrt{ }$ \\
\hline sorry & $\sqrt{ }$ & $\sqrt{ }$ \\
\hline zealous & $\sqrt{ }$ & $\sqrt{ }$ \\
\hline \multicolumn{3}{|c|}{ DoubIe adjectures (conturued) } \\
\hline
\end{tabular}




\begin{tabular}{|l|l|l|}
\hline Natural kind & V & $\mathrm{X}$ \\
\hline Role & V & $\mathrm{X}$ \\
\hline Implement & $\sqrt{ }$ & $\mathrm{X}$ \\
\hline Artwork & $\sqrt{ }$ & $\mathrm{X}$ \\
\hline
\end{tabular}

large, nearby, colour adjectives, nationality adjectives, available

\begin{tabular}{|l|c|c|}
\hline Natural kind & $X$ & J \\
\hline Role & $X$ & V \\
\hline Implement & $X$ & J \\
\hline Artwork & $X$ & J \\
\hline
\end{tabular}

perfect, prize, ultimate, modem, bottom, top, fake

\begin{tabular}{|l|c|c|}
\hline Naiural kind & J & $\checkmark$ \\
\hline Role & $\mathrm{X}$ & $\mathrm{X}$ \\
\hline Implement & $\mathrm{X}$ & $\mathrm{X}$ \\
\hline Artwork & $\mathrm{X}$ & $\mathrm{X}$ \\
\hline
\end{tabular}

dependable, black, white, and red(e.g. red (Indian) man or maybe communist), red(literally red), handy, aggressive?

\begin{tabular}{|l|c|c|}
\hline Natural kind & $X$ & $\sqrt{ }$ \\
\hline Role & $X$ & $\sqrt{ }$ \\
\hline Implement & $X$ & $\sqrt{ }$ \\
\hline Artwork & $X$ & $X$ \\
\hline
\end{tabular}

sharp, reliable, active

\begin{tabular}{|l|c|c|}
\hline Natural kind & $\mathrm{X}$ & $\mathrm{X}$ \\
\hline Role & $\mathrm{X}$ & $\checkmark$ \\
\hline Implement & $\mathrm{X}$ & $\checkmark$ \\
\hline Artwork & $\mathrm{X}$ & $\mathrm{X}$ \\
\hline
\end{tabular}

electronic, temporary, makeshift

\begin{tabular}{|l|l|l|}
\hline Natural kind & $\mathrm{X}$ & $\sqrt{ }$ \\
\hline Role & $\mathrm{X}$ & $\sqrt{ }$ \\
\hline Implement & $\checkmark$ & $\checkmark$ \\
\hline Artwork & $\checkmark$ & $\sqrt{ }$ \\
\hline
\end{tabular}

actual, imitation, genuine 
Nabil Abdullah was born in 1967 in Yemen. He graduated from High School 1985. From there he went to the University of Mosul, Iraq, where he obtained a B.Sc. degree in Computer Science in August 1991. He is currenty a candidate for the Master's degree in Computer Science at the University of Windsor and hopes to graduate in the Fall of 2003 . 